\title{
THE INCENTIVES AND FEASIBILITY FOR DIRECT MEASUREMENT OF SPENT NUCLEAR FUEL CHARACTERISTICS IN THE FEDERAL WASTE MANAGEMENT SYSTEM
}

\author{
Manuscript Completed - August 1988 \\ Date Published - August 1989
}

\author{
Report Prepared by \\ E. R. Johnson Associates, Inc. \\ 10461 White Granite Drive, Suite 204 \\ Oakton, Virginia 22124 \\ Under \\ 41X-SA094V
}

Funded by

Office of Civilian Radioactive Waste Management

DB040214A

\author{
Prepared for \\ Oak Ridge National Laboratory \\ Oak Ridge, Tennessee 37831-6285 \\ operated by \\ MARTIN MARIETTA ENERGY SYSTEMS, INC. \\ for the \\ U.S. DEPARTMENT OF ENERGY \\ under contract DE-AC05-84OR21400
}




\section{DISCLAIMER}

This report was prepared as an account of work sponsored by an agency of the United States Government. Neither the United States Government nor any agency Thereof, nor any of their employees, makes any warranty, express or implied, or assumes any legal liability or responsibility for the accuracy, completeness, or usefulness of any information, apparatus, product, or process disclosed, or represents that its use would not infringe privately owned rights. Reference herein to any specific commercial product, process, or service by trade name, trademark, manufacturer, or otherwise does not necessarily constitute or imply its endorsement, recommendation, or favoring by the United States Government or any agency thereof. The views and opinions of authors expressed herein do not necessarily state or reflect those of the United States Government or any agency thereof. 


\section{DISCLAIMER}

Portions of this document may be illegible in electronic image products. Images are produced from the best available original document. 
TABLE OF CONTENTS

1.0 INTRODUCTION 1-1

2.0 SUMMARY AND CONCLUSIONS 2-1

3.0 REQUIREMENTS FOR WASTE CHARACTERISTICS INFORMATION 3-1

AND CANDIDATE CHARACTERISTICS FOR DIRECT MEASUREMENT

3.1 Design, Operational and Performance Data Needs 3-1

3.1.1 Waste Characteristics Data Needs 3-4

3.1.2 Waste Characteristics Data Needs 3-5

3.1.3 Waste Characteristics Data Needs 3-6

3.1.4 General Summary of Data Needs $3-8$

3.2 Needs Based on Regulatory or Rule Requirements 3-9

3.3 The Nature and Accuracy of Potential Sources 3-11

of Waste Characteristics Data

3.4 The Principal Factors Affecting the Selection 3-16 of Operational Data Sources

3.5 Summary of Waste Characteristics Needs and the 3-18 Role of Direct Measurement

4.0 MEASUREMENT SYSTEMS AND OPERATING CHARACTERISTICS 4-1

4.1 Reactor Measurements and Calculations 4-2

4.1.1 Core Power Measurement Accuracy 4-3

4.1.2 Energy Allocation to Individual 4-3

4.1.3 The Accuracy of Administrative $4-5$

4.2 Neutron and Gamma Measurements $4-6$

4.2.1 The Measurement of Neutron and Gamma 4-7

4.2.2 Interpretation of Measurements and 4-7

4.2.3 Accuracy of Neutron and Gamma 4-10 
TABLE OF CONTENTS (continued)

4.3 Thermal Output 4-11

4.3.1 Calculation of Heat Generation Rates 4-11 4.3.2 Experimental Measurements of Heat 4-13

4.3.3 Summary of the Potential Requirements 4-19 for Calorimetry

4.4 Spent Fuel Isotopic Content and Reactivity 4-20

4.4.1 Special Nuclear Material Accountability 4-20 4.4.2 Reactivity Monitoring 4-21

4.5 Dimensions and Weight 4-24

4.6 Condition and Defects 4-24

4.6.1 Visual Inspection 4-25

4.6.2 Sipping System $4-26$

4.6.3 U1 trasonic Sys tem 4-27

4.6.4 Effectiveness of Inspection Methods 4-28

4.7 Crud Sampling/Removal 4-29

5.0 LIFE CYCLE COSTS SPENT FUEL MEASUREMENTS

6.0 ALARA CONSIDERATONS 6-1

7.0 NEED AND LOCATION FOR MEASUREMENT 7-1

7.1 Primary Conclusion 7-1

7.2 Requirements for Direct Measurement 7-3

8.0 REFERENCES 8-1

APPENDIX A THE RELATIONSHIP BETWEEN TECHNICAL LIMITS, DESIGN LIMITS, DESIGN LOADINGS AND ACCURACIES OF DATA

APPENDIX B ACCURACY OF UTILITY BURNUP MEASUREMENT

APPENDIX $C$ NEUTRON AND GAMMA MEASUREMENTS

APPENDIX D LIFE CYCLE COSTS 


\section{LIST OF TABLES}

Table No.

Description

Page

2-1 Summary of Direct Measurement Costs and Accuracies 2-3

3-1 Waste Facility Design and Operations for Waste 3-13

3-2 Operational Needs and Alternative Sources for Waste 3-14 Characteristics Data

4-1 Comparison of Calculated and Measured Decay Heat 4-12 Generation Rates

5-1 Summary of Measurement Costs 5-2

\section{LIST OF FIGURES}

Figure No.

Description

Page

4-1 Boil-off Calorimeter System 4-14

4-2 Spent Fuel Calorimeter in the E-Mad Calorimeter Pit 4-15

4-3 General Electric-Morris Operation In-Pool Calorimeter 4-17 and Associated Equipment 
THE INCENTIVES AND FEASIBILITY FOR DIRECT MEASUREMENT OF

SPENT NUCLEAR FUEL CHARACTERISTICS IN THE FEDERAL WASTE MANAGEMENT SYSTEM

$1.0 \quad$ INTRODUCTION

The purpose of this work is to assess the nature and extent of the need for direct measurements of spent fuel characteristics within the utility and federal portions of the waste management system, and to evaluate the capability and limitations of various measurement devices for meeting those needs. The need for direct measurement is evaluated relative to the alternative sources of the spent fuel characteristics data required for the safe and effective operation of the system. The results of this work are intended to support Federal Waste Management System (FWMS) planners by identifying the probable and potential requirements for direct measurements and for making related programmatic decisions based on the adequacy or development requirements for appropriate measurement technologies to support the needs of facility and equipment designers and operators.

The designers and operators of the FWMS need to know the characteristics of the spent nuclear fuel (SNF) and related wastes that will be handled, processed, stored, transported and ultimately emplaced underground for final disposal. There are typically two basic sources of this needed information: (i) historical records of measurements made when the fuel was being fabricated or was producing energy; and (ii) direct measurements made during handling prior to disposal. Historical records would include the design and fabrication records of the nuclear fuel assembiies and the subsequent utility records of reactor and core operations.

An underlying theme of this work is that the FWMS will be a production-oriented system in which any functions that are not needed for safe and effective operations will not be included. Applying this productionoriented requirement to the need for direct measurements means that any direct measurements that are not required for regulatory and/or safety reasons can be justified only if they result in operational improvements that are more substantial than the added operational impacts of making the measurement. 
There are many special waste characteristics that will or may be measured for developing design models or for other design purposes, but are not needed during operations; there are al so a number of possible measurements that would be "nice to have" but are not absolutely necessary for operations. These latter categories of measurements are not candidates for those routine production-oriented measurements that are the subject of this report.

Established special nuclear material (SNM) accountability practice for both new and irradiated nuclear fuel involves measurement-based data on original weights and enrichments followed thereafter by item control. Subsequent changes in SNM content are developed using measurement-based assembiy burnups to determine fissile uranium depletion and fissile plutonium production using measurement-based computational methods. Direct measurement of fissile content is not a requirement. SNM accountability for final disposal of spent fuel is now being investigated, but requirements have not been developed. Although such requirements could include direct measurements, this is a specialized area of measurements and is not explicitly included herein.

The principal characteristics of the measuring devices are the accuracy of the measurement and related calculations, the cost of the equipment installation and operation, the extent to which the measurement process intrudes on operations including both duration and degree of interference, and their accuracy/cost characteristics relative to al ternative ways of meeting the same requirements. If direct measurements are to be utilized, the accuracy obtained thereby must be greater than is available from alternative sources, and this increased accuracy must result in cost savings which are greater than the costs and impacts of direct measurement.

This report is organized to provide a systematic review of the overall requirements for spent fuel characteristics data, the specific characteristics that could be measured, the operational requirements, accuracies and costs of the specific measurements, and a comparison of the value and costs of direct measurements as compared to the use of alternative sources. Following the Surmary and conclusion in section 2.0, the requirements for specific types of waste characteristics data and candidate data for measurements are developed in Section 3.0. Specific direct 
measurement systems, including accuracies and operation characteristics are described in Section 4.0 and the corresponding life cycle costs are developed in section 5.0. In Section 6.0 the impact of ALARA principles on the requirements for direct measurements is summarized. In section 7.0 the alternative sources of data are discussed and compared to the value and cost of direct measurement and conclusions are developed with respect to each of the candidate measurements. 


\subsection{SUMMARY AND CONCLUSIONS}

The purpose of this work is to assess the need for direct measurement of waste characteristics and to identify the capabilities and limitations of measurement devices for meeting that need relative to alternative sources of waste characteristics data.

The potential sources of measurement need were reviewed, including (i) the design and operational needs for operating the FWMS in a safe and economic manner, (ii) regulatory needs related to heal th and safety, (iii) special nuclear material accountability needs, and (iv) requirements of the Standard Contract. It was observed that the last three of the preceding four sources were performance-oriented, rather than prescriptive, and hence any measurement needs in these areas generally translated into the first area. It was further observed that the design of fixed facilities, which is based on upper-limit characteristics, does not require direct measurements. It was therefore concluded that the primary source of potential measurement needs is in support of FWMS operations, particularly in the appropriate matching of waste characteristics with the design characteristics of various casks and waste packages, and with final emplacement requirements.

The primary waste characteristics needed for operational support were identified as initial enrichment, fuel burnup and age of the fuel, from which other important characteristics can be developed, including gamma, neutron and thermal outputs of the fuel. The primary alternative sources for these data are (i) utility measurements of discharge burnups, discharge dates and form and condition of the fuel, which are transmitted to DOE, and ( $i$ ) the direct measurement of gammas, neutrons, thermal output or form and condition characteristics. In choosing between these two alternatives, it was noted that in a production-oriented system such as the FWMS, a program of direct measurement could be justified only if (i) it were specifically required by regulations or operational safety, or ( $i i)$ if it provided data that were more accurate than the alternatives, and from which operational savings could be realized that were greater than the cost of measurement. Based on this observation the analysis focused primarily on the accuracy of data from the alternative sources, and also on the costs of direct measurement. 
The accuracy of waste characteristics developed from utilitysupplied data was compared with the accuracy obtainable from direct measurements. With respect to utility-supplied data it was concluded that because utilities measure total core power within about $1 \%$ and make extensive in-core measurements of power distribution, assembly-average burnups at end of life can be determined to within about $2 \%$ of actual values. With respect to direct measurements, it was determined that if fuel age is known, fuel burnups can be determined to within about $3 \%$ provided that the measurement system is calibrated with assemblies of known burnup and age. However, it was also noted that if neither fuel burnup or age is known, current radiation measurement technology can determine burnup to about $5 \%$ accuracy but cannot measure fuel age with enough accuracy to confirm discharge dates for fuel aged more than about 10 years. Since most of the fuel will have ages above 10 years, the inability to measure age accurately applies to most of the fuel that will be handied. With respect to the direct measurement of decay heat, there is agreement with ORIGEN2 calculations using utility-supplied burnup and ages to within about $10 \%$, but there are indications that much of this uncertainty may be due to measurement uncertainties related to absolute calibrations.

Because direct measurements require equipment and staff, the costs of direct measurement at both utility sites and DOE facilities were also evaluated. These costs are summarized in Table 2-1. It is noted that the unit costs of direct measurement tend to be lower at DOE facilities because of higher equipment utilization, the greater productivity of staff in routine production operations, and the tendency to measure several assemblies at a time rather than single assemblies. A summary of the accuracies of direct measurements and of utility-supplied data on radiation characteristics is also shown in Table 2-1. It can be noted in the table that direct measurements required expenditures and provide data that are less accurate than equivalent data provided to DOE from utility records.

Based on the preceding, the primary conclusion of this work is that unless required for safety or regulatory reasons, direct measurements of fuel characteristics will not normally be justified because the information gained thereby would be less accurate than obtainable using utility-supplied data on fuel burnup, age and initial enrichment.

क AT uncertainties given in this report are at the one standard deviation level. 
TABLE 2-1

SUMMARY OF DIRECT MEASUREMENT COSTS AND ACCURACIES

Measurement Type

A. Radiation Characteristics

Neutron/Gamma Scan

Calorimetry

$\stackrel{3}{\vdots}$

\section{B. Form and Condition}

Visual Examination
Weighing
Dimension
Sipping
Uitrasonic

Cost to Measure in Utility Pool, \$/KgU

Cost to Measure at DOE Facility, \$/KgU

\section{PWR}

5.36

3.90

7.31

6.00

0.84

2.32

$$
\begin{aligned}
& 3.29 \\
& 0.72 \\
& 1.97 \\
& 3.89 \\
& 4.65
\end{aligned}
$$$$
1.55
$$$$
3.16
$$

4.83

\section{Accuracy \\ of Direct \\ Measurement}

$3 \%$ on Burnup

$15 \%$ on Age

$10 \%$ on Heat

$10 \%$ on Burnup

$2 \%$ on Burnup $0 \%$ on Age
Accuracy of

Alternative

Utility Data
NA to Form/Condition
NA to Form/Condition
$N A$ to Form/Condition
NA to Form/Condition
NA to Form/Condition 
The direct consequence of the primary conclusion is that waste characteristics derived from utility-supplied data should be the primary source of data for planning operations in both the utility and DOE systems. However, it is also clear that waste characteristics measurements must be made where necessary to meet operational safety or regulatory requirements. Therefore, the application of current and possible future safety/regulatory requirements was evaluated for each element of the waste management system. This evaluation indicates that programs of direct waste characteristics measurements are justified in only three circumstances:

(1) Visual identification and inspection of spent fuel is required of the utilities just prior to the loading of from-reactor transport casks

(2) Visual identification and inspection of spent fuel is required at the time of cask unloading at the DOE facility that unloads the from-reactor shipment

(3) Possible future regulations or safety requirements may result in direct waste characteristics measurement. In this regard there are three currently-identified situations for which there are viable non-measurement data sources, but for which the possibility of future direct waste characteristics measurement requirements cannot be dismissed:

- to confirm burnup-credit transport cask loadings

- to confirm waste package loadings for thermal impacts

- to confirm waste package loadings in compliance with possible future sa feguards requirements.

Three observations as to the limitations of current measurement technology are also noted:

(1) In order to independently verify both burnup and age of an assembly or waste package, two measurements of different radiation characteristics are necessary. The best current technology for making these measurements on fuel that is cooled greater than 10 years is a combination of neutron counting and of high resolution gamma spectroscopy on Cs-137. However, the current experimental accuracies are such that 
resulting burnup accuracies are about $5 \%$ and age accuracies are about $15 \%$. Because most of the spent fuel going through the system will have ages greater than 10 years, these accuracies apply to the majority of spent fuel. Unless the accuracies of the neutron and gamma measurements improve significantly, any goals requiring the independent verification of age by direct measurement do not appear achievable, except where relatively poor accuracies are acceptable.

(2) The $10 \%$ uncertainty of waste thermal output measurements via calorimetry is greater than can be obtained from neutron and gamma measurements. Further, the latter measurements can be made more quickly, at much less expense, and with much less operational impact than calorimetry. Calorimetry does not therefore appear to be a suitable candidate technology for production measurements in the waste management system.

(3) The neutron and gamma measurement technologies discussed herein are considered to be proven technologies within the accuracy limits noted above, and for semi-production operations in a wet environment. Thus the principal uncertainties with respect to use of these technologies in the FWMS are related to their use in a dry environment and their extension to production measurement operations. Since this does not appear to be a major extrapolation, demonstration of these technologies under dry production conditions can await the definition of actual need for such measurements.

Consistent with the preceding, the principal recommendations of this work are:

(1) In order to obtain the characteristics of spent fuel needed for operational planning in the DOE system, primary reliance should be placed on utility data, including the fuel burnup and discharge date, the as-fabricated data and any unusual events noted during the operation or storage of the fuel. In connection with the recommended reliance on utility data, certain subsidiary recommendations are made:

(a) An assessment should be undertaken concerning the actual utility experience with errors in fuel handing and in data acquisition, analysis and retention, and how the eriors were detected. These factual data are essential for making realistic estimates of error rates and of the probable nature and level of undetected errors in utility data and in subsequent DOE operations.

(b) The various in-core monitoring and core analysis systems being used by utilities should be evaluated to determine if there is a significant range of burnup accuracies among utilities. 
(c) The methods and quality levels of fuel records acquisition and retention at the utilities, at the utility-DOE data transfer interface, and within $D O E$ should be evaluated as a system to assure the ultimate availability to DOE of all necessary fuel data at the appropriate quality level.

(2) A utility program of waste identification and visual inspection is required for each assembly or canister just prior to loading into the from-reactor transport cask in the utility pool. A similar program of identification and inspection is required at the DOE facility which unloads the from-reactor transport cask.

(3) It is recommended that the layout of waste packaging and handling facilities include space that could be utilized for direct neutron/gamma measurement of waste package loadings. This recommendation is based on avoiding major disruptions in facility designs and related schedule delays should future regulations or final licensing require the direct measurement of waste package loadings for either thermal performance safety or safeguards reasons. 
The purpose of this section is to relate the basic requirement for safe and effective operation and performance of the overall waste disposal system to potential requirements for specific measurements in various parts of the system. This is done by reviewing the sources and nature of the requirements for information on waste characteristics, the alternatives for providing that information, and those requirements that could or must be met by direct measurement. The related issues of accuracy requirements and the cost and impact of the measurement process are al so addressed.

The needs for waste characteristics information originate with the fundamental requirement that the design, operation and performance of the FuMS be realized in a safe, effective and economic manner. The data needs, and how they support this goal are defined in this section, first by reviewing the specific data needs in each of the major FWMS elements: transportation, MRS and the repository. The second objective is to identify any additional data needs that currently or prospectively originate with the need to comply with relevant standards, regulations and rules. With the overall need for waste characteristics data thus identified, the possible sources of such data a re summarized, including both (i) historical data based on past measurements during fabrication and energy production, and ( $i i)$ direct measurements made when the waste characteristics data are actually needed. Finally the criteria are developed for choosing between the use of either historical data, or the use of directly measured data.

\subsection{DESIGN, OPERATIONAL AND PERFORMANCE DATA NEEDS}

The purpose of this section is to identify the specific waste characteristics data needs associated with the design, operation and performance within each of the three principal FuMS el ements: Transportation, MRS, and Repository. The needs derive directly from the functional requirement of safe, effective and economical performance of the FWMS.

There is an important distinction between the types of waste characteristics data needed at the time of design and the types needed during operation. The design of fixed facilities for radioactive materials requires 
upper limit data, typically with some design margin included. This design approach is based in part on the fact that increments of shielding, or the sizing of key dimensions do not generate great cost differences when done at the time of original design and in part on the fact that the operational benefits of design margins can be significant. In effect, this means that the designer of fixed facilities needs only upper limit characteristics. The principal fixed facility operational concern is that waste be below the design limits. This can be assured through use of available data and normal operational radiation monitoring. A special program of direct measurement is not justified for this purpose.

The design of the various waste containers (transport casks, storage casks and waste packages) requires that the relevant waste characteristics at particular design points be supplied, and good economic practice also requires that the spectrum of waste characteristics be considered in selecting the design points themselves. However, reasonable data, some of them projected data on future wastes, are available for these purposes at the time of design. Similarly, the design for underground waste emplacement requires knowledge of certain waste characteristics, particularly heat and age at the time of projected emplacement. Again, the data are available since they are the same as are needed for waste package design.

In summary, the waste characteristics data that are needed for the design of fixed facilities, various waste containers and repository emplacement are upper 1 imit data or data at discrete design points. Much of the waste for which the facilities must be designed will not have been discharged at the time of design and hence the upper limits for fixed facilities and discrete design points for various containers and emplacement must be developed from actual and projected waste characteristics data. Data that are adequate for design purposes are available. A program of systematic measurements on the waste that has been discharged would not be justified because of the uncertainties that would still exist with respect to future waste discharges. A variety of special purpose design-oriented or licensingoriented waste measurements will probably be required but these do not involve the production oriented measurement programs that are the subject of this report.

In contrast, the need for waste specific characteristics data in the operational stage of the FWMS is significant. Data are clearly needed on 
dimensions, fuel condition and integrity to the extent that these would impact handling operations or processing, such as consolidation or packaging. Another principal reason for the operational need for waste-specific data is that there are strong impact reduction and economic reasons for (i) selecting and loading the various waste containers (transport casks, storage casks and waste packages) so that each container is loaded as closely as possible to its design limit, and ( $i i)$ for emplacing each waste package underground so as to minimize the usage of the disposal horizon. In addition, data that would result in uniform package heat control would be of operational benefit by eliminating the need to vary package spacing in the repository. The availability of accurate waste-specific characteristics data will thus contribute directly to the safe, effective and economic operation of the FWMS. Depending upon the availability and accuracy of alternative data sources, direct measurement programs in support of operations may be justified. Later parts of this section discuss the nature and accuracy of potential data sources, including operational measurements and provide a summary of the operational needs for specific waste characteristics data.

The literal verification of FWMS performance within each FWMS element virtually implies direct measurement, but does not necessarily imply the direct measurement of waste characteristics. For example the performance measurement of weld integrity is not a measurement of waste characteristics. As applied to waste characteristics, verification of performance transiates into verification of container loading or waste emplacement, relative to appropriate limits. In general, the functional need for such performance measurements can be gauged by identifying the probability and consequences of various errors that go undetected in the absence of performance verification measurements.

The following discussion of waste characteristics data needs within each major FWMS element covers both the operational and performance verification waste characteristics data needs, and includes discussion of the probability and consequences of committing errors that go undetected because direct measurements were not made. 


\subsubsection{Waste Characteristics Data Needs in Transportation}

The operational transport process begins with the dispatch of a cask to the utility site. The cask body and basket have been selected by DOE to assure both dimensional and nuclear compatibility with the fuel that has been selected for shipment. The data needed to as sure this compatibility have previously been provided to DOE by the utility in accordance with the terms of the Standard Contract (10CFR961), and include mechanical design details, initial enrichment, fuel burnup and age (date of discharge) plus any special data related to unusual fuel condition such as fuel integrity failure or distortions.

The utility puts the cask through its receiving process, ending with the empty cask submerged in the spent fuel pool, ready to be loaded with spent fuel. Prior to loading the individual assemblies, the utility staff will have given each assembly a thorough visual inspection to assure correct identification and that the condition of the assembly is properly characterized. Once fully loaded and sealed, the cask is decontaminated and monitored to assure that it is in compliance with cask certificate limits for transport. At this point, if the cask has been radiologically overloaded for any reason, such as incorrect cask selection or fuel assembly mishandling, that error will be detected in the routine monitoring process and the cask would have to be reloaded. Thus, the consequences of an adverse cask loading error are not safety-related, other than for increased occupational radiological exposure associated with cask overloading and reloading. In effect, routine post-loading cask monitoring serves the loading verification function.

At present the design and use of burnup-credit transport casks are being evaluated. Preliminary results indicated that the use of such casks is both feasible and beneficial, relative to casks designed using the very conservative assumption that the fuel is fresh, unburned fuel (Sanders, 1987). The direct result of taking burnup credit is that cask baskets are less expensive and the cask can hold more fuel assemblies. The overall result is that fewer shipments are needed, and both the costs and impacts of the spent fuel transport process are reduced.

If the burnup-credit design approach is used, it will add an additional requirement on cask loading: assurance that a minimum-burnup 
requirement is met. The precedent established by the 1 icensed acceptability of administrative controls and utility fuel data records in connection with the use of burnup-credit spent fuel racks lends encouragement that a similar approach would be acceptable for use of burnup-credit shipping casks. The probability and consequences of a fuel handling error in cask loading will have to be evaluated as part of the certification process. Depending upon the criticality design margins that are used, the consequences of such an error would not normally include a criticality incident. In PWR pools, with high levels of dissolved boron in the pool water, criticality is highly improbable, if not impossible. With the much smaller BWR fuel assemblies, the potential reactivity impact of a single adverse fuel handling error is much smaller than for PWR fuel, and again depending upon safety margins, criticality appears highly improbable. Nonetheless, until actual certification of specific burnup-credit casks with specific criticality margins and loading procedures occurs, the possibility that direct measurements will be required with burnup-credit casks cannot be excluded.

In summary, with the possible future exception of burnup-credit-cask loading, there are no waste characteristics data requirements for transportation cask operations that explicitiy require the direct measurement of waste characteristics. Thus the choice among waste characteristics data sources in from-reactor transport is not dictated by operational or verification-related requirements.

\subsubsection{Waste Characteristics Data Needs in MRS}

When the casks are unloaded at the first DOE facility (either the MRS or the repository) to receive utility-loaded casks, every assembly or canister must be inspected to confirm identity, to check the physical condition of the fuel, and to note any differences from the utility characterization of that fuel. Thereafter, the fuel may be consolidated into canisters, and/or loaded into storage casks, and will ultimately be loaded into from-MRS transport casks for shipment to the repository. The waste packages may be configured at the MRS, but the discussion of this process is included below, as part of the repository discussion.

The major MRS functions require waste characteristics data to assure that design and/or operational limits are not exceeded. At present the 
MRS facilities, processes and storage casks are in the conceptual design stage and specific design and operational criteria and limits, have not been finalized. However, the loading of storage casks and from-MRS transport casks is expected to parallel the loading of from-reactor transport casks as to both data requirements and verification needs. Therefore, the prior observations on data needs for loading from-reactor transport casks are likely to apply to the loading of casks at the MRS. The other handling and processes, such as consolidation at the MRS appear to be less sensitive to specific waste characteristics data, since such activities occur in facilities and equipment that are designed for remote handling under upper-limit conditions. Thus the operational consequences of any substitution-type handling errors in these processes appear minimal.

In summary, there is a clear requirement for identification and visual inspection of utility-delivered wastes at the first DOE facility receiving such wastes, including the MRS. Except for this, there are no waste characteristics data requirements for MRS operations that explicitly require the direct measurement of waste characteristics. (Note that any MRS waste package processing is discussed as part of the Repository discussion, below.) Thus the choice between waste characteristics data sources within the MRS is not dictated by currently-known operational or verification-related requirements.

3.1.3 Waste Characteristics Data Needs in the Repository

Waste characteristics data are needed for planning and executing the two primary functions of the repository: (i) preparing the waste package and (ii) emplacing the waste package. The waste package loading operation is preceded by the selection of specific fuel assemblies or canisters to make up individual waste packages. The objective is to select the waste package (if there is more than one) and match it to the fuel characteristics such that the package is physically as full as possible, but without exceeding appropriate technical limits. The latter is typicaliy imposed by the temperature of the hottest fuel rod, which can be translated into a maximum thermal output of the package (i.e., a Kw/package limit). Thus the package loading function requires waste characteristics data on, or relevant to the heat output of, every assembly or canister making up each waste package. 
In the emplacement of waste, the typical goal is to minimize usage of the repository horizon and mining costs by spacing the waste emplacement boreholes as closely as possible, without exceeding any of the various repository loading limits. These limits are typically imposed by waste heat output integrated over 50 years, 300 years, 1000 years, or other relevant period depending upon the particular limit. The heat output of each package and the age and/or burnup of its contents at the time of emplacement are needed for the integrated heat evaluation.

The principal alternative sources of the waste package and emplacement data include utility data on the fuel and the direct measurement of the waste. There are no current requirements that would dictate a choice in favor of either alternative. The potential need for performance verification would focus on the waste package and its loading to no-greater-than appropriate limits. The possible need for such verification is likely to be addressed at the time of final waste package design and licensing. Such an evalution would typically estimate the probability and consequences of an adverse loading error. Because the consequences of such an error depend on final design requirements and design margins, it is not possible at present to predict whether performance verification, presumably by direct measurement, will be a requirement of the final waste package and repository design and licensing process. However, there are important factors in operation which tend to minimize the consequences of an adverse error in waste package loading. The loading limit is typically imposed by the desire to keep fuel clad temperatures below about $380^{\circ} \mathrm{C}$, above which long-term cladding creep could lead to clad integrity failure (Johnson, 1987). The consequences of an adverse waste package loading error depend not just upon the erroneously-loaded fuel. They also depend upon (i) its position within the waste package, ( $i i)$ how close the other fuel in the package is to the loading limit, and ( $i i_{i}$ ) how much effective safety margin there is between the loading limit and the design limit. Thus clad integrity failure is not necessarily a consequence of an adverse loading error. Furthermore, it is important to note that fuel cladding is not the only barrier to the release of fission products--the waste package itself and the surrounding host rock also act as barriers. In fact many long-term repository performance analyses assume that a substantial fraction of fuel cladding has failed. Thus, even if 
clad failure is the consequence of an isolated loading error, the consequences do not appear to be significant. With respect to the integrated heat limits on repository emplacement density, it is noted that these long-term effects are the composite from many waste packages. Thus aberrations in any one package, such as from a loading error, are literally lost in the time-averaging process, with the result that individual loading errors have no significant impact on those factors which impose repository emplacements limits.

In summary, the loading and emplacement of repository waste packages require the availability and use of waste characteristics data, and in particular the thermal output of spent fuel. There are no current waste characteristics data requirements for repository waste package loading or emplacement operations that explicitly require the direct measurement of waste characteristics. At present, the consequences of adverse errors in waste package loading do not appear to be significant enough to warrant a program of waste package loading verification by direct measurement. Final resolution of this verification issue must, however, await final design and licensing of the waste package and repository.

\subsubsection{General Summary of Data Needs}

This section has summarized the specific waste characteristics data needs associated with the design, operation and performance of the principal elements of the FWMS. Particular attention has been given to those situations, such as performance verification, in which direct measurements are potentially the only acceptable source of waste characteristics data. The primary conclusions of this review are:

(1) The design of fixed facilities, equipment, and specific containers such as casks and waste packages requires waste characteristics at discrete design points. There are adequate sources of such design data and direct measurements are not a necessary or typical source of such data.

(2) There is a clear requirement for identification and visual inspection of fuel assemblies or canisters by utilities, prior to loading into from-reactor transport casks, and a parallel requirement for identification and visual inspection at the DOE facility which first handles such fuel assemblies. 
(3) There are no waste characteristics data requirements for FWMS operations that explicitly require the direct measurement of waste characteristics. Thus the choice between alternative sources of such data is not dictated by FWMS operations requirements.

(4) There are no current situations in which performance verification by direct measurement is a clear requirement. There are two circumstances in which a future requirement for direct performance verification measurement, though improbable, cannot be excluded, pending resolution at the time of final design and licensing. Those circumstances include the possible use of burnup-credit transport casks, and the measurement of waste packages after loading.

\subsection{NEEDS BASED ON REGULATORY OR RULE REQUIREMENTS}

The purpose of this section is to identify data requirements, including any requirement for direct measurement that originates in relevant standards regulations and rules. The federal regulatory structure includes a number of procedural regulations which are generally relevant to regulated activities but are not specific to nuclear waste. The specific regulations that may directly impact the need for waste characteristics information are:

For Transport and Transport Packages:

49 CFR 173.389 through .398 (DOT) Shippers-General Requirements For Shipments and Packaging-Radioactive Materials

10 CFR 71 (NRC) Packaging of Radioactive Material for Transport and Transportation of Radioactive Material Under Certain Conditions.

For Spent Fuel Storage: In Reactor Pools:

10 CFR 50 (NRC) Domestic Licensing of Production and Utilization Facilities

For Spent Fuel Storage: at MRS or at Utility Sites:

10 CFR 72 (NRC) Licensing Requirements for the Storage of Spent Fuel in an Independent Spent Fuel Storage Installation (ISFSI)

For Repositories:

10 CFR 60 (NRC) Disposal of High-Level Radioactive Wastes in Geologic Repositories 
For Radiological Protection: 10 CFR 20 (NRC) Standards for

Protection Against Radiation

For Special Nuclear Material Accountability:

10 CFR 70 (NRC) Domestic Licensing of Special Nuclear Material

10 CFR 74 (NRC) Material Control and Accounting of Special Nuclear Material

For the DOE-Utility Contract Terms and Conditions: 10 CFR 961 (DOE)

Standard Contract for Disposal of Spent Nuclear Fuel and/or HighLevel Radioactive Waste (Rule)

Review of the above regulations shows that these regulations are uniformly performance-oriented rather than prescriptive. In some special situations (i.e. 10 CFR 50 Appendix K, ECCS Evaluation Model) use of specific analysis methodologies or assumptions is prescribed. On occasion (i.e. 10 CFR 60.113 Performance of Particular Barriers After Permanent Closure, and also in 10 CFR 20) specific limiting numerical values are stipulated. However, in no case do the regulations stipulate a direct measurement that must be made or a measurement technology that must be used. The reason for this is in the procedure that is to be followed: the regulations identify performance criteria; regulatory guides are developed to identify acceptable practices that will meet the criteria; the applicant for a license designs his facility or equipment using this guidance to meet the criteria and identifies how he will operate in compliance with the guidance and criteria, including any characteristics that may need to be measured; a license is then issued which embodies the design and which stipulates the technical specifications within which the facility or equipment will be operated, and the methods by which such operation will be verified. The license holder then operates his facility and makes those operating measurements that are necessary to demonstrate that he is within this license 1 imit. The Standard Contract does not impose waste characteristic measurement requirements on $D O E$, but does require that the utilities provide key measured fuel characteristics data to DOE, data which the utilities develop and use as a part of their operational fuel management systems. In this sense the Standard Contract assures a primary fuel characteristics data source. 
The special case of potential future changes in Special Nuclear Material (SNM) Accountability regulations requires particular mention. At present, well-established SNM practice in spent fuel management is based on identification and item count, and does not require the direct measurement of waste characteristics. However, examination of the issues surrounding the geologic disposal of fuel has started, including the issue of how IAEA safeguards requirements will be met. It is not currently possible to identify the nature of any changes that may be required, but the possibility of a requirement for direct waste characteristics measurements prior to disposal cannot be excluded. However, resolution of this issue is likely to be based on institutional considerations and does not appear to be directly related to operational health and safety issues. For that reason, the particular issue of IAEA safeguards will not be addressed further in this report.

In summary, the regulations that govern the design and operation of the FWMS are performance oriented and do not directly prescribe specific measurements that must be made, or the measurement technologies that must be used. It is the FWMS license applicant, DOE, that will identify the waste characteristics data needed to design, and ultimately to operate the facilities and equipment within license limits and will identify the sources of the needed data including possible direct measurement of some of the characteristics. As noted, there are no current regulatory requirements which directly prescribe waste characteristics measurement. However the future development of regulatory guides or the future licensing of specific FaMS design features could introduce requirements for direct waste characteristics measurement. The prior section identified two situations which appear to have a small, but non-zero probability of introducing such regulation-derived needs for direct measurement.

\subsection{THE NATURE AND ACCURACY OF POTENTIAL SOURCES OF WASTE CHARACTERISTICS DATA}

The purpose of this section is to describe the basic nature of the various potential sources of nuclear waste characteristics data and to identify the implications of this in terms of data availability and accuracy. 
The specific waste characteristics data needs of system designers and operators are summarized in Table 3-1. A review of the nature of these data needs shows that the designers of fixed facilities, equipment and containers need data at particular design points as distinguished from accurate data describing the spectrum of characteristics. Further, because the design process necessarily precedes the discharge of much of the waste, projected waste characteristics would have to be used and no program of direct measurement of existing wastes could appreciably or significantly reduce the uncertainties inherent in predicting the future. For these various reasons, the data needed by system designers are excluded from the data that could be supplied by direct measurement.

Thus, the primary waste characteristics data that could be supplied by data sources that include direct measurement are the data needed directly in operations for minimizing costs and for assuring that waste characteristics fall within the design envelope and/or below the design limits of facilities, equipment and containers. Table 3-2 summarizes the waste data that are needed for operational purposes and identifies the specific candidate measurement and the primary alternative (non-measurement) data source. These data are those items from Table 3-1 that have an operational significance and can be supplied through measurement. The data categories in Table 3-2 have been divided into the two major categories of: (i) radiation and nuclear data, which have primary dependences upon fuel burnup; and (ii) form and condition data which rely principally on conventional (non-nuclear) measurement processes in a radiation environment. The former category represents a major portion of data needs, for which there is a single primary alternative source of data: utility records of burnup measurements and discharge dates. From this primary source, plus the use of experimentally calibrated calculation methods, all of the required data in the radiation and nuclear data category can be developed, as alternatives to direct measurement. 
TABLE $3-1$

HASTE FACILITY DESIGN ANO OPERATIONS REQUIREMENTS FOR WASTE CHARACTERISTICS INFORMATION

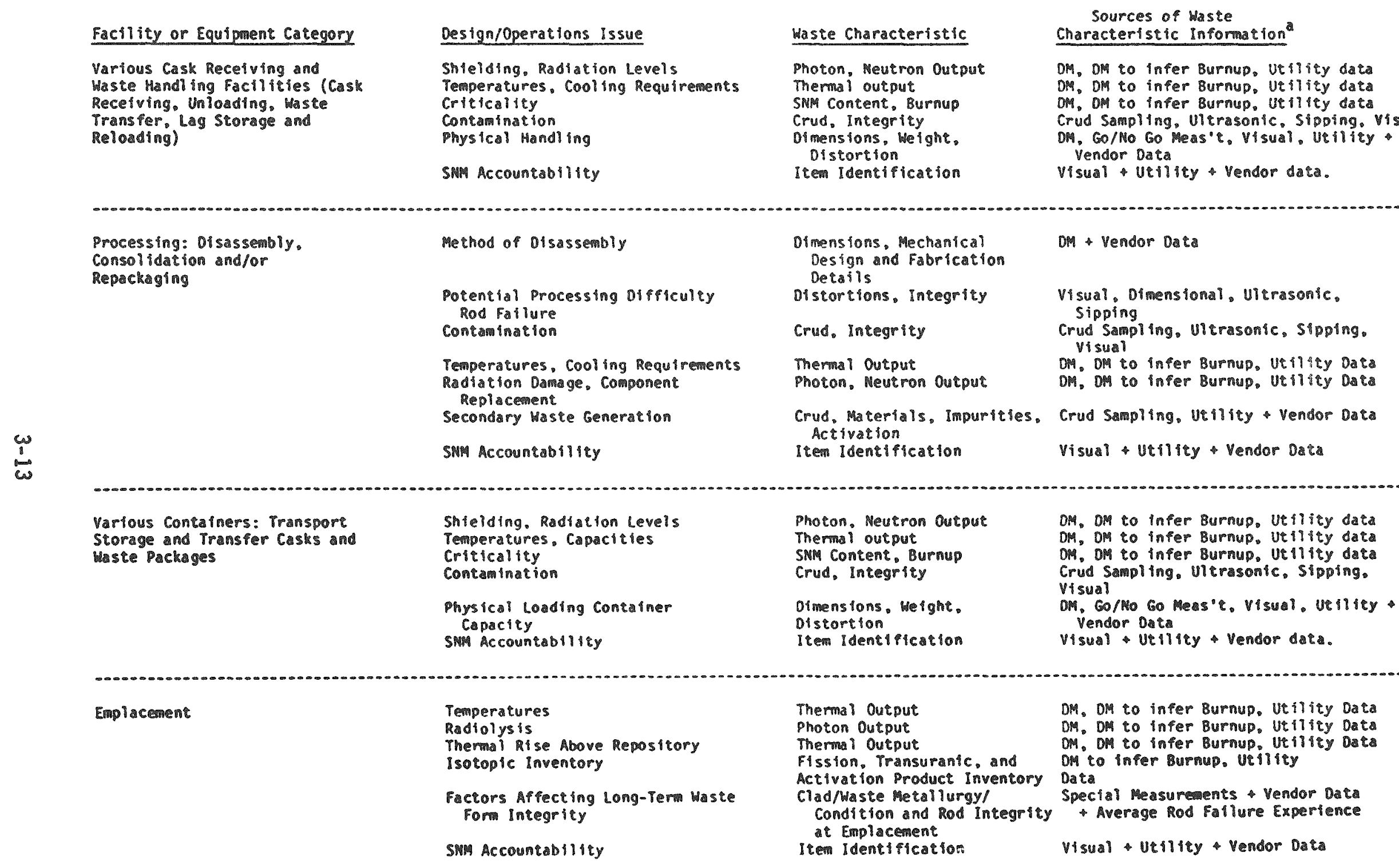

aM is Direct Measurement plus analytic calcuiations for interpretation. 
TABLE 3-2

OPERATIONAL MEEDS AND ALTERMATIVE SOURCES FOR WASTE CHARACTERISTICS DATA

\section{Operations Issue}

\section{A. MADIATION ANO NUCLEAR DATA}

Shielding, Radiation

Temperatures, cooling

Source Terms (s accouncabitity)

Criticality

$\varliminf_{\infty}^{\infty}$

\section{B. FORH AMD CONOITION DATA}

Identf fication, SM Accountabil ty

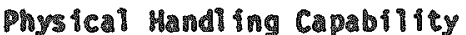

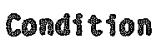

Contaxination haste characteristic

-Photon output
- Neucron output

-Thermil output

-Isotopics. SNm Content

-Reactivity

Item identification

- Ofmensions (nomau)

- Hetght

- Distortion

- Incegrity

- Integrity

- Crud
Candidate Direct reasurement

Gama Spectrometry

Neutron Counting

Calorimetry

Gamma Spectrometry, Meutron counting, destructive onalysis

Neutron counting (source

multiplication) and

power spectral analys is

Direct visual or electromechanical reading of mechanical 10.

ofmensional measurements

Weighing

Dimensional measurements

vitrasonic, sipping

Uitrasonic, sipping

Crud weasurement, sampling and analys is
Alternative Data Source

Utility records of burnup measurements and discharge date plus caiculations of isotopics and resultant photon. neutron and thermal output.

Utility records of burnup measurements. pius calculations of isotoples and calculation reactivity.

\section{(No adequate Il ternative)}

Fabrication daca. via utlity

Utillty fuel handing pecords or distortion messurements. (If any)

utifty operational data or integrity measurenents (if any)

Utiาริty operational data or integrity measurenents (ff any)

utility crud measurements (fi any) 
As noted, virtually all required data on nuclear waste characteristics are available from at least two potential sources: (i) historical utility records based on measurements taken during fabrication and operation: (ii) measurements and related calculations performed at the time of waste handling. Regardless of source, all valid waste characteristics data are available through some combination of (i) direct measurement, (ii) measurement-validated analytical calculations and (iii) administrative control of the data records and the association of the data with specific units of waste. Correspondingly, the accuracy of any waste data is an appropriate combination of uncertainties in each of the three areas of measurement, calculations and administrative controls. This is illustrated in the following examples.

As an example of waste characteristics data based on historical records, consider utility-supplied data on the discharged burnup (Mwd/MTU) of a single spent nuclear fuel assembly. The burnup is based on (i) the continuous measurement of fluid flows and temperatures from which total reactor thermal power is determined, (ii) the allocation of that power, integrated in time (energy) to the specific assembly, by a combination of direct core power shape measurement plus analytic calculations repeated periodically in time and (iii) the administrative control of the data and its assignment to the specific assembly whose various locations in the core during successive cycles are visually identified and administratively controlled. The accuracy of the reported assembly burnup will be based on the accuracy of the total core power measurement and the accuracy of the measurements and calculations by which a proportion of core power is allocated to the individual assembly. In addition, a data uncertainty difficult to quantify, must be acknowledged for the small but finite possibility of administrative errors in the management of the data including its attribution to the specific assembly. It should further be noted that burnup is not a primary waste characteristic, but is one of the two independent variables which determine primary waste characteristics: burnup, plus the cooling time since discharge can be used, via measurement-validated calculations, to determine all of the waste nuclear characteristics such as gamma, neutron, and thermal outputs, as well as isotopic content of the waste. 
As a comparison, consider the measurement of burnup when the same assembly is being processed in the DOE system prior to disposal. First, burnup, which is the time integral of power output in the reactor per unit mass can only be measured during energy production, prior to its discharge from the reactor. However, burnup can be inferred, following discharge, from a measurement of the gamma spectrum of the fuel, the intensity of the neutron output, or of the thermal power output, using the same measurement-val idated calculation methods mentioned above. Thus, the typical direct measurement of waste characteristics involves measurement of gamma or neutron output, from which burnup is inferred, and from which other primary waste characteristics such as thermal output or isotopic content are also inferred: burnup is useful as an intermediary to obtain the other primary waste characteristics. The accuracy of the direct measurement will be determined from the experimental setup, its calibration and the accuracy of the secondary or primary calibration standard, plus counting statistics and other random errors. The accuracy of the other primary characteristics will be based on the accuracy of the direct measurement combined with the accuracy of the analytical model used to infer burnup and derive the other primary waste characteristics. In addition, a data uncertainty must al so be acknowledged for the small possibility of administrative errors.

The above two examples, one using historical data, and the other using direct measurement, demonstrate that waste characteristics data are available through a mixture of measurements, calculations and administrative control and that the principal overall accuracy differences between data a) ternatives result from the differences in the accuracies, mix and timing of these three components.

It should be further noted that it is not possible to generalize, a priori, as to the superiority of either source of data. The following section summarizes the factors which are important in choosing between potential alternative data sources in specific situations.

3.4 THE PRINCIPAL FACTORS AFFECTING THE SELECTION OF OPERATIONAL DATA SOURCES

The purpose of this section is to summarize the principal factors and relationships that are important in deciding whether an operational 
program of directly measuring waste characteristics is necessary or justified. It was noted above that the principal need for waste characteristics data is the operational need for waste-specific data to permit loading of the various waste containers as close as possible to their loading limit. The basic choices of operational data sources are (i) the measurement-based historical data on fuel fabrication, fuel energy production and any subsequent processing in the utility and/or DOE portions of the system, and (ii) the direct measurement of needed waste characteristics as they are required within the DOE system. Except for certain data related to current mechanical condition of the waste (crud accumulation and mechanical distortion due to abnormal events) all operational waste characteristics data can be obtained from either source.

In choosing between these two sources of operational data, an important factor is that direct operational measurements add to the capital and operating costs of a facility. An obvious operational impact is the potential for increased occupational radiation exposure and related ALARA considerations as discussed in section 6. Further there may be other operational impacts such as additional in-process waste inventory, a small but finite additional risk of physically damaging the waste during measurement handling, and a small but finite potential reduction of average plant throughput rate because the measurement process is on the critical path of operations. It is evident therefore that a program of direct operational measurement must lead to benefits that exceed the associated additional costs and operational impacts, or it cannot be justified in a production environment. Since the data are being used to load the various containers and the repository, the principal source of benefits from direct measurements would have to be an increase in container and/or repository loadings and any associated increase in facility throughput rate. The following paragraph summarizes the conditions necessary for realizing such increased loadings.

Appendix $A$ describes the general considerations governing the operational loading of containers and/or repositories with respect to the appropriate technical limits which govern such loading. The principal factor identified in Appendix $A$ is that any loadings must be below the technical limits by an amount that is governed by the desired confidence level and is directly proportional to the accuracy of the data used to make the loadings. 
This means that the data which have the greatest accuracy will permit the closest approach to container and repository loading limits. In the case of direct measurements, the benefits from increased loadings must be at least equal to the costs of direct measurements. These factors combine to give the following two questions which both must have affirmative answers before an operational program of direct measurements can be justified in comparison to the use of historical data:

- Are the measured data more accurate than the historical data?

- If so, is the accuracy advantage of measured data large enough that the benefits from increased loadings are at least equal to the costs and operational impacts of a direct measurement program?

In summary, when direct measurements a re not a regulatory or safety requirement, the decision between direct measurements and alternative data sources can be made on the basis of operational costs and impacts. In these circumstances, it is a minimum requirement that direct measurements produce data that are more accurate than data available from alternative sources. Furthermore, the measured data must be sufficiently more accurate that benefits can be realized that are greater than the cost and impact of measurement. Given these criteria the accuracy of alternative data sources is as important as the accuracy of direct measurements.

3.5 SUMMARY OF WASTE CHARACTERISTICS NEEDS AND THE ROLE OF DIRECT MEASUREMENT

This section has reviewed the requirements and usage of various types of waste characteristics data needed in the design and operation of the Federal Waste Management System. Particular note was taken of circumstances in which the direct measurement of needed characteristics is, or may be specifically required. The two basic sources of waste characteristics data, (i) measurement-based utility records, and (ii) direct measurement, were reviewed and compared, and the criteria for choosing between these were identified. The principal conclusions of this section are: 
(1) There is a clear requirement for identification and visual inspection of spent fuel assemblies and/or canisters by utilities, prior to loading into from-reactor transport casks, and a parallel requirement for identification and visual inspection at the DOE facility which first receives and unloads such waste.

(2) There are no waste characteristics data elements needed for FWMS operations that must be obtained by direct measurement. Thus the choice between alternative sources of such data is not dictated by FWMS operations requirements.

(3) There are no current situations in which process performance verification by direct measurement of waste characteristics is a clear requirement. There are two circumstances in which a future requirement for direct performance verification measurement, though unlikely, cannot be excluded prior to the time of final design and licensing. These two circumstances involve (i) the possible use of burnup-credit transport casks and (ii) waste disposal package loading.

(4) In order to be the preferred source of operational data, the use of direct measurements must have benefits that are greater than the costs and operational impacts of making direct measurements. In order to have such net benefits, the accuracy of direct measurements must not only be greater than the accuracy of utility data, but must be sufficiently more accurate that operational and cost benefits can be realized. Such accuracy benefits should be at least equal to the costs and operational impacts of making the direct measurement. For these reasons the relative accuracies of direct measurements and of utility data become the dominant factors in selecting the source of operational data in all situations in which direct measurement is not a safety or regulatory requirement. 


\subsection{MEASUREMENT SYSTEMS AND OPERATING CHARACTERISTICS}

The purpose of this section is to characterize the measurement systems that are capable of providing the various waste characteristics identified in Table 3-2. Each measurement system is characterized as to its equipment, its operational requirements and impacts, and the accuracy of the resulting data. Costs of using these systems are estimated in Section 5.0. This section characterizes, in sequence, the measurements of data in the two major categories of (i) radiation output and nuclear characteristics, and (ii) form and condition, identified in Table 3-2. The principal issues that are to be addressed within each of these two major categories are summarized in the following two paragraphs.

Spent fuel burnup and age are the primary independent variables which determine the radiation and nuclear characteristics of spent fuel. Fuel burnup, which is the integrated fuel thermal power output (i.e., energy) can be measured directly only when the fuel is producing power. Thereafter fuel burnup can be inferred from direct measurements of its radiation ouput and/or nuclear characteristics. The linkage between burnup/age and radiation/nuclear characteristics is via measurement-validated analysis -ethods, and the results of the measurement-validation process quantify the accuracy with which the linkage is made. A principal issue in choosing Letween the use of utility data and the use of directly-measured data is the relative accuracy of these two data sources. Section 4.1 therefore focusses on the accuracy of utility-measured burnup data, Section 4.2 focusses on the accuracy of neutron and gamma measurements and Section 4.3 discusses direct thermal measurement. Fuel isotopics and reactivity measurements are in section 4.4, completing the discussion of radiation and nuclear characteristics.

The various items of data in the form and condition category are used for identification and operational planning, and in particular for planning dimension-sensitive processes such as consolidation or for handling off-standard situations such as damaged, distorted or leaking fuel. Data related to condition is the most important in the sense that condition indicates any changes from the as-fabricated physical condition of the fuel, which is the normal operational expectation. The principal issue with respect 
to form and condition data concerns the definition of the level of changes from original condition that constitute potential operating problems and the nature and extent of measurements that are needed to assure detection of that level of change. The later parts of this section address the nature and need for measurements of dimensions, weight, conditions, defects and crud deposits.

\subsection{REACTOR MEASUREMENTS AND CALCULATIONS}

The purpose of this subsection is to provide estimates of the accuracy of utility-supplied information on burnup, and to summarize the factors which determine that accuracy. The primary sources of fuel burnup and age information are the measurement-based operational records and the fabricators' fuel descriptions kept by utilities. Measured and integrated total reactor themal power is allocated to individual fuel assemblies via calculation and measurement of reactor power shapes. The age of discharged fuel is based on the date of reactor shutdown (loss of criticality) prior to final discharge of the fuel. These data are used by the utilities for a variety of purposes including fuel cycle optimization, fuel reload planning, fuel performance warranty adjustments with fuel vendors, and for special nuclear material accountability reporting. These records are administratively controlled and are tied to specific fuel assemblies by the fuel assembly identification number stamped on the upper fitting of the assembly. When fuel is consolidated or reconstituted at the reactor, the consolidation/reconstitution records provide the traceability to the resulting consolidated canister identification number or reconstituted assembly identification number.

The accuracy of the by-assembly burnup data that is developed as described above is determined by the accuracy of the individual steps and includes:

(1) The accuracy of the measurement of integrated reactor thermal power.

(2) The accuracy of the combination of in-core measurements and analytical methods by which total reactor power is allocated to individual assemblies. 
(3) The degree of certainty that the administrative aspects of fuel assembly placement in-core and the record-keeping are accurately executed.

The detailed discussion of the first two of the above items is provided in Appendix $B$. The conclusions from this appendix and the discussion of the third item are provided below.

\subsubsection{Core Power Measurement Accuracy}

The ASME test code for nuclear steam supply systems describes the methods, measurements and required accuracies for measuring the total core (fuel) thermal power of pressurized and boiling water reactors. It is based on a complete steady state energy rate measurement across a defined envelope that includes the nuclear steam supply system. It stipulates the accuracy levels for the individual flows, temperatures, and pressures that must be measured. This process is described in more detail in Appendix $B$. The net result of these requirements is an overall core thermal output uncertainty of somewhat less than $1 \%$ at the time of measurement. The effects of transients, below-full-power operations and the possibility of instrument calibration drift between periodic calibrations all tend to increase the uncertainty associated with routine operational power level measurements. The net effect of these operational factors is judged to yield an average accuracy of about $1 \%$ for the operational power level measurements that are a primary input to fuel burnup determination.

As will be seen, this level of core power measurement uncertainty is small, compared to the other uncertainties that contribute to the overall uncertainty in fuel assembly burnups. This excellent accuracy of core power measurements is a major reason that utility fuel burnup data have very favorable overall accuracy. The accuracy with which total core power can be assigned to individual fuel assemblies is now summarized.

\subsubsection{Energy Al location to Individual Fuel Assemblies}

At any point in time, total core power is allocated to individual fuel assemblies by determining the spatial distribution of power within the core. Appropriate portions of that power are then assigned to individual assemblies, based on their location within the core. The core power 
distribution is determined by directly measuring neutron and/or gamma fluxes at many different locations within the core and interpreting these measurements using detailed, experimentally-validated analysis methods. Energy, the time-integral of power, is determined from a sequence of these interpreted measurements covering the whole cycle of energy production between each refueling. This process is then repeated for each cycle. Thus, a single fuel assembly is credited with an appropriate portion of the core energy for each cycle during which it is in-core. This total energy output divided by its total initial uranium mass, gives the assembly's average burnup at discharge.

The accuracy of the fuel assembly burnups that results from the power and energy allocation process is a complex combinaton of the accuracies of individual measurements plus their integration process, and the resultant beneficial statistical combination of independent uncertainties, which operates to improve, in aggregate, the relatively poorer accuracy of individual measurements. An accuracy analysis is described in Appendix B. This analysis relies on a notable combination of soundly conceived experimental and analytic work and complete documentation (Rothleder, 1985). That work, sponsored by the Electric Power Research Institute, includes a complete program of measurements, analysis and results associated with the first cycle of the zion 2 plant operation. The documentation of that work is sufficiently complete to permit direct statistical analysis that lets the data themselves identify the underlying uncertainties.

The following table presents a summary of the results of the analysis of uncertainties in the burnups of individual fuel assemblies, as inferred from the Zion 2, Cycle 1 data. These data are based on the operational in-core monitoring system (movable fission chambers). The following table shows the progression of uncertainty reduction in going from the uncertainty at a single point and time, to a single assembly (axial integration) at a point in time, to a single assembly over a cycle (integration in time, over a single cycle), to a single assembly over 3 cycles (time integration over 3 cycles). The last item in the table converts the relative energy allocation to an absolute burnup uncertainty by including the $1 \%$ uncertainty in power level measurement. 
Uncertainty Mode

Individual measurement at single time and position

Assembly measurement at single time (axial integration)

Assembly measurement over one cycle (time integration)

Assembly measurement over 3 cycles (cycle integration)

Conversion of relative to absolute burnup (power measurement)

\section{\% Uncertainty*}

$10 \%$

2.3 to 4.8

2.9

1.7

2.0

* One standard deviation

The conclusion of the above is that when utilities use current experimentally-validated computational models, correctly normalized to start-of-cycle conditions and adjusted periodically on the basis of in-core measurements, reported discharge burnups have a standard deviation equal to $2 \%$ of actual absolute burnups for fuel with 3 or more cycles of irradiation. The uncertainties in batch-average burnups, which are the average of the many assemblies in a typical batch, will be less than $2 \%$, but above the lower limit of $1 \%$ uncertainty imposed by thermal power measurement.

The basic reason for the relatively small uncertainty in individual fuel assembly burnups should be noted: it is based on a very large number of individual measurements in both time and space, and the commitment of major resources to obtain and interpret the measurements. From this perspective, it is not surprising that quite accurate results are obtained.

\subsubsection{The Accuracy of Administrative Controls}

It was noted that the overall accuracy of fuel burnup data should include consideration of the possibility that the reported fuel burnup of a particular assembly is in error through either a fuel handling error (mis-location) or the mis-assignment of data records to that assembly. There are well structured, substantial and functional self-checking administrative systems set up to preclude such errors, including QA-oriented operational procedures for fuel handling and for analysis results, as well as special nuclear material accountability procedures. However, it is known that a few temporary mislocation errors have occurred, and have been detected during the self-checking portions of the aforementioned procedures. However, 
actual data on these types of errors have not been reported. Further, it appears that such data may be needed for probability and consequence analysis during licensing. As best as can be determined, the frequency of such errors is small enough that it would not influence the overall accuracies identified earlier, and no specific allowance has been made for this type of uncertainty.

It is recommended that actual data be sought and collected on the nature and frequency of (i) spent fuel handling errors, and (ii) the ris-assignment of data.

\subsection{NEUTRON AND GAMMA MEASUREMENTS}

The purpose of this section is to describe neutron and gamma measurement systems and to quantify the accuracy with which these systems can measure fuel characeristics, and the accuracies of the fuel burnup and age that can be inferred therefrom. This section summarizes a more detailed discussion provided in Appendix $C$. The direct measurement of neutron and gamma photon emissions from spent fuel assemblies or packages can be used to determine the burnup and/or age of the spent fuel. The significance and accuracy of such determinations depend upon a variety of factors that occur within the two basic steps that are needed. These two steps are:

(1) The detector, its recording system, and the subsequent analysis must be able to discriminate between the radiation of interest and the intense general radiation field, and

(2) The resulting data must be interpreted in terms of burnup and/or age at the point of measurement, and must be further interpreted as to what fraction of a fuel assembly or container it represents, and what this implies with respect to the whole assembly or container.

Although neutrons and gammas are very different forms of radiation and therefore require different detectors, the basic processes of measurement, recording, analysis and interpretation involve similar issues. Therefore, this section reviews combined neutron and gamma measurement and interpretation issues together before describing specific neutron measurements and gamma measurements and their respective accuracies. 


\subsubsection{The Measurement of Neutron and Gamma Radiation}

The primary candidate detectors are fission chambers for neutrons and high resolution gamma (HRG) detectors, because of their relative selectivity in high radiation fields. The basic systems consist of a stand that holds the fuel to be measured and positions the detectors and supporting equipment (high voltage for the fission detector and liquid nitrogen for the HRG detector), signal conditioners which assure that detector pulses are accurately transmitted to the recorder, and recorders that count each event in accordance with its energy. At the completion of each measurement, computer programs analyze the data, subtract background and provide the net measurement of the radiation and its statistical accuracy. In the case of neutrons, the measurement is the total neutron count or neutron count rate. For the HRG gamma detector, the events being measured are counts in specific narrow energy bands that are characteristic of selected individual fission products or pairs or groups of fission products. To the extent practical, the counting periods, and total counts are chosen such that the statistical uncertainty is considerably less than the uncertainties arising in the interpretation. Also, the counts can be at a single specific location on the fuel, or at various discrete points or continuously along the assembiy. Finally, multiple detectors may be involved. Once the counting data are obtained, the interpretation of the data is undertaken, the methods and issues of which are now discussed.

\subsubsection{Interpretation of Measurements and Accuracy of Results}

Appendix $C$ summarizes the many practical problems encountered in the measurement of spent fuel neutron and gamma emissions and in the interpretation of the measurement to produce needed characteristics of known accuracy. The Appendix mentions the problems of absolute counting and interpretation and notes that the practice that has evolved is to calibrate a measurement system with fuel or canisters of known characteristics, or to self-calibrate with a family of assemblies of known average characteristics. Detailed, experimentally-validated analysis methods are then used to interpret the calibration and the measurement data in terms of needed characteristics. In this regard two factors should be noted: 
(1) Spent fuel burnup and age are the two primary characteristics that are needed from the interpretation process. There are, in theory, situations where better accuracy could be obtained by avoiding the conversion to burnup-age, and then to other characteristics. However, in practice, conversion to burnup-age is normally needed because there is usually a mismatch between the characteristic needed, and the best measurement technology for the situation. Thus, spent fuel burnup and age have emerged as the preferred independent spent fuel characteristics from which all other needed characteristics can be derived, through validated analys is methods.

(2) If it is necessary to determine both burnup and age by independent measurement, two measurements of different isotopes or radiation types are necessary. However, when this is done on fuel of age greater than 10 years, the accuracies of both burnup and age are very poor, as compared to the situation in which age is known. In the latter case only a single measurement is then required to establish burnup. Because the majority of spent fuel to be handled in the FWMS is older than 10 years, the primary focus of this work is measurements made to determine just one parameter, fuel burnup, when the age of the fuel is known.

The general relationship between measured count rates, burnup, age, and intepretation can be described in terms of the quantitative relationship between the parameters, as follows:

$$
\frac{c}{c_{r}}=\left(\frac{B}{B_{r}}\right)^{p}\left(\frac{t}{t_{r}}\right)^{-m}
$$

where: $\quad C=$ count rate of fuel being measured

$B=$ burnup of fuel being measured (unknown)

$t=$ age since discharge, of fuel being measured

$C_{r}=$ count rate of reference fuel

$B_{r}^{r}=$ burnup of reference fuel

$t_{r}^{r}=$ age of reference fuel

$p^{r}=$ sensitivity coefficient for burnup, determined by analysis

$m$ = sensitivity coefficient for time, determined by analysis.

Since the count rates, reference burnup and age, the age of fuel being measured, and the two sensitivity coefficients (See App IC of DOE/RH0184) are all known or observed, the burnup can be inferred, using Equation (1) as: 


$$
B=B_{r}\left(\frac{c}{C_{r}}\right)^{\frac{1}{p}}\left(\frac{t}{t_{r}}\right)^{\frac{m}{p}}
$$

The uncertainty in $B, \delta B$, can be determined from the above, assuming independent uncertainties:

$$
\left(\frac{\delta B}{B}\right)^{2}=\left(\frac{\delta B}{B_{r}}\right)^{2}+\frac{1}{p L}\left(\frac{\delta C^{2}}{C}+\frac{\delta C_{r}^{2}}{C_{r}}\right)
$$

Eq. (3)

where: all $\delta$-terms are respective uncertainties at the same uncertainity level, such as 1 standard deviation.

(This result assumes that $m$ and $p$ in Equations (1) and (2) are known values.)

Equation 3 shows that the uncertainty in burnup is the sum (in quadrature) of uncertainties in the reference burnup, the measurement count rate and the reference count rate. Additional terms could have been included to account for analytical (interpretation) uncertainties, but these have been ignored because they are dependent primarily on the degree of separation between the reference and measured conditions. Two items are worthy of particular notice in the above uncertainty equation:

(1) Because the percentage uncertainty in the measured burnup includes the reference burnup uncertainty plus other terms, it is greater than the percentage uncertainty in the reference burnup. In particular, if the reference burnup is the utility-reported value, the measured burnup uncertainty is greater than the uncertainty in utility-reported burnup.

(2) The second term on the right of Eq. (3) is due to count rate uncertainties for both the reference and measurement cases, including variances due to reproducibility within the experimental setup. In particular, the second term has a $1 / p$ factor. Although the value of $p$, the sensitivity factor on burnup, normally (such as for gammas or heat) has a value close to unity, the particular value of $p$ for neutrons is in the range of 3 to 4 . That is, neutron production is proportional to the third or fourth power of burnup. This means that for neutron measurements, the uncertainties due to the experimental setup and count rate statistics are substantially reduced giving neutron measurements the potential for inferring relatively accurate burnups, as compared to gamma measurements. 


\subsubsection{Accuracy of Neutron and Gamma Measurements}

Appendix $C$ discusses the details of actual spent fuel measurement experience with (i) neutron measurements using fission chambers, (ii) high resolution gamma measurements using low-temperature germanium detectors for Cs-137 and ( $i$ ii) gross gamma measurements using ion chambers. The following is a summary of the uncertainties in the count rates and the resulting uncertainties in ( $i$ ) inferred burnup when the age is known and (ii) inferred burnup and age when both must be inferred by direct measurement. These uncertainties are all based on an uncertainty in the reference burnup of $2 \%$, and do not include any allowance for uncertainties in the analytical methods involved. The accuracies are based on sensitivity parameters for 20-year-cooled fuel of $30,000 \mathrm{Mwd} /$ MTU burnup.

AGE KNOWN

\begin{tabular}{lcc} 
Measurement Technology & $\begin{array}{c}\text { Uncertainty } \\
\text { in Count Rate }\end{array}$ & $\begin{array}{c}\text { Uncertainty in Inferred } \\
\text { Burnup, Age Known }\end{array}$ \\
\cline { 2 - 3 } Neutron Fission Chamber & $6 \%$ & $2.9 \%$ \\
HR Gamma on Cs-137 & $3 \%$ & $4.7 \%$ \\
Gross Gamma Ion Chamber & $10 \%$ & $15 \%$
\end{tabular}

AGE NOT KNOWN

Measurement Technology

Neutron + HR Gamma

Neutron + Gross Gamma

\begin{tabular}{lr}
\multicolumn{2}{c}{ Uncertainty in Inferred } \\
Burnup & $\frac{\text { Age }}{}$ \\
$5.1 \%$ & $17 \%$ \\
$7.1 \%$ & $32 \%$
\end{tabular}

There are three significant conclusions that can be inferred from the above, and which are further discussed in Appendix $C$. These are:

(1) In spite of an unimpressive count rate accuracy (6\%), neutron measurements permit inferences of burnup to within about $3 \%$ when age is known. Neutron measurements yield burnup uncertainties that are lower than obtained using high resolution gamma technology and substantially lower than obtained using gross gammas. The principal reason is the very high sensitivity of neutron production to burnup.

(2) When age is not known, two measurements are required. The burnup uncertainty increases significantly as compared to the situation when the age is known. The uncertainty in time is very large, and cannot be used to distinguish between discharges. Although the pairing of neutron and high resolution gamma detectors gives more accurate results than 
the pairing of neutron and gross gamma detectors, neither is usable for accurate time prediction. Note that this conclusion applies in general to all fuel beyond 10 years from discharge.

(3) The accuracy of the burnup inferred from neutron measurement, $2.9 \%$ in the example shown herein, is less than that of the reference burnup, which is $2 \%$. As noted earlier, this is because the inferred burnup uncertainty includes the reference burnup uncertainty plus measurement uncertainties.

\subsection{THERMAL OUTPUT}

A primary characteristic of a spent fuel package (either fuel assembly or consolidated fuel rods) is the rate of heat generation of that package. The heat generation will determine peak temperatures to be experienced within the package and both near-field and far-field temperature distribution in the host rock. It is the purpose of this section to compare calculated and experimental means of determining the current and near-term heat generation rate of spent fuel and, in particular, to assess the accuracy of each.

\subsubsection{Calculation of Heat Generation Rates}

There has been a continuing effort to correlate calorimeter measurements of decay heat generation rate with the ORIGEN series of computer program predictions of that heat generation rate. A review of that effort is

appropriate here. F. Schmittroth (Schmittroth, 1984) presents comparison of measured and ORIGEN2 calculated heat generation rates for 19 PWR spent fuel assemblies. A summary of his results is shown in Table 4-1, giving average values of the ratio of calculated to measured decay heat generation rates for spent fuel assemblies from three reactor plants. These fuel assemblies encompassed burnups from 26,000 to 39,000 MWD/MTU and cooling times from 2.4 to 8.2 years. 
TABLE 4-1

COMPARI SON OF CALCULATED AND MEASURED

\section{DECAY HEAT GENERATION RATES}

Plant

San Onofre

Wiscons in Electric Power

Turkey Point
Ratio of Calculated to Measured

Decay Heat Generation Rate

1.048

0.964

1.038

In each case the calculated and measured values of decay heat generation rate compare with some bias but little scatter. The positive bias for the San Onofre results is attributed to uncertainty as to cobalt impurity content in the stainless steel cladding.

Schmittroth concludes that the ORIGEN2 calculations are good to within 5\% of calorimetric measurements for cooling times between 3 and 8 years. Preliminary comparison of ORIGEN-S results indicate that, at a cooling time of 10 years, ORIGEN-S gives a heat generation rate which is about $10 \%$ higher than the ORIGEN2 results due to an overprediction of actinide production by the ORIGEN-S code.

Based on earlier calorimetric measurements of three of the same Turkey point fuel assemblies, J. C. Ryman et al (Ryman, 1982) also found agreement within $5 \%$ for ORIGEN-S calculation at a 2.5 year cooling period. These authors generated tabulated values of heat generation rates for PWR fuel assemblies for eight combinations of burnup and ${ }^{235} U$ enrichment. These tabulated values form the basis of NRC Regulatory Guide 3.54 on spent fuel heat generation.

Experience with BWR fuel assemblies is summarized by M. A. Mckinnon et al (MCKinnon, 1986) by presenting ORIGEN2 results for Monticello spent fuel assemblies as well as earlier data on Dresden and cooper fuel. It is concluded that the calculated results are accurate to within $10 \%$ and that the calculated results may be better than measured results. Indeed, one of the problems identified here is with calibration and operation of the calorimeter.

These comparisons of experimental results with ORIGEN calculations implicitly include uncertainties associated with the utility-reported fuel 
assembly burnups. However, as noted earlier, in Section 4.1 , the utility data on burnups is probably in the $2 \%$ accuracy range, and hence probably does not contribute significantly to the comparison uncertainties.

\subsubsection{Experimental Measurements of Heat Generation Rates}

The limited experience with calorimetry of spent fuel has been summarized in the preceding section. This section will describe the calorimetric equipment and consider the costs and benefits of the experimental measurement of heat generation rates.

There are only two calorimeters extant which have been used to measure heat generation rates of spent fuel. One is at the Engine Maintenance and Disassembly (EMAD) facility at the Nevada test site and the other is at General Electric's Morris Operation (GE-MO). The first of these calorimeters is located in a hot cell environment and the second is in a fuel storage pool. Fortunately, these two calorimeters thus cover the gamut of likely site possibilities for experimental measurement of heat generation rates of spent fuel. Unfortunately, however, both of these calorimeters require immersion of the spent fuel or its package in water (or other liquid medium): to the extent that immersion of waste packages in water is not acceptable, future development of dry calorimeters such as those based on flowing gas may well be indicated.

The EMAD calorimeter is described in detail by creer and Shupe (Creer, 1981). It is a direct contact boil-off calorimeter system shown schematically in Figure 4-1 and in detail in Figure 4-2. This system was chosen for its rapid attainment of thermal equilibrium conditions and for ease of operation in a hot cell. The principle of operation of this system is to measure the differential rate of condensate collection between a reference run with an electric heater and an experimental run with both spent fuel and the electric heater used as heat generators. In the actual construction, a secondary measurement of condensation was performed by weighing the collected condensate. The following items are quoted from the conclusions of the report. It must be remembered that this report dealt with single fuel assemblies and that, in a larger system required to handle waste packages, the system time constant may be expected to be greater than that quoted here. 


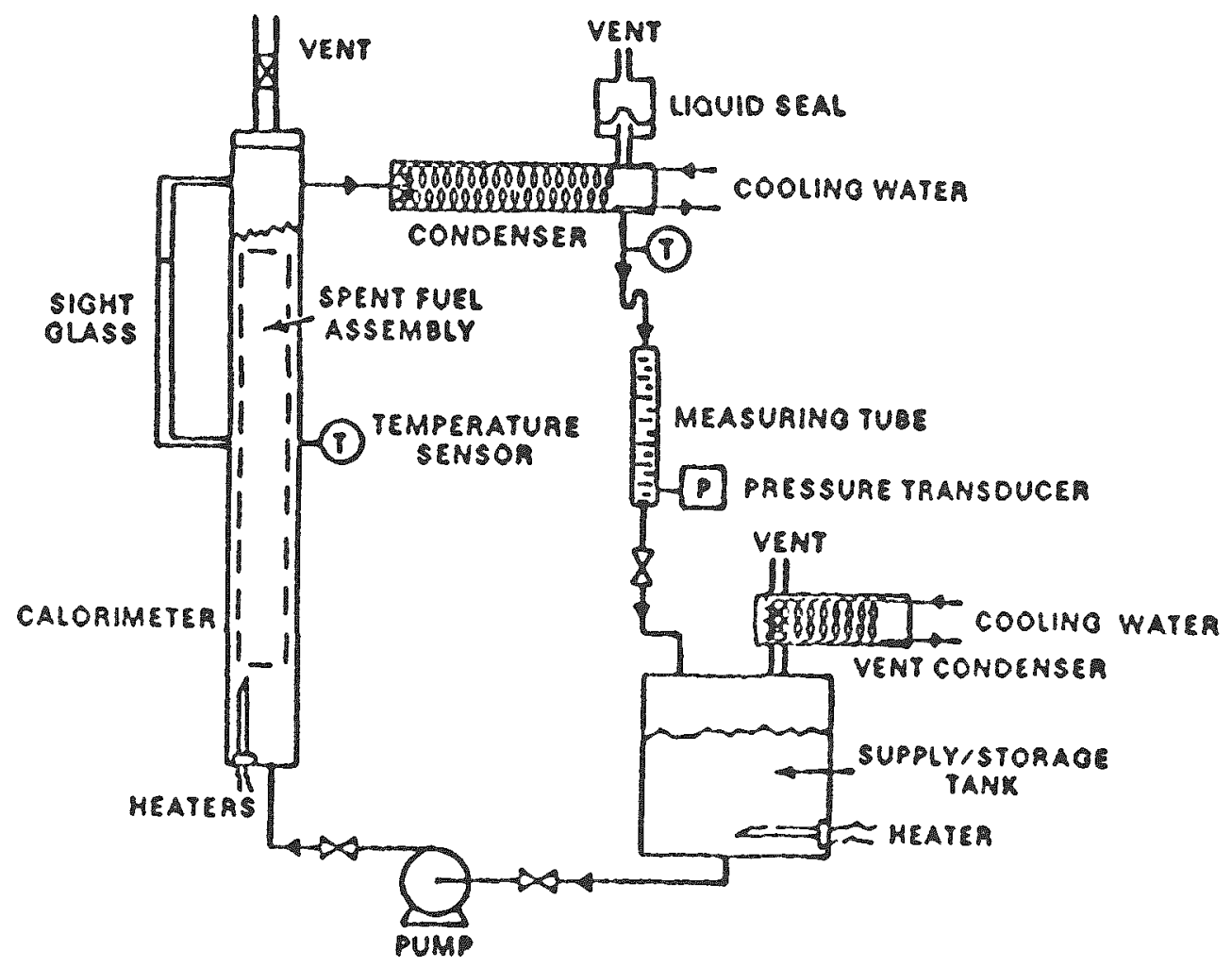

FIGURE 4-1

BOIL-OFF CALORIMETER SYSTEM 


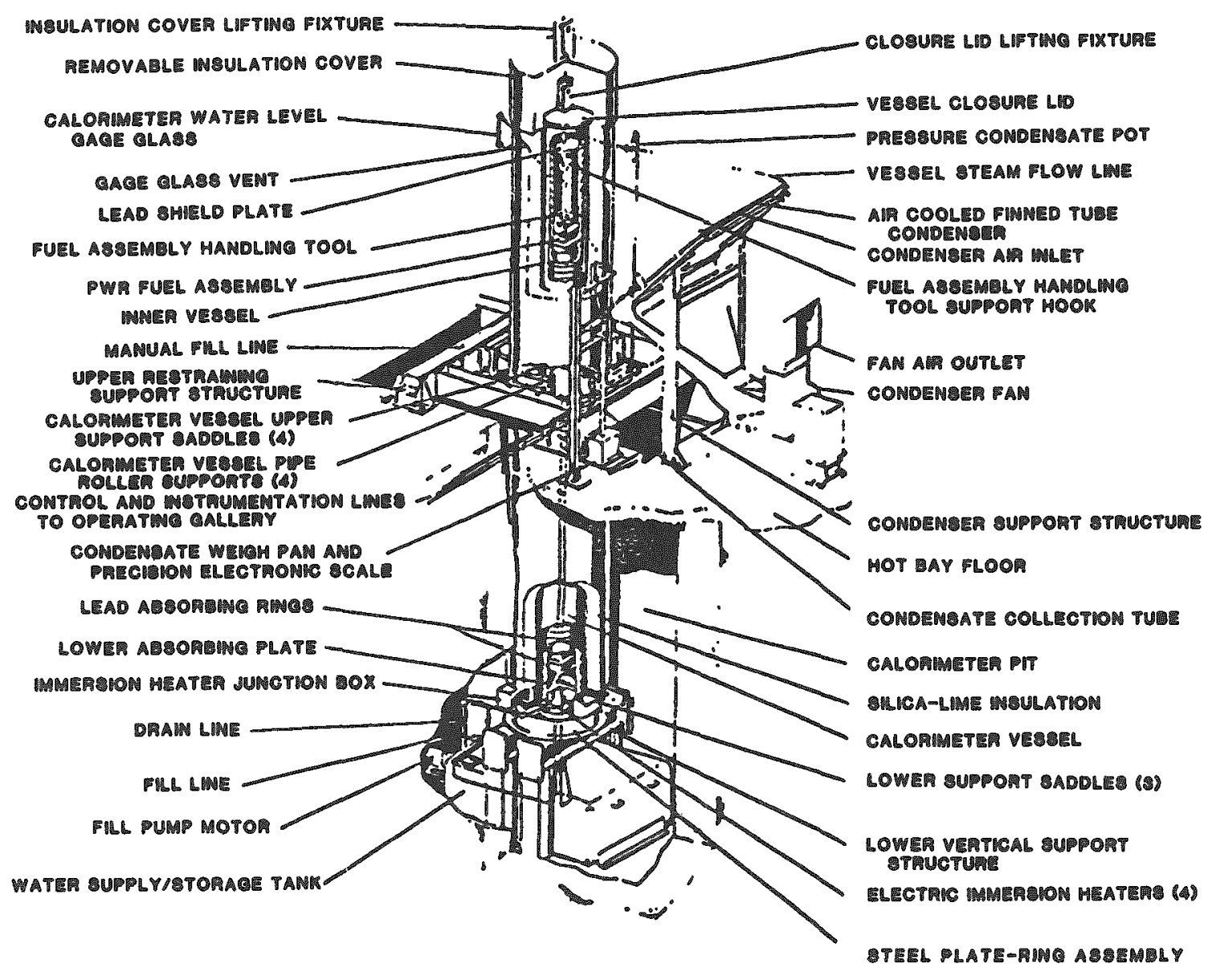

FIGURE 4-2

SPENT FUEL CALORIMETER IN THE E-MAD CALORIMETER PIT 
- "The calorimeter system has excellent stability and the system time constant is sufficiently short to permit calorimetry during an eight hour period. The system is compatible with hot cell operations and should be used as prototype for future packaging facilities.

- Heat generation rate measurement accuracies within $5 \%$ of true values can be obtained with the calorimeter in the range between 0.5 and $2.5 \mathrm{~kW}$."

The GE-MO calorimeter is described (as an adjunct to the reporting of experimental data) by Mckinnon et al (Mckinnon, 1986). This in-pool calorimeter may be operated as either a static or recirculating water calorimeter in which the increase in internal temperature with time is measured; it is shown schematically in Figure 4-3. The GE-MO calorimeter has been used to measure the heat generation rates of both PWR and BWR spent fuel assemblies with apparent success. Among the recommendations of the Mckinnon et al report referenced above, however, are the following quotations which pinpoint concern with calorimeter calibration and operation:

- "The source of the differences that exist among calibration curves needs to be determined.

- Calorimeter operational methods need to be investigated further to determine the cause and effect relationships between operational method and calorimeter precision and accuracy."

Even with experience gained in the operation of these two calorimeter systems on spent fuel assemblies, it must be recognized that there is no experience with the calorimetry of large waste packages nor with the dry calorimetry that might be required in DOE facilities. Furthermore the technical difficulty that is evident in obtaining accurate fuel calorimetry results in a laboratory setting puts into serious question whether such results can be obtained in a production setting. It is expected that the time to reach thermal equilibrium in larger systems and particularly in gaseous heat transfer media will be much longer than that experienced with the measurement of intact fuel assemblies in the systems described above. The evident technical difficulty of production measurements, the time constraint and the estimated considerable cost of the calorimeter, its attendant hot 


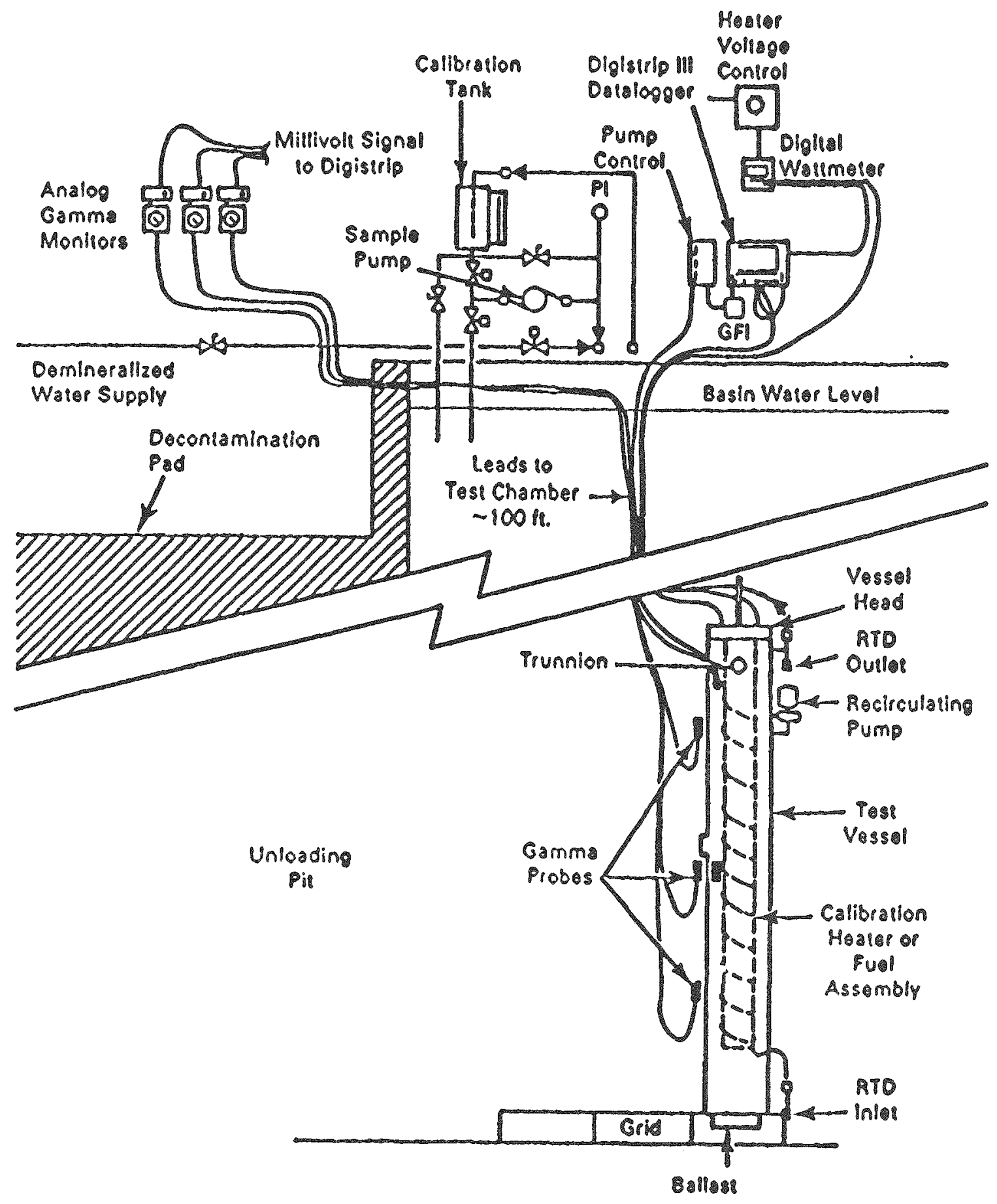

FIGURE 4-3

GENERAL ELECTRIC-MORRIS OPERATION IN-POOL CALORIMETER

AND ASSOCIATED EQUIPMENT 
cell, and its operating costs would seem to preclude the routine calorimetric determination of heat generation rate of every waste package.

Useful insights into the viability of production calorimetry can be gained by reviewing the nature of potential requirements for calorimetry. The accuracy of waste heat output, al though important throughout the FWMS, is not an issue of major safety consequence except in connection with the waste package, where it governs waste temperatures and long-term repository rock temperatures. Thus, production calorimetry has its greatest viability in the direct measurement of heat from waste packages or from the individual assemblies or canisters that are about to be loaded into a waste package.

Although calorimetry has the perceptual advantage of directly measuring absolute heat output, the primary limiting factor in waste package loading, there are viable alternatives for determining heat output. These include neutron and gamma measurements which correlate in known ways with heat output. The measurement systems using these alternatives require calibration. A direct method of calibration would be to use a reference waste package whose known heat output was measured via calorimetry, either at the repository or in a laboratory environment. However, because neutron and gamma measurements are geometry-sensitive, each different waste package and internal loading geometry would have to be represented among the calibration standards. A much simpler and equally effective approach would be based on the fact that the whole purpose of direct measurement is to identify fuel or packages which are different from expectations because of a prior data or handling error somewhere in the system. A system based on neutron or gamma measurements could readily detect such errors if it were, in effect, self-calibrated. This would involve measuring many waste units of the same geometry and using the average of the measurements and the average of the historical data as the basis for calibration. Outliers would be identified by comparing the individual measurements and the relative individual expectations based on waste data. Outliers, presumably caused by prior errors would be as clearly identifiable under this self-calibration process, as they would have been under calibration using absolute standards. Thus, there appear to be viable alternatives to calorimetry that are equally capable of identifying possible errors in waste package loadings. 


\subsubsection{Summary of the Potential Requirements for Calorimetry}

In summary, the following conclusions have been noted in connection with the potential direct calorimetric measurement of waste thermal power:

(1) Calorimetry of fuel assemblies in a non-production environment has been demonstrated with two different systems. Accuracies of $5 \%$ have been achieved within individual systems but a cross-comparison between systems indicates a potential for additional systematic errors associated with the absolute calibration of the calorimeter. The adaptability of current calorimetry systems and experience to a production basis at similar accuracy levels is, at best, of uncertain outcome.

(2) The most viable potential application of calorimetry to operational measurements, is in the identification of possible errors in waste package loadings. In this application, there appear to be simpler and less costly alternatives of comparable or superior capability in the detection of waste package loading errors. It therefore appears unlikely that production calorimetry, even on a sampling basis, is a viable measurement technology for the FWMS.

(3) There are no current requirements for the measurement of waste packages for the detection of possible loading errors. Further, as indicated in Section 3.1.3, it is not clear that the consequences of loading errors are of sufficient impact to justify the costs and impacts of a measurement program. Nonetheless, until final design and licensing, an uncertainty will remain as to the $u 1$ timate operational requirement for the direct measurement of waste packages. Further, a similar uncertainty prevails with respect to the ultimate implementation of IAEA safeguards and the possible institutional requirement for direct waste package measurement. Given the absence of any current requirement, and the current absence of a clear technical justification, for a waste package measurement, no recommendation for such a measurement or for a measurement method can be given. However, there are current uncertainties in both the operational requirements arising from the final design and licensing process, and the resolution of IAEA safeguards requirements in an institutional sense. It therefore appears prudent to suggest that designers of repository surface facilities include a provisional location for potential remote on-line measurement of waste packages, until these uncertainties are resolyed. 


\subsection{SPENT FUEL ISOTOPIC CONTENT AND REACTIVITY}

The purpose of this section is to identify the needs of FWMS designers and operators for data on the isotopic content of spent fuel, and on spent fuel reactivity. Possible sources of this data are summarized, including direct measurement and analytical derivation from measurement-based data.

The radiation source terms for the design of gamma and neutron shields and for thermal design depend upon the individual contributions of every isotope that is in the fuel, including fission products, actinides and activation products. However, it is the magnitude and time behavior of the aggregate radiation outputs of all isotopes that is of primary interest to the designer, and not the details. Developers and validators of design tools may require detailed isotopic data, but that is a specialized need that is not of direct concern to FWMS designers and operators. Therefore, if the designers have access to aggregate radiation output data and its time behavior, they do not normally have a requirement for the detailed isotopics underlying the aggregate data. There are two general exceptions to this statement.

(1) Safety evaluations frequently require inventories of volatile isotopes such as iodine, cesium, xenon or krypton, or of biologically sensitive isotopes such as C-14 or TC-99 which are of interest in long term repository performance evaluations. These needs can be met as they are identified, via knowledge of the burnup and age of the fuel in question. These needs would not nomally be met by direct measurement.

(2) Special nuclear material accountability and reactivity safety impose requirements on fissile material content that can be met by either direct measurement or by analytical calculations based on data derived from measurements. The remainder of this section summarizes data needs in these areas and the alternatives for meeting these needs.

\subsubsection{Special Nuclear Material Accountability}

Once nuclear fuel leaves the fuel fabricator, special nuclear material (SNM) accountability is maintained by item control. To the extent that the contents of the fuel rods have been altered through irradiation, it is standard practice to characterize the fuel on the basis of its assembly average burnup and to provide the isotopic depletion and buildup of fissile 
material based on that burnup. The fissile material is calculated using computer programs that have been calibrated against direct isotopic measurement of fissile material (see for example, Eich, 1986), using measured fuel assembly burnups that have been obtained from measured total reactor power and measurements of core power distribution (Rothleder, 1985).

SNM accountability of nuclear fuel via item control and reactor-measurement-based calculation of fissile content has been the accepted practice for power reactor fuel for over 30 years. However, it is recognized that SNM accountability for permanent disposal is an issue that is just starting to be addressed, including the issue of how IAEA safeguards will be met. Any measurement methods that may or may not ultimately be required are not reasonably predictable and therefore cannot be sensibly addressed in the context of FWMS design and operation at the present time. Further, resolution of this issue is likely to be based on institutional considerations and does not appear to involve operational issues which are the primary focus of this report. This is a topic to be monitored, particularly with respect to special measurements that may ultimately be required, but will not be addressed further.

\subsubsection{Reactivity Monitoring}

The prevention of inadvertent criticality in equipment and facilities handing fissile material is a major concern of all system designers and operators. The principal method of criticality control is to limit the amount of fissile material within a given space to an amount that is known to be less than the critical amount. One of the practical problems of doing this with spent fuel is a knowledge of the actual fissile content of the fuel. A very practical issue in this regard is the design of "burnup-credit" rail transport casks for spent fuel shipment: if it is known that the fissile content of the fuel has been significantly depleted, the cask can be designed to hold up to $50 \%$ more spent fuel than if it cannot be assumed that any depletion has occurred, and the cask must be designed as if the fuel were fresh fuel. There are at least three different approaches to this problem, each of them based on measurements. These are:

(1) The direct measurement, via non-destructive techniques, of the fissile content of the fuel. 
(2) The direct measurement of reactivity.

(3) The use of experimentally calibrated calculation of fissile material content using fuel burnups determined from the direct measurement of core thermal power and the direct measurement of power distribution.

The direct measurement of the fissile content of a spent PWR fuel assembly has been demonstrated on an experimental basis at zion using a fairly simple system (Untermyer, 1983). $\mathrm{A} \mathrm{BF}_{3}$ detector adjacent to the mid-plane of an assembly counts neutrons. Then a $C f-252$ spontaneous fission source is positioned on the opposite face of the fuel assembly, away from the $\mathrm{BF}_{3}$ counter, and a new set of counts is taken. The first set of counts (without the source) provides a direct measure of burnup, when calibrated with fuel of known burnup; and the difference between the second and first sets of counts provides a direct measure of assembly fissile content when cal ibrated against fresh fuel of known fissile content. With some refinements, it was believed that total fissile content could be estimated to within $1 \%$ using this method. The pre-reprocessing fuel measurement system mentioned earlier (Bernard, 1986) includes neutron measurements that are used in conjunction with computer based analyses, to calculate plutonium content to less than $1 \%$ uncertainty, as measured by destructive analysis in reprocessing. A minimum burnup of 16,000 Mwd/MTU and at least 3 years' cooling are required to achieve that accuracy.

Criticality control in most of the FWMS is achieved by using dry operations and storage, which assures subcriticality for all enrichments below $5 \%$. However, in the criticality design of transport casks it is generally assumed that the cask is flooded. One method for assuring that loaded casks are subcritical is to measure reactivity directly. The direct measurement of reactivity by means of the power spectral density of neutron level fluctuations has been a proven technology for many years, particularly when fluctuations are cross-correlated with reactivity perturbations. However, the technique requires bulky recording and computational equipment and specialized personnel. Recent advances in analytical approach, computer technology and instrumentation may make this a more practical technology. A method developed at ORNL (Mihalczo, 1985) uses a Cf-252 spontaneous fission 
source inside a special detector whose signal is then cross-correlated with two other detectors in real time computations to calculate reactivity. The system has not yet been demonstrated in the high gamma and neutron background of spent nuclear fuel. Such a demonstration appears to be worthwhile.

The third method of reactivity monitoring relies on the known burnups of individual assemblies and also uses established and functional spent fuel placement procedures and records to assure that no fuel below a known lower burnup limit is loaded into a transport cask. This is a measurement-based system because the fuel burnups have been determined from extensive power, and power distribution measurement and are probably known with better accuracy than alternative measuring systems can provide. Coupled administrative - physical controls on pool bridge movements have been consistently used in conjunction with burnup-credit storage racks, and the extension of these same controls to burnup-credit cask loadings in these same pools appear to be straightforward.

In summary, the designers and operators of FWMS facilities do not normally require detailed isotopic compositions of spent fuel, except for fissile isotopes. In those cases where isotopic contents are needed, such as for safety or performance evaluations, the required isotopics can be developed using computational methods, such as the ORIGEN2 program, and do not require measurements. Spent fuel fissile isotope contents are needed for both SNM accountability and for criticality. SNM accountability requirements are being met by a combination of item control and burnup measurement, from which fissile isotopic content is calculated. Direct measurement is not required, although the disposal portion of the FWMS may ultimately be governed by requirements that are different from those currently in use. Criticality control in most of the DOE system is achieved by assuring dry operations and storage, and operational criticality computations or measurements are not normally required. However, if transport casks are designed to take reactivity credit for burnup, the direct measurement of reactivity is one of the alternatives, if the conditions of the measurement are the same as the imiting conditions or can be extrapolated accurately to such conditions. The feasibility of the direct measurement of spent fuel criticality should be established. Another alternative is to load burnup-credit casks using the 
established and well proven administrative methods of criticality control that are currently in use in utility pools for loading and unloading burnupcredit storage racks.

\subsection{DIMENSIONS AND WEIGHT}

The dimensional envelope of the spent fuel assembiy is a matter of concern in the loading of the assembly into a canister or cask basket. Precise determination of assembly dimensions could be determined at the reactor site by using an envelope measuring stand in the spent fuel pool. As a practical matter, the final test of dimensional acceptability should be the fit of the assembly into the cask basket. In this way, the cask basket itself provides a practical dimensional verification; in the event that a fuel assembly cannot be easily loaded into the cask basket, it will have to be classified as non-standard fuel and subjected to special handling.

The weight of the spent fuel assembly can be found by incorporating a load cell in the hoist. The physical measurement of the weight of the assembly could provide a check on the administrative records and fuel assembly identity. However, because it is not a requirement, does not have an operational use and would duplicate information available from other sources, weighing is discretionary but not necessary.

\subsection{CONDITION AND DEFECTS}

It is a requirement of the Standard Contract that any lack of integrity of the spent fuel be documented prior to shipment from the reactor site. Administrative records and a brief visual inspection will be adequate to determine the fuel identity. The question at hand is whether the operating data on fuel integrity is adequate, or whether an integrity measurement program is required. It should be noted that there are no known non-destructive techniques that guarantee detection of all fuel defects.

The following subsections consider the inspection methods which may be used to determine the form and condition of the spent fuel either at the reactor site or at the DOE receiving facility. 


\subsubsection{Visual Inspection}

A visual inspection of each assembly for purposes of verifying the identity and condition of the assembly is a contractual requirement. Beyond establishing the identity of the fuel assembly, the objectives of such an inspection are to detect grossiy failed fuel rods and any structural damage to the assembly skeleton. As a matter of independent verification of identity, confirmation of fuel integrity, and as a check on possible damage during transport, it would seem prudent to conduct a similar inspection upon receipt of the spent fuel at the DOE facility.

The visual inspection must be done with care in order to be useful . close visual inspection of the assembly over its entire length on all four sides under good back illumination is required to detect damage to interior rods. Such inspection could be conducted either by high resolution closed circuit television or by borescope.

A remotely operated borescope, fiberoptic viewer, or camera combined with a closed circuit television (CCTV) which provides object viewing in air or underwater can be used to determine/verify the general overall condition of spent fuel assemblies and identify any major defects or deformities. A variety of these systems are available which can include useful and desirable features such as recording, video enhancement, hard copy documentation, optical focus, zoom lenses, and motorized remote control of the viewing head on a flexible cable, suitable for underwater operation.

A representative system available from Westinghouse Electric Corporation, Horseheads, New York, provides a complete closed circuit TV camera system consisting of two major components -- camera head and camera control unit. The camera head contains a removable cartridge that includes the lens, the camera tube assembly, a low noise video preamplifier and the remote focus motor. The camera head can be equipped with a variety of viewing assessories permitting rotating right angle and straight on viewing with or without internal lights. The camera control unit provides all necessary system controls including optical focus, image reversal, light intensity, image rotation, and also contains a small view finder monitor. In addition, a video recorder can be used to provide a permanent inspection record. 


\subsubsection{Sipping System}

Sipping of either the water surrounding spent fuel assemblies or the percolated fission gases are techniques that can be used to determine if the assembiy contains any fuel rods with perforations in the cladding. Fuel assemblies whose cladding has developed perforations allow radionuclides to escape resulting in increased coolant activity. A representative sipping system offered by Lake Shore, Inc., Iron Mountain, Michigan combines gas and water sipping capabilities plus providing the ability to take water samples for chemical analysis.

The gas sipping technique provides for concentration of the activity sample in a small void created at the top of the sealed sipping container. After the fuel is inserted into the sipping cylinder, the 1 id is pneumatically closed and the cylinder flushed to remove any contamination external to the fuel assembly. A controlled volume of water is then blown out the outlet line, creating an air pocket within the cylinder lid. The fuel remains totally immersed in water during the entire process. The air pocket is then evacuated to approximately 25 inches $\mathrm{Hg}$. This pressure differential effectively enhances the percolation of fission gas contaminants to the sipping container lid and up through the scintillation detector chamber. The system maximizes the concentration of the gaseous radionuclide within a reduced in-line sample volume and incorporates counting and analysis electronics capable of compensating for any background activity.

Similarly, to perform water sipping testing, the fuel assembly is placed in the sipping cylinder which is flushed to eliminate external contamination. Once the fuel assembly is flushed, the water is circulated to entrain leaked activity sources. During this circulation process, the water is passed through a "wrap-around" type chamber, surrounding a sodium iodide detector. The detector output is fed to a multi-channel analyzer for cumulative pulse-height spectrum analys is of leaked contaminant build-up within the closed-lop circulation system. The resulting spectra and alphanumeric information are then recorded for each fuel assembly. Also, a station in line with this circulation loop is provided for taking water "grab" samples for remote chem-lab analysis.

In this representative system water analysis necessitates entrainment of leaked radionuclide activity throughout the entire sipping 
container whereas the gas analysis concentrates the activity sample in the small gaseous void, thereby affording greater sensitivity. A semi-automatic control system minimizes inconsistent readings due to fluctuations in operator performance. This control system eliminates time sequence variations in the operating steps (e.g. flush, blowdown and purge) inherent in a manually controlled system. This capability is critical to precise leaker identification and quantification.

Sipping performed at Dresden Unit 2, with the system described above, positively identified all of the reaking fuel assemblies and distinguished them from the non-leaking assemblies tested.

\subsubsection{Uitrasonic System}

Both B\&W and Brown Boveri have recently made available ultrasonic inspection systems for detecting failed fuel rods in fuel assemblies. The ultrasonic detection is based on the presence of water inside the fuel rod and, therefore, its application to rods which have been in dry storage for an extended period is in some doubt.

In the $B \& W$ system, each probe consists of an ultrasonic transmitter and a receiver mounted on the end of a single flexible blade. The transmitter generates an uitrasonic pulse that produces a plate wave that travels almost completely around the fuel rod to the receiver. Since the fuel rod is surrounded by water, some of the puise energy is lost into the surrounding water as the signal travels around the fuel rod. On an intact fuel rod, which is dry on the interior, almost no energy is lost to the internal contents of the fuel rod. Thus, for a totally dry fuel rod, a large amount of the incident ultrasonic energy travels from the transmitter to the receiver. When the ultrasonic signal interacts with water on the inside rod wall of a leaking fuel rod, pulse energy is lost into the internally contained water and a smaller amount of incident ultrasonic energy travels from the transmitter to the receiver. This difference in transmitted energy is detected by the system and thereby identifies which fuel rods are leaking.

The manipulator mechnically inserts an array of ultrasonic probes into a fuel assembly just above the lower end fitting and traverses these 
probes past each fuel rod in the assembly. The manipulator is attached to a base plate that is installed on top of the fuel storage racks and can be adjusted to accommodate a range of storage rack designs.

The B\&W system operates from a trailer mounted control center which can be located up to 500 feet from the manipulator and uitrasonic probes. Visual contact with the operation is maintained via video display. Direct voice contact with the spent fuel handing bridge operator is al so provided to permit coordination of fuel movement to and from the system.

The Brown Boveri (BBR) Uitrasonic system is very similar to the B\&W system. The main difference is that the BBR system employs ultrasonic pulses passing between a transmitter and a receiver attached to separate probes that are traversed along opposite sides of each fuel rod.

According to BBR, the average inspection time per fuel assembly with their system is 30 - 50 minutes, including fuel assembly transport from the storage pool and return. To minimize the total time required for production line inspections BBR provides a two position inspection station. This allows one fuel assembly to be in position for inspection while a second assembly is being moved to or from the second inspection position, thus reducing the inspection time to approximately 15 to 25 minutes per fuel assembly.

By comparison, exclusive of setup time, examination of one fuel assembly with the $B$ \&W system requires between about 5 to 15 minutes depending on the fuel assembly and probe configuration. On this basis, with a two position inspection station, the total time required for production line inspections would not exceed fifteen minutes per fuel assembly.

\subsubsection{Effectiveness of Inspection Methods}

Experience with shipping and storage of spent fuel, much of which is presumed to have been defective, has given no indication of problems. Even dry storage of fuel has been accomplished without incurring degradation of the cladding (Johnson et al, PNL-4189). The concern with storage in air is the oxidation of the $\mathrm{UO}_{2}$ to $\mathrm{U}_{3} \mathrm{O}_{8}$ and the consequent expansion and cladding disruption. However, in controlled tests in air at $229^{\circ} \mathrm{C}$, it was found that 
only one of four intentionally introduced cladding defects showed indications of failure whereas there was no degradation of the three other defects after 5962 hours (Einziger and Cook, NUREG/CR-3708 and HEDL-TME-84-17).

Based on the experience and testing of spent fuel described above, it is concluded that defects which are not found in a thorough visual examination are not likely to cause problems in the shipping or limited dry storage of spent fuel. A requirement for sipping or other non-destructive testing at the reactor site does not appear to be supportable. Furthermore, the performance of such testing at the DOE receiving facility is not warranted since there is no useful response to positive indication of cladding defects other than canistering of the fuel which is a matter of routine in any case.

\subsection{CRUD SAMPLING/REMOVAL}

The term "crud" refers to a deposit found on the fuel rod surfaces as well as in other parts of the primary coolant system of the reactor. It is a deposition of corrosion products carried by the primary coolant stream and is radioactive as a result of neutron activation; it may also contain radioactive species released from breached fuel rods during reactor operation. The crud may be a dense adherent layer or it may only be loosely adherent. Some of the crud may be easily dislodged and there is the potential for spread of contamination in handling fuel assemblies.

Duke Power has reported that a large amount of crud was scraped off the rods while effecting bundle disassembly during the demonstration of rod consolidation in the Oconee fuel pool. One author (Bailey, PNL-3582) concludes that "crud on spent LWR fuel can have a very significant influence on the risk of transporting and handling operations with such fuel". There can be no doubt that there is a risk of dislodging the crud during handling and shipping operations. However, management of that risk may be properly assigned to a system which will be designed both for control of particulate contamination and for decontamination of the shipping casks and handling equipment. Thus, it is concluded that there is no need for crud sampling or removal at either the reactor site or the DOE receipt facility. It may be anticipated that any spread of contamination will be well controlled at the DOE facility. 


\subsection{LIFE CYCLE COSTS OF SPENT FUEL MEASUREMENTS}

The purpose of this section is to summarize the total life cycle and unit cost estimates for each of the types of measurements that may potentially be required in the utility or DOE portions of the waste disposal system. These costs provide a basis for cost comparisons between alternative measurement approaches and help give other perspectives on the issue of measurement. Some typical perspectives are mentioned in the conclusions of this section. The costs of measurement could also have been important, had this work determined that the accuracy of measured data was superior to the accuracy of alternative data. However, Section 4.0 indicates that the accuracy of direct spent fuel measurements is generally not as good as the accuracy of characteristics obtained using utility data. For this reason, the performance of cost-benefit evaluations of measurement program viability, as mentioned in section 3.4, is not required. The use of measurement cost data in such cost-benefit evaluations is therefore not illustrated in this report.

Life cycle costs are based on estimates of equipment costs, estimates of replacement equipment costs at appropriate times in the life of the operation, and on annual operating costs. All costs are estimated in 1987 dollars and discounted at a rate of $3 \%$ to the year 1987 from the year in which the costs are incurred. In addition, the levelized unit cost in $\$ / \mathrm{kgu}$ is calculated. This unit cost, if paid on each unit at the time of measurement, would resuit in a revenue stream that would have a total discounted value equal to the total discounted value of the cost stream. This unit cost is the total discounted value of all costs, divided by the total discounted fuel quantities valued at one dollar per unit. These level costs provide a useful means of comparing different types of measurements which have markedly different expenditure timings, or which have markedly different capital-cost/operating-cost characteristics.

The details of the cost evaluations for each of the measurement systems discussed in Section 4.0 are provided in Appendix D. These include the costs of measurenents at reactor sites and at DOE facilities. One of the principal costing assumptions for at-reactor measurements is that equipment will be purchased for that unit, and operated by utility staff, rather than using a service organization. The remainder of this section summarizes the results of those cost evaluations. 
The capital costs and man-hour requirements for measurement, which are the principal determinants of cost, and the resultant unit costs based on a $3 \%$ discount rate are summarized in Table 5-1. The detailed assumptions and costs underlying these data are described in Appendix 0 .

TABLE 5-1

SUMMARY OF MEASUREMENT COSTS

(\$1987)

\section{Measurement}

At-Reactor

Visual Inspection

Sipping

UTtrasonic Testing

Calorimetry (100\%)

Dimensions

Gamma Scanning

Weighing

At-DOE

Visual Inspection

Weighing

Sampling Calorimetry (9\% of packages)

Neutron and Gamma Counting

Combined Calorimetry/ Counting

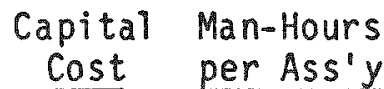

$(\$ 000)$

$$
212
$$

452

862

419

214

648

30

1218

55

1838

$552 \overline{5}$ per Ass'y

$9.6 / 6.7^{d}$

6.2

4.1

12.5

3.3

13.3

1.4

$6.7 / 4.7^{2}$

1.0

$64 / \mathrm{pkg}$

$20 / \mathrm{pkg}$
Level Unit Cost $\$ / \mathrm{KgU}$

\begin{tabular}{lll}
\hline PWR & & BWR \\
& & \\
2.60 & & 3.29 \\
3.16 & & 3.89 \\
4.83 & & 4.65 \\
3.90 & & 6.00 \\
1.55 & & 1.97 \\
5.36 & & 7.31 \\
0.40 & & 0.72
\end{tabular}

All Fuel

1.22

0.21

2.32 ( $\mathrm{Kg}$ measured)

0.28 (overall $\mathrm{Kg}$ )

$\underline{0.84}$

1.12

\section{$\overline{\text { a PWR/BWR }}$}

${ }^{b}$ Excludes cost of hot-cell space

A number of factors can be noted in a review of Table 5-1. The at-reactor measurements tend to have a relatively high unit cost because the equipment is assumed to be amortized over the spent fuel of only a single reactor. Furthermore all of the measurements are on single assemblies. This latter also causes the BWR unit costs to be higher than PWR costs, via the smaller mass of the BWR assembly. The exception to this generalization is for ultrasonic testing which is capital intensive, and for which the lower burnup of BWR fuel provides a larger weight base over which to amortize the 
investment. In contrast, the unit costs of measurement at DOE facilities are lower because of several factors including, (i) the high and continuous utilization of the measurement systems, (ii) a relatively higher average productivity of labor because of continuous, routine operations, and (iii) in the case of packaged wastes, fewer units to be handied because one package contains several assemblies. In the case of calorimetry, only $9 \%$ of the packages are assumed to be measured. It should be noted that for $100 \%$ calorimetry, an investment of $\$ 20.2$ million would be required for 11 parallel systems.

It was concluded in section 4.0 that the use of utility data, including discharge dates and utility-measured burnups, can provide more accurate waste characteristics than can be obtained by direct measurements. That conclusion, plus the conclusions in that section as to the limited operational value of some measurements, and the relatively high cost of measurements at utilities identified in this section indicates that as a general ruie direct measurements are not justified at utilities, other than the identification and visual inspections that are essential for certification of waste identification and condition at the point of transfer to DOE.

Even though the unit costs of direct measurement are lower in the $D O E$ system, the same observations concerning the superior accuracy of characteristics determined from utility-supplied data and the limited operational value of direct measurements, lead to a similar conclusion: direct measurements are not normally justified by operational requirements within the DOE system, regardiess of the fact that the unit costs of measurement may be relatively low. 


\section{$6.0 \quad$ ALARA CONSIDERATIONS}

The purpose of this section is to review the potential conclusions of this work with respect to the "as low as is reasonably achievable" (ALARA) principles, and identify ALARA-related modifications to those conclusions where appropriate. The guidelines and criteria for minimizing occupational and public radiation exposure and radioactive effluent releases are given in 10 CFR 50, Appendix I, and hence apply explicitly to power reactors and measurements that might be made therein. The requirement for addressing ALARA considerations is also stipulated in 10 CFR $72(.67(b)$ and $.74(d))$, which appl ies to MRS design and operation. It is not explicitly mentioned in 10 CFR 60 for application to the repository but must clearly be addressed.

It is clear that ALARA considerations must be addressed as a part of any recommendation favoring the use of direct measurements because the process of measurement clearly increases occupational exposure as contrasted to a no-measurement situation. The measurement of radioactive waste involves at least some increase in radiation exposure, directly in the measurement itself, and/or. indirectly through maintenance of the measurement equipment. However, it should al so be noted that if a direct measurement is justified, it is likely to have operational benefits that offset or even exceed the direct costs and impacts of measurement, including ALARA impacts. Thus the following consideraton of ALARA issues includes both the impacts and benefits of direct measurement.

It is noted in this report that each fuel assembly requires a visual inspection by the utility just prior to loading into the cask in which it will be delivered to DOE. The purpose of this inspection is to identify the assembly and accurately characterize its condition in order to meet the contractual requirement for certification of the fuel at the time of delivery to DOE. A related recommendation is that DOE identify and inspect each delivered fuel assembiy at the point of its first handling in the DOE system. The principal increase in radiation exposure would probably be experienced at the utility, where the inspection involves additional staff time above the fuel pool where radiation levels typically average upward from $1 \mathrm{mr} / \mathrm{hr}$. The increase at the DOE facility is probably less because the inspection is done remotely in a hot cell using technologies and equipment selected for 
production operations with ALARA considerations in mind. Because the requirement for utility certification of fuel identity and condition is a clear contractual requirement, there do not appear to be val id al ternatives to direct inspection. Thus, ALARA considerations could influence the type of inspection equipment that would be used, but not the requirement for inspection. Furthermore, the purpose of the inspection is to provide accurate characterization of fuel condition. These data are of subsequent operational value in reducing unforseen operational difficulties and improving contamination control, both of which have operational ALARA benefits. In summary, there does not appear to be a valid basis for altering the recommendation of delivery and acceptance inspections because of ALARA considerations.

The major finding of this work is that utility data on spent fuel burnup can in most instances provide waste characteristics that are more accurate than data obtained via direct measurement of the waste. Thus, in most instances, direct measurements cannot be justified. ALARA considerations reinforce this major conclusion.

This report also notes two instances in which the future evolution of design and licensing could conceivably result in a requirement for direct waste measurements. In both instances the ultimate decision on the need for direct measurement would involve consideration of design and safety issues, including ALARA. In these instances, the application of ALARA must await future developments, and does not influence the current conclusion. For the same reason, ALARA considerations do not alter the recommendation that repository surface facility layouts provide sufficient space for possible waste package measurement stations until the final design and 1 icensing of those facilities resolves the current uncertainty.

In summary, ALARA factors do not alter the recommendation of utility and DOE inspections of spent fuel at the point of delivery and acceptance, al though ALARA factors are likely to influence the manner in which such inspections are made. ALARA considerations reinforce the other primary conclusion regarding the general superiority of utility data over directly measured data for the conduct of DOE operations. The other observations in the report are generally ALARA-neutral because they relate to future application of ALARA principles. 
Preceding sections have identified the needs for data on nuclear waste characteristics, the alternative sources and accuracy of such data, and the costs of direct measurements. The purpose of this section is to discuss the needs for specific data in each portion of the waste disposal system and identify those areas in which measurements are required.

The primary need for waste characteristics data that might be satisfied through direct measurement is in support of operations of the waste disposal system. Specifically, costs and operational impacts are minimized if the various waste containers (casks, packages, etc.) are selected so as to best match the waste characteristics. The primary waste characteristics are spent fuel burnup and age because all other characteristics such as gamma, neutron and thermal outputs, and isotopics can be obtained if fuel burnup and age are known. The primary sources of waste characteristics data are (i) utility measurements of burnups and discharge dates, and (ii) direct measurement of gamma, neutrons, thermal output, or other appropriate characteristics. Uniess specifically required by regulations or for operational safety, operational measurement of specific fuel characteristics are justified only to the extent that they can provide data that are more accurate than the alternatives, and from which operational savings can be realized that are greater than the cost of measurement.

7.1

PRIMARY CONCLUSION

A primary conclusion of this work can now be derived from prior sections, concerning the relative accuracies of utility-supplied data and of direct measurements. Because utilities use detailed in-core measurement and related analysis systems in connection with power reactor operations, the burnup of individual fuel assemblies is known to within about $2 \%$ for equilibrium fuel cycles. Utility-supplied batch average burnups are more accurately known, probably approaching the measurement accuracy of total reactor core thermal power. Burnups are known accurately because they are based on regular and extensive measurements of reactor power and power distribution. While the utility-reported burnups are a direct measurement of the amount of energy derived from fuel, they are not a direct measure of the 
radiation or decay heat output following fission. The latter relationship has been developed from literally thousands of individual measurements on isotopes, which are then aggregated into computer-based models, such as ORIGEN2, that predict the gamma, neutron and thermal output of spent fuel as a function of burnup and cooling time (age). The detalled and aggregate predictions of these models are then validated (Roddy 1987). and can be used thereafter to made the conversion from burnup and age to gamma, neutron, and thermal output, and vice versa.

With respect to direct measurements of gamma or neutron output, calibration of the counting equipment with fuel of known burnup and age and identical geometry is an essential element of the measurement. Therefore, the accuracy of burnup and age inferred from gamma and/or neutron measurements cannot be better than the accuracy of burnup and age of the reference fuel used in calibration. If fuel age is known, neutron counting can measure burnups to within about $3 \%$, which includes the $2 \%$ uncertainty in the reference fuel burnup. However, if neither burnup nor age of an assembly are known, burnup can be measured to within about $5 \%$, but with current measurement technology, fuel age cannot be measured with enough accuracy to confirm discharge dates with reasonable certainty for fuel ages greater than 10 years. With respect to the direct measurement of decay heat, there is agreement with ORIGEN2 calculations to within about $10 \%$, but there are strong indications that much of this uncertainty is due to calorimetry measurement uncertainties rather than to actual differences. The principal conclusion then, is that the use of utility-supplied data on the measurement of spent fuel burnups and age will give more accurate operational data than direct measurements of the gamma, neutron and thermal outputs of spent fuel. It is further noted that current measurement technology cannot provide an independent measurement of fuel age that is sufficiently accurate to confirm spent fuel discharge dates of fuel older than about 10 years.

Therefore, the primary conclusion of this work is that unless a measurement is required for operational safety or regulatory reasons, direct measurements of fuel characteristics will not normally be justified because the information gained thereby would be less accurate than obtainable using utility-supplied data on fuel burnup and age. The underlying reason for this 
is that burnup and age are the independent variables, the utilities are the only ones in the position to measure these independent variables directly, and the utilities make these direct measurements very accurately. The possibility that errors could be added to the utility-supplied data through fuel or data-handling errors appears to be small, but needs to be quantified. All utility operations are subject to pre-approved procedures, recordkeeping, and quality assurance practices that include independent confirmation of the final result of all significant operations. Although an industry-wide quantification has not been made of the probability of mislocating fuel assemblies as a result of handling operations, it is known to be very low. Therefore, there is a sound technical basis for accepting the utilitysupplied data as being an accurate characterization of the burnup and age of the fuel. Assuming that a similar level of QA is utilized within the DOE system, such data will continue to be the most accurate source of waste characteristics data whenever the fuel is handled within the DOE system.

The preceding general conclusions with respect to the need for waste characteristics measurements is now discussed for each specific point in the waste disposal system at which measurements might be made.

7.2

REQUIREMENTS FOR DIRECT MEASUREMENT

The above conclusion concerning the superior accuracy of utility-supplied data on spent fuel, as contrasted to directly-measured data has general implications to those parts of DOE operations involving the matching of waste characteristics to casks, waste packages and emplacement spacing: direct measurements are not justified as the source of data for operational planning. However, that primary conclusion does not apply to measurenents required for operational safety or regulatory reasons. Because direct measurement is the only immediate way to detect cask or waste package loading errors, measurements are required when the probability and consequences of an adverse loading error have safety significance. Also, direct measurements are needed when they are required by a regulation or contract. The following summarizes the prior observations of this report with respect to direct measurements within each of the major elements of the system. The primary focus is on safety-related, regulatory and contract-mandated needs for direct measurement, under the assumption that 
operational needs for waste characteristics data will be met using utility data.

From-Reactor Cask Loading: The Standard Contract between each utility and DOE requires that the utility certify as to the identity and condition of each assembly delivered to DOE, as loaded in a from-reactor transport cask. The only realistic basis for such a certification is a direct visual identification and examination of each assembly to assure that any visually-detectable distortions or failures of structural parts or fuel rods are identified and accurately described. This contractual requirement for a visual examination also satisfies SNM accountability requirements for identification at the point of physical transfer, and is also sound business practice for transfer of title and legal ownership.

The principal issues related to operational safety and regulations at the point of loading spent fuel into transport casks in utility pools are (i) criticality, and (ii) loading the cask at, or below, its i icense (certificate) limit. With respect to criticality, if the cask is not a burnup-credit cask and the initial enrichment is no greater than the cask certificate limit on enrichment, the probability of a criticality incident is virtually nil, and cask loading measurements related to criticality have never been required. If the cask is a burnup-credit cask, it must be loaded with fuel whose burnup is no less than the minimim burnup that is licensed for its particular enrichment. There are three possible bases for assuring that the loaded cask meets the license subcriticality requirements: (i) use utility burnup records and cask loading procedures which parallel those already in successful use with burnup-credit storage racks, (ii) measure burnup via neutron counting, using assemblies of known burnup and age for calibration, and (iii) measure reactivity directly. It is likely that the selection among these three options will be done at the time of final design and licensing, based on cask reactivity design margins and evaluations of the probability and consequences of fuel loading errors. Therefore, if burnup-credit casks are to be used, the possible need for direct measurements related to reactivity control during cask loading cannot be determined until the requirement for such a measurement is negated or confirmed at the time of burnup-credit cask design and certification.

Once the cask is loaded, the principal concern is that the external radiation and temperatures be below license limits. The cask survey process that assures below-limit loading includes standard measurement processes that are not the subject of this work. However, this routine measurement is important because it provides assurance against cask overloading: a cask found to exceed external limits would have to be partially unloaded to achieve transportability. Hence special measurements are not required to confirm cask loading. 
In summary, the use of utility data on fuel burnup plus proven administrative procedures for controlling cask loading provides the most accurate data for loading from-reactor transport casks. The possible use of burnup-credit transport casks might generate a future requirement for direct reactivity-related measurements at the time of cask loading, but there are established and functioning alternatives to direct measurement. This possible future requirement for direct measurement cannot be resolved with certainty until the time of final burnup-credit cask design and certification.

Acceptance at First DOE Facility: A visual identification and inspection of each assembly or container at the point of unloading is required for positive identification of each item, to provide independent confirmation of cask loading, and to check for possible damage as a result of transportation. Identification and inspection is also a requirement of SNM accountability which is applied on the basis of item identification.

A variety of other measurements could be proposed at the point of first DOE acceptance, on the basis of independent confirmation of characteristics, including both the radiation and nuclear data, and the form and condition data categories that were described in Table 3-2. However, unless independent confirmation were a regulatory requirement, such measurements would not yield data of greater operational significance than data already available. Measurements in the radiation and nuclear data category would yield data that are less accurate than data developed on the basis of utility-supplied burnup and age; and the form and condition measurements do not appear to have operational value over what is available or what is assumed in design. For example, utilities must identify distorted and/or failed fuel as a condition of fuel acceptance, and must encanister any fuel that may be the source of particulate contamination. Any lesser category of failure is not likely to cause operational consequences within the DOE system. The measurement of crud does not have operational significance to the DOE system because the presence of crud and other potential sources of particulates is anticipated in design and provision is made for handling it. Quantitative data on crud have no additional operational value.

In summary, the only measurement of fuel that appears justified at the point of waste acceptance in the first DOE facility is a visual identification and inspection of each assembiy or container at the point of transport cask unloading. Any other measurements provide information that is less accurate than, or duplicates information available from utilities, or provides information that does not affect operations.

Selection of Fuel for Reconfiguration or Packaging: Fuel is selected for consolidation, reconfiguration and/or packaging on the basis of particular characteristics, such as age (oldest first) or thermal output (coldest first, or blended). A typical objective is 
to match the waste characteristics to the container or package so as to minimize the numbers of containers or packages. The accuracy of waste characteristics may be important because it determines how closely the container design limit can be approached, as was discussed in Section 3.4. Again, direct measurement of characteristics or use of characteristics derived from utility burnup and age data are the alternatives. Because the utilitysupplied burnup and age data give characteristics that are both more accurate and available without the expense of a measurement program, use of the utility-supplied data will provide the best waste characteristics information needed for packaging or reconfiguration.

Loading of MRS Storage and From-MRS Transport Casks: The issues in MRS storage and from-MRS transport are similar to the issues in from-reactor transport. The differences, if any, will be because of differences in the criticality area, which will be dependent upon the form of the fuel in the MRS storage and from-MRS transport casks and on the cask designs. However, unless direct measurement is required by the cask license, the superior accuracy of waste characteristics determined from utility-supplied burnup and age data makes it the preferred data source, as was the case in fromreactor transport.

Waste Package Loading and Emplacement: The primary waste characteristic in waste package loading and package spacing is the thermal output of the spent fuel. The heat-imposed limits translate into a maximum acceptable $\mathrm{kw} /$ package output at the time of loading and a maximum thermal deposition per unit area of repository horizon, with the integrating period for heat deposition being dependent upon which of a potential variety of thermal limits proves to be the ultimate limit. The integrated heat output depends upon both the heat output and the age at the time of emplacement. Waste package calorimetry therefore appears at first glance to be a natural candidate for direct measurement. However, calorimetry proves to be the least accurate and most expensive of the alternatives, and there is substantial question that laboratory wet calorimetry can be adopted for production measurements. Calorimetry therefore appears to be unsuitable for direct production measurements of waste packages. Neutron measurements were shown to be the most accurate of the direct measurement technologies. Further, if both heat output and age were to be measured, two different measurements are required and the accuracy of the age determination is very poor for fuel of age greater than 10 years. Again, utility data proved to be the most accurate source of data for planning waste package loading and emplacement.

Thus, the potential need for direct measurements is again 1 imited to situations involving safety and/or regulatory requirements. specifically, the dominant safety/regulatory issue involves the probability and consequences of a waste package loading error. It is not clear that there are significant safety consequences of isolated waste package loading errors. Nonetheless, until final 
design and licensing of the waste package and the repository it is not possible to say that confirmatory measurements of waste package loadings will not be required. Further, although current regulations do not require specific measurements, current US safeguards requirements are being examined with respect to spent fuel disposal and the implications of applying IAEA safeguards to that process. Al though the incentives for any changes from current regulations are institutional, it is possible nonetheless that changes could invoke direct measurements. Again, until final actions are taken, the possibility of a requirement for direct measurement of waste package loadings cannot be dismissed. Given the lack of a current requirement or clear evidence of a future requirement for direct waste package measurements, no current recommendations for production measurement of waste packages can be made. Nonetheless, it would be prudent for the layout of waste packaging and handling facilities to include space that could be utilized for direct measurement of waste package loadings. In this way, future resolution of this issue can be accommodated without major disruptions in facility designs or related delays in schedules.

In summary, this section has observed that utilities are able to directly measure the primary independent variables of burnup and age, and to do so with an accuracy that is superior to other measurement methods. Because of this, it is concluded that the utility-supplied data on burnup and age should be the primary source of data on fuel characteristics throughout the utility and DOE waste management systems and a program of direct measurements in support of DOE operational planning cannot be justified except in three circumstances:

(1) Visual identification and inspection of spent fuel is required of the utilities just prior to loading of from-reactor transport casks.

(2) Visual identification and inspection of spent fuel is required at the time of cask unloading at the DOE facility that first unloads the from-reactor shipment.

(3) Where explicitly required by future regulations or operational safety requirements. In this regard, there are three currently-identifiable situations in which the possibility of a future direct measurement requirement cannot be dismissed: 
- to confirm burnup-credit transport cask loadings for operational safety reasons.

- to confirm waste package loadings for repository performance reasons, and

- to confirm waste package loadings in compliance with future safeguards requirements. 


\subsection{REFERENCES}

BARNER 1985. J. 0. Barner, "Characterization of LWR Spent Fuel MCCApproved Testing Material-ATM-101", Pacific Northwest Laboratory, PNL-5109, Rev. 1, June 1985

BERNARD 1986. P. Bernard, G. Frejaville, J. Pinel, "Fuel Assembly Identification in French Reprocessing Plants" Centre d'Etudes Nucleaires de Cadarache, in Proceedings of the Institute of Nuclear Materials Management, June $22-25,1986, \mathrm{pg} .653$

CREER 1981. J.M. Creer and J.W. Shupe, Jr., "Development of a WaterBoiloff Spent Fuel Calorimeter System", Pacific Northwest Laboratory, PNL3434, May 1981.

CREER 1987. J.M. Creer et al, "The TN-24P PWR Spent-Fuel Storage Cask: Testing and Analyses", Electric Power Research Institute, EPRI NP-5128, April 1987

CROFF 1980. A.G. Croff, "ORIGEN-2 - A Revised and Updated Version of the Oak Ridge Isotope Generation and Depletion Code", Oak Ridge National Laboratory, ORNL-5621, 1980

DOE 1987. "Characteristics of Spent Fuel, High Level Waste, and Other Radioactive Wastes Which May Require Isolation", U.S. Department of Energy, DOE/RW-0184 (6 Volumes), December 1987

DZIADOSZ 1986. D. Dziadosz et al, "The Castor-V/21 PWR Spent-Fuel Storage Cask: Testing and Analyses", Electric Power Research Institute, EPRI NP4887, November 1986

EICH 1986. W. J. Eich et al, "Cell Isotopic Benchmarking", Electric Power Research Institute, EPRI NP-4574, October 1986

GOLDSTEIN 1984. N. P. Goldstein and R. W. Chickering, "Development of a Burnup Meter for Irradiated Fuel", Westinghouse Electric Corporation, WCAP10536, February 1984

JOHNSON 1987. A. B. Johnson, Jr., et al, "Recommended Temperature Limits for Dry Storage of Spent Light Water Reactor Zircaloy-Clad Fuel Rods in Inert Gas", Pacific Northwest Laboratory, PNL-6189, May 1987

MCKINNON 1986. M. A. MCKinnon et al, "BWR Spent Fuel Storage Cask Performance Test", Pacific Northwest Laboratory, PNL-5777 Vols. 1 and 2, February 1986

MCKINNON 1987. M. A. MCKinnon et al. "The MC-10 PWR Spent-Fuel Storage Cask: Testing and Analyses", Electric Power Research Institute, EPRI NP. 5268, July 1987 
MIHALCZO 1985. J.T. Mihalczo et al, "252-Cf-Source-Driven Neutron Noise Analysis Measurements for Coupled Uranium Metal Cylinders" Trans. Am. Nucl Soc., 49, 241 (1985)

PARKOS 1977. G. R. Parkos and G. F. Volby, "Gamma Scan Measurements at Zion Station Unit 2 Following Cycle 1", Electric Power Research Institute, EPRI NP-509, October 1977

PHILLIPS 1983. J. R. Phillips et al, "Experience Using A Spent-Fuel Measurement System", Los Alamos National Laboratory, in Proceedings of the Institute of Nuclear Materials Management, July 10-13,1983 pg. 175

RODDY 1987. J.W. Roddy and J. C. Mailen, "Radiological Characteristics of Light Water Reactor Spent Fuel", Oak Ridge National Laboratory, ORNL/TM10105 , December 1987

ROTHLEDER 1985. B. M. Rothleder, "PWR ARMP System Benchmarking, Volume 1: Zion Unit 2, Cycle 1". Electric Power Research Institute, EPRI NP-4148, Volume 1. September 1985

RYMAN 1982. J. C. Ryman et al, "Fuel Inventory and Afterheat Power Studies of Uranium-Fueled Pressurized Water Reactor Fuel Assemblies Using the SAS2 and ORIGEN2 Modules of Scale With An ENDF/B-V Updated Cross Section Library", Oak Ridge National Laboratory, NUREG/CR-2397, September 1982.

SANDERS 1987. T.L. Sanders, R. M. Westfall and R. H. Jones, "Feasibility and Incentives for the Consideration of Spent Fuel Operating Histories in the Criticality Analysis of Spent Fuel Shipping Casks", Sandia National Laboratories, SAND87-0151, August 1987

SCHMITTROTH 1984. F. Schmittroth, "Origen2 Calculation of PWR Spent Fuel Decay Heat Compared With Calorimeter Data", Hanford Engineering Development Laboratory, HEDL-TME 83-32, January 1984.

UNTERMEYER 1983. S. Untermeyer II, "Development and Test Methods for the Nondestructive Assay of Spent-Fuel Assemblies, Electric Power Research Institute, EPRI NP-2812, January 1983 
APPENDIX A

THE RELATIONSHIP BETWEEN TECHNICAL LIMITS, DESIGN LIMITS, DESIGN LOADINGS AND ACCURACIES OF DATA 
APPENDIX A

THE RELATIONSHIP BETWEEN TECHNICAL LIMITS, DESIGN LIMITS,

DESIGN LOADINGS AND ACCURACIES OF DATA

The purpose of this Appendix is to develop and discuss an important aspect of facility and equipment design--the relationship between technical limits, design limits, design loadings and the accuracies of the data available for each of these elements. The basic concept is that in design of a facility or component, some primary technical limit is encountered, beyond which unacceptable performance is likely to be encountered: the prudent designer picks a design point below the technical limit to provide a margin of safety: and the facility or component operator subsequentiy loads the facility or component below the design point by an amount sufficient to assure, with a stipulated high degree of confidence, that the design point will not be exceeded. The degree of confidence depends directly on the accuracy (i. e., standard deviation) of the data on which the operational loadings are being based.

The relationships between a technical limit, a design point, a design loading and the accuracies of the data are depicted in Figure A-1 for the situation in which the data supporting the technical limit, $T$, has uncertainty, and the data supporting the design loading, $L$, also has uncertainty. The degree of uncertainty is depicted on the vertical axis as probability curves characterized by the standard deviations, $\sigma_{T}$ for the technical limit and $\sigma_{L}$ for the data on which loadings are being based. With a design margin, $M$, that is fixed, the uncertainty in the design limit, $D$, is equal to the uncertainty in the technical limit. Under these circumstances, if the design loading is to be below the design limit by an amount that assures a design margin with a specified level of confidence, the separation, $S$, is given by:

$$
s = k \longdiv { \sigma _ { T } ^ { 2 } + \sigma _ { L } ^ { 2 } }
$$

Eq. A-1 


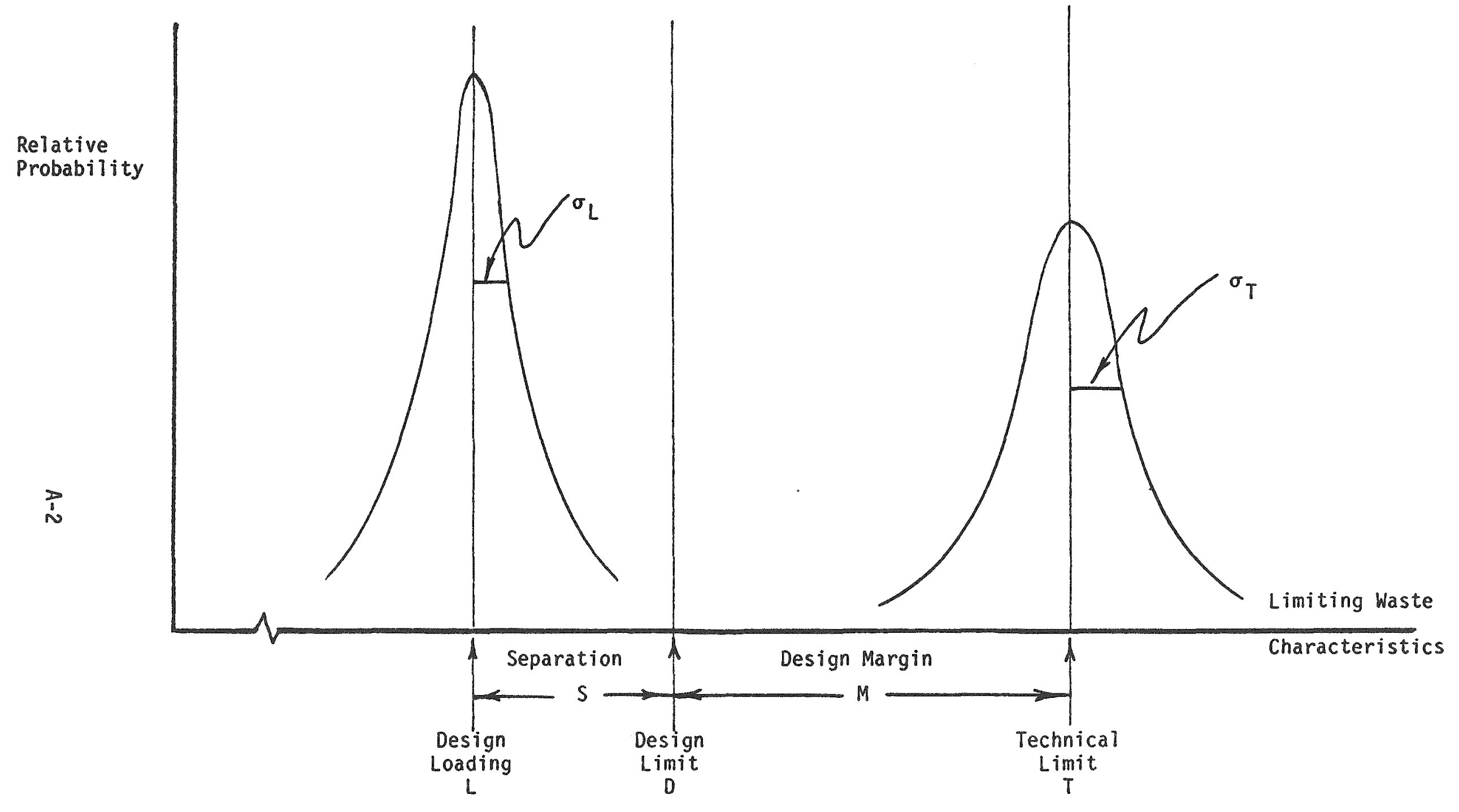

FIGURE A-1

RELATIONSHIPS BETWEEN DESIGN FACTORS AND DATA ACCURACY 
where $k$ is dependent on the desired confidence level and is given by:

\begin{tabular}{cc} 
Confidence Level & $\begin{array}{c}\text { Factor } \\
k,\end{array}$ \\
\cline { 2 - 2 } $90 \%$ & 1.28 \\
$95 \%$ & 1.65 \\
$99 \%$ & 2.33 \\
$99.9 \%$ & 3.09 \\
$99.99 \%$ & 3.70
\end{tabular}

The confidence levels given in this table assume that both the technical limit and the design loading are normally (Gaussian) distributed. If the distribution of one or both of the random variables is not normal, but is known, then the appropriate $k$ factor can be calculated to give a specified confidence level. In many situations, the design limit is set directly in a standard or regulation, or the technical limit is known exactly (such as in criticality). In these circumstances there is, in effect, no uncertainty in the technical limit $\left(\sigma_{T}=0\right)$ and the separation is given by:

$$
S=k \sigma_{L}
$$

It is apparent in comparing Equations $A-1$ and $A-2$ that the nature of the design limit can have a significant impact on the potential benefits from improved accuracy in the waste characteristics data: if the design limit acknowledges the uncertainty in the technical limit, benefits from improvements in the accuracy of waste characteristics could be significantiy reduced because of the parallel importance of the technical limit uncertainty (Eq. A-1). However, if the design limit is specified directly, Equation A-2 applies, and benefits from improved accuracy in waste characteristics data translate directly into increased design loadings.

The relationship between technical limit, design limit, design loading, and the accuracy of the data used for loading is important to the choice between use of directly-measured dta and historical data. Figure A-2 compares the design loadings when using more-accurate and less-accurate data. The third and fourth points on the $x$-axis represent design loadings based on more accurate and less accurate data when the required level of confidence is $99 \%$ that the design 1 imit will not be exceeded. At this confidence level, the 
design loading is 2.33 standard deviations below the design limit. Also shown on the $y$-axis of Figure A-2 are the relative probability curves for the moreaccurate and less-accurate data. These curves show the relative probability of actual values of the waste characteristic when the most probable values are 2.33 standard deviations below the design point. Under these circumstances $99 \%$ of the area under each relative probability curve falls below the design limit, this being the definition of $99 \%$ confidence. However, in order to achieve the same level of confidence, the design loading based on the less accurate data must be below the design loading based on the more accurate data by an amount given by:

$$
\text { Reduction }=2.33\left(\sigma_{2}-\sigma_{1}\right)
$$

As an example, if the less accurate and more accurate data had standard deviations of $8 \%$ and $5 \%$ respectively, the waste loadings based on the more accurate data could be $7 \%$ greater $(2.33 \times(8 \%-5 \%)$ than with the less accurate data, at equal confidence levels. This example serves to demonstrate that as a minimum, a program of direct measurement must produce more accurate data than available from alternative sources in order that there be any benefit from direct measurements. The accuracies of data from any source must include appropriate allowances reflecting the relative possibilities of administrative error in handling the data and in attributing the data to specific waste units. 


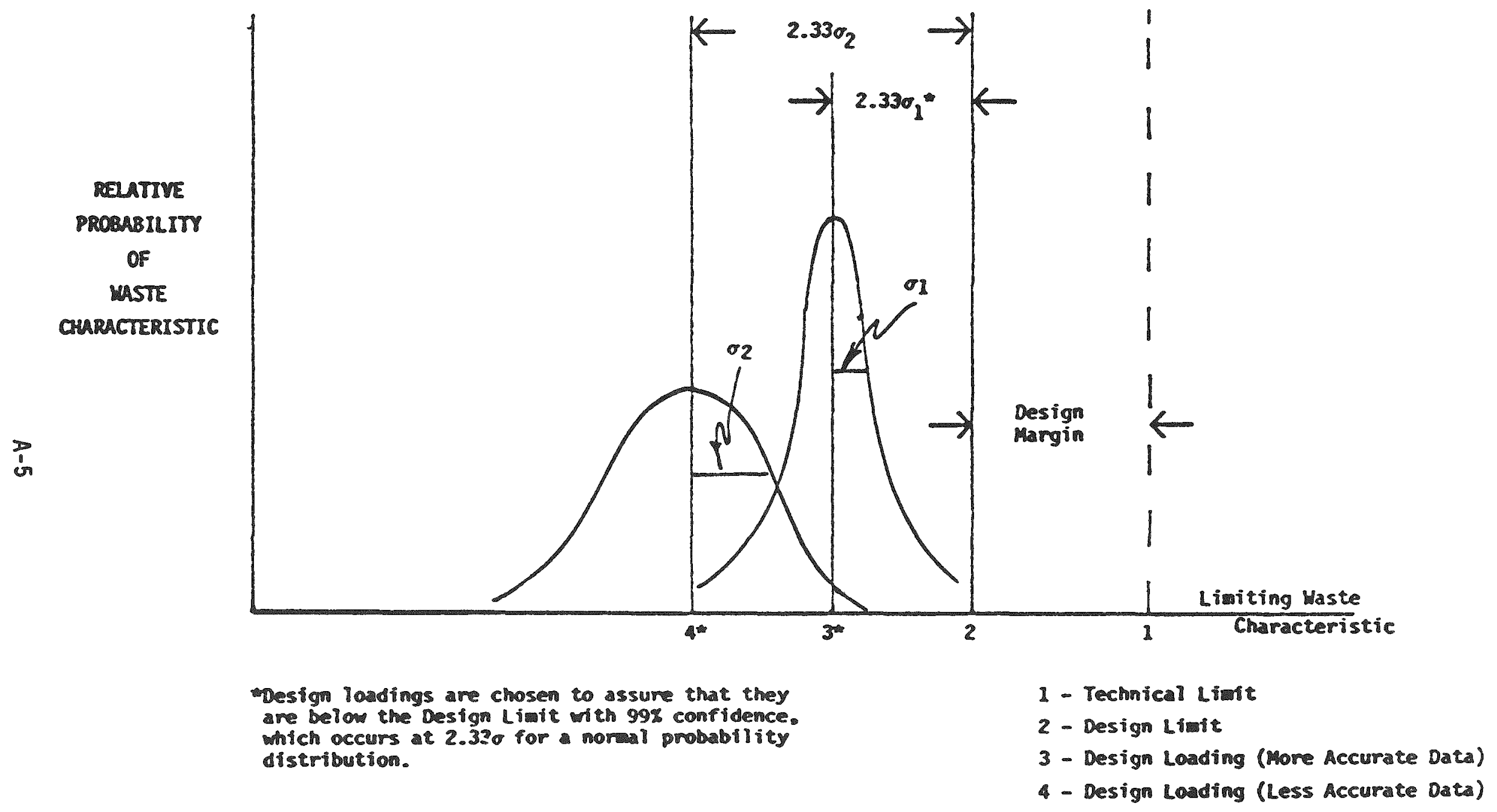

FIGURE A-2

RELATIONSHIP BETWEEN TECHNICAL LIMIT, DESIGN LIMIT, AND OESIGN LOADINGS 
APPENDIX B

ACCURACY OF UTILITY BURNUP MEASUREMENT 
APPENDIX B

TABLE OF CONTENTS

Page

1.0 CORE THERMAL POWER MEASUREMENT ACCURACY B-2

2.0 ENERGY ALLOCATION TO INDIVIDUAL FUEL ASSEMBLIES B-3

$\begin{array}{lll}3.0 & \text { CONCLUSION B-14 }\end{array}$ 


\section{APPENDIX B \\ ACCURACY OF UTILITY BURNUP MEASUREMENT}

The purpose of this Appendix $B$ is to provide estimates of the accuracy of utility-supplied information on burnup, and to summarize the factors which determine that accuracy. The primary sources of fuel burnup and age information are the measurement-based operational records and the fabricators' fuel descriptions kept by utilities. Measured and integrated total reactor thermal power is allocated to individual fuel assemblies via calculation and measurement of reactor power shapes. The age of discharged fuel is based on the date of reactor shutdown (loss of criticality) prior to final discharge of the fuel. These data are used by the utilities for a variety of purposes including fuel cycle optimization, fuel reload planning, fuel performance warranty adjustments with fuel vendors, and for special nuclear material accountability reporting. These records are administratively controlled and are tied to specific fuel assemblies by the fuel assembly identification number stamped on the upper fitting of the assembly. When fuel is consolidated or reconstituted at the reactor, the consolidation/reconstitution records provide the traceability to the resulting consolidated canister identification number or reconstituted assembly identification number.

The accuracy of the by-assembiy burnup data that are developed as described above is determined by the accuracy of the individual steps and includes:

(1) The accuracy of the measurement of integrated reactor thermal power.

(2) The accuracy of the combination of in-core measurements and analytic methods by which total reactor power is allocated to individual assemblies.

(3) The degree of certainty that the administrative aspects of fuel assembly placement in-core and the record-keeping are accurately executed.

The following sections address each of the above and their relative contributions to overall accuracy. 
The accuracy of total core (fuel) thermal power measurement is about $1 \%$, and as will be seen, this is small compared to the other accuracies that contribute to the overall accuracy of by-assembly burnup data. Because the less accurate factors dominate, the very good accuracy of total core power measurement does not contribute to or influence the overall accuracy of fuel assembly burnups in a significant way. The ASME Test Code for Nuclear Steam Supply Systems (ANSI PTC 32.1-1974) describes the methods, measurements and required accuracies for measuring the total core thermal power of pressurized and boiling water reactors. It is based on a complete steady state energy rate measurement across a defined envelope that includes the nuclear steam supply system. Its primary components are the energy rate in steady state steam flow as measured by steady state feedwater flow and the enthalpy difference between the steam (temperature and quality measurement) and the feedwater (temperature measurements). Measured energy losses and credits are included for blowdown (if any), letdown and makeup (PWR), seal water, component cooling water, electrical power inputs to pumps, heaters and miscellaneous equipment, and radiative and convective losses. The test code requires the use of calibrated flow measurement devices and readouts capable of measuring feedwater flow to within $0.7 \%$. All other flow measurements are to be of sufficient accuracy that, in total, they do not affect overall power level measurement by more than $0.1 \%$. Temperature measurements are to be made within $0.25 \%$ and pressure measurements are to be made within $0.5 \%$. There are several methods suggested for the measurement of quality. The net result of these various measurement accuracies, assuming independent sources of error, is an overall core thermal output uncertainty of somewhat less than $1 \%$ at the time of measurement. Subsequent operational measurements use the same instruments or instruments calibrated to the original measurements, such that the original full power, steady state accuracies should be substantially maintained during operations. The effects of transients, below full power operations, and the possibility of instrument calibration drift between periodic calibrations all act in the direction of tending to increase the uncertainty associated with routine operational power level measurements. The net effect of these operational factors is judged to yield an accuracy of about $1 \%$ for operational power level measurements. 
The accuracy of the allocation scheme by which total core power is assigned to individual fuel assemblies is in the range of $3 \%$ to $6 \%$ depending upon the nature of the in-core instrumentation and the software used to simulate the in-core power distribution and interpret the in-core measurements. This uncertainty level dominates the overall accuracy of the burnups of individual fuel assemblies. The purpose of this subsection is to summarize the methods by which the combination of measurements and calculation are used to allocate total core energy to the individual fuel assemblies in the core, and the factors affecting the accuracy of that process. The in-core measurement systems, the computational systems used to interpret the measurements and allocate energy, and the probable accuracy of the resulting allocation are described.

The in-core measurement systems are installed by the nuclear steam supply system (NSSS) vendor as a part of the original NSSS scope of supply. There are differences among the four NSSS vendors but the systems all provide for arrays of fixed and movable detectors for measuring gamma flux (ion chambers) or neutron flux (fission chambers or flux wires). The detectors are positioned so as to make measurements at several points along the axis of the fuel assemblies in specific core locations, and several of these axial strings are located in representative sections of the core to monitor radial power distribution. Typically one quarter or one eighth of the core will be more heavily instrumented to obtain local detail that will be assumed, via symmetry, to apply to the rest of the core. The rest of the core will be more lightly instrumented to measure gross power distribution. Movable detectors are used to cross calibrate fuel detector readings. The net result of these in-core systems is the ability to provide relative measurements at many discrete points throughout the core. However, these relative measurements must be interpreted in order that they represent relative power levels. For example, fission chambers measure principally the thermal neutrons that result from the slowing down of fast neutrons, which in turn result from fissions in the near vicinity of the fission chamber. The thermal neutron levels are also sensitive to nearby neutron absorbers which, unless they are fuel rods, are not related to local power levels. In effect the fission chamber provides a local average measurement that can be related to local 
power level via an appropriate analytical model which takes local absorbers into account. Flux wires, in which a particular wire component is activated by thermal neutrons, produce a similar local average measurement that is continuous axially which can be related to local power. Ion chambers measure the gammas from fissions in the vicinity of the ion chamber, which can be related to local power somewhat more directly than neutron measurements. The size of the volume over which the local averaging occurs is a sphere of a few inches in diameter, with the detector at the center, and with the fuel moderator and neutron absorbers closest to the detector having more significance than those farther away. Since the spacing between detectors is typically greater than the effective sensing diameter of the detectors, there is typically no measurement information as to what is occurring between detectors. Thus the software that must be used in conjunction with the detectors has two minimum performance requirements: it must be able to relate the detector readings to relative flux and power; and it must be able to accurately provide the same types of information in the substantial portions of the core that are not instrumented and measured.

The software that is a necessary complement to the in-core monitoring systems is available from a number of sources and at various levels of core and fuel detail. These same sources will also provide the results of using these software systems on a regular service basis in support of reactor operations and other functions. The software and/or services are available from the original NSSS vendor who supplied the in-core system and the initial fuel loading. They are also available from reload fuel vendors, and from specialty service organizations. Most of these sources utilize proprietary techniques, which may explain the relative paucity of publicly available information on these systems and their accuracies. Fortunately, the utilities, through the Electric Power Research Institute (EPRI) have developed a core analysis system (the Advanced Recycle Methodology Program, ARMP) to support the operational, fuel management and special nuclear material (SNM) accountability needs of utilities operating nuclear power units. The ARMP system, with its ability to interpret and use in-core measurements, to provide flux and power distribution data, and to reflect changes in fuel and nuclear absorber characteristics as fissionable and absorbing material is consumed, is typical of all such operational systems 
(Rothleder, 1985). Most of these systems can be made to represent fuel and core behavior at a level of detail that goes well beyond operational needs, and would also require significant resources in terms of staff and computer capability. As a result, these systems are typically utilized only to the level that is judged necessary for supporting operations. The primary operational requirement is the regulatory requirement that the reactor operator be able to predict control rod positions and/or coolant boron concentrations (PWR) within defined limits throughout a cycle. An additional requirement is that the core power distribution be known sufficiently well to assure that the highest local power density is below the licensed limiting power density at all times. These require a very detailed physical and neutronic representation of the system at the start of a cycle, and a less detailed representation of the system thereafter to represent the effects of burnup increases, including fuel depletion. Although the principal criterion is accuracy in the neutron balance (reactivity), this requires an accurate representation of power distributions. These, plus the direct measurement of total core thermal power, provide the burnup increments per unit of time. These in turn are needed for representing the effects of fuel burnup on fuel characteristics, for subsequent reactivity balances and power distributions. Fuel assembly burnup information is also needed in fuel reload planning by utilities and fuel vendors. Burnup is also needed in connection with vendor warranties of fuel performance, but because warranties are based on batch average or core average burnups, the accuracy of individual assembly burnups is not a major concern. The primary mode of SNM accountability for fuel assemblies is item control, rather than detailed content control. The accuracy of individual assembly burnups, although desirable, is not crucial to SNM accountability. In summary, the primary driving force for accuracy in fuel assembly burnup measurement is derived from the primary regulatory based requirement for accurate reactivity balances, as measured by the difference between actual and predicted control rod positions (BWR) or boron concentrations (PWR). Since accuracy in reactivity balances requires accuracy in power distributions, from which burnup increments are directly determined, the needed accuracy of individual assembly burnups is derived directly from the accuracy needs in reactivity balances. 
The measurement based benchmarking of the PWR ARMP system provides an excellent opportunity to estimate the accuracies of in-core measurements and calculations available from core monitoring systems. This benchmarking was done on the first cycle of the Zion-2 core. The 193-assembly, 3250 MWT core consists of a central $2 / 3$ portion checkerboarded with 65 Region 1 assemblies (2.25\% initial enrichment, no burnable absorber rods) and 64 Region 2 assemblies $(2.79 \%$ enrichment and an average of about 16 burnable absorber rods per assembly). The outer portion of the core consisted of 64 Region 3 assemblies $13.29 \%$ initial enrichment and an average of about 12 burnable absorber rods in every second assembly). At the end of the first cycle, the core average burnup was 17,860 MWD/MTU of which Regions 1, 2, and 3 averaged 19,950, 19,170, and 14,430 MWD/MTU, respectively. The core is instrumented with movable fission chambers to give axial profiles in the central thimble of each of 58 fuel assemblies in various locations throughout the core.

The portions of this benchmarking that are relevant to the accuracy of burnups are the various measurements and calculations of power shapes. Measurements of axial average neutron reaction rates were made in most of the 58 instrument locations at each of 10 different times during the first cycle, and were compared with calculations at each time. Measurements of end-ofcycle relative assembiy powers (i.e., axial averages) were made using high resolution gamma spectroscopy, based on $L A^{140}$ decay, and these were compared with calculations. The same $L A^{140}$ decay equipment was used to measure end-ofcycle axial power distributions along fuel assemblies and these were compared with calculations. The primary calculations were done with the nodal code (the SIMULATE program, in this instance) that is typical of the programs used to reflect changes in power distributions during a cycle, once it has been normalized to start-of-cycle conditions using a detailed spatial neutronics program (PDQ in this case) plus start-of-cycle measurements. The general conclusion of the benchmarking is that power shapes are modelled very well except for one or two assemblies in each octant with high flux gradients adjacent to the baffle reflector at the outer boundary, and with assymetric loadings of burnable poison rods.

The ARMP benchmarking described above did not include any estimates of the burnup accuracy that is determined from the core monitoring and calculations. However, it provided a number of related accuracies that can be 
used to infer burnup accuracies. Including the anomalous high-flux-gradient outliers, the standard deviation of a relative power calculation as compared to measurement at a point is about $6 \%$, based on a comparison with end-of-cycle gamma scan data. However, the average power of an assembly is based on the axial average of the points along the assembly. The percentage uncertainty of an average is less than the percentage uncertainty of its individual elements because of statistical probability that some independent errors will cancel. The comparison of calculated and measured axial average power of individual as semblies showed a standard deviation of $2.3 \%$, as compared to the at-a-point uncertainty of $6 \%$, also based on end-of-cycle conditions. As noted above, the movable in-core fission chambers were used to obtain, axial-average relative powers at interim times, but no at-a-point individual data were reported. The comparisons between calculation and fission chamber measurements done at each of the 10 interim times during the first cycle showed standard deviations ranging from 2.3 to $5.0 \%$. This is higher than the end-of-cycle comparisons which were based on the more accurate gamma scan measurements.

Because burnup is the time integral of power, the uncertainties in burnup must be estimated using the uncertainties in relative power at each of the time steps. The estimating method must reflect the nature of uncertainties in relative power, and in particular must distinguish between uncertainties which are correlated in time and those which are random. Recognizing that the uncertainties are reflected in the difference between calculation and measurement, it is reasonable to anticipate that uncertainties correlated in time may be mostly due to systematic factors in the calculations and that random uncertainties may be associated more with the measurements. Physically, it should be noted in particular that errors in power distribution and burnup are in fact partialiy self-correcting: an excessive power estimate generates an excessive burnup estimate, which reduces reactivity, which depresses power. This same physical behavior is what causes cores to burn themselves down to quite flat power distributions. Thus, the existence of a systematic error can be identified in the uncertainty data if positive errors for a particular fuel assembly tend to decrease, or negative errors tend to become less negative in successive time steps.

The detailed data at the 58 instrument locations in the Zion 2 core have been analyzed for the series of 10 time steps during Cycle 1 . These data 
has been attributed, assuming 1/8-core symmetry, to the assemblies in one octant of the core, as identified in Figure B-1. There are 31 assemblies shown, of which 28 have an instrumented thimble in at least one octant of the core. Where there is more than one observation attributed to a particular assembly, the mean of the measurements is shown in Table B-1. However, the individual measurements were used in the statistical analysis. Table B-1 summarizes the uncertainty data at each assembly and for each time step (identified by core average), taken directly from Appendix $C$ of the EPRI report. Also shown are the $A$ and $B$ coefficients in a linear least square fit of the data for each individual assembly, based on:

\% Uncertainty at Burnup $\left(\frac{\text { Gwd }}{\text { MTU }}\right)=A+B\left(\frac{\text { Gwd }}{\text { MTU }}\right)$

By comparing the residual standard deviation for each linear fit with the standard deviation of the replicate measurements, it is shown that a linear fit is an adequate representation of the relationship between $\%$ uncertainty and burnup. The "A" coefficient is the \% uncertainty at zero burnup and the "B" coefficient describes the trend of \% uncertainty (\% change per 1000 Mwd/MTU). Examination of these coefficients shows a very clear dependence of $\%$ uncertainty on burnup, a dependence that is far from random. It is noted that for core positions identified by rows $9-12$, the slope, B, is positive in all cases with but one exception (D12). On the other hand, for rows 13-15, the slope, $B$, is negative in all cases, again with but one exception (G13), and in the case of this one exception, $B$ is just slightly positive. Figure $B-2$ shows the relationship between estimated slope and row number. This figure depicts rather graphically the nature of the systematic error in calculations of burnup for the initial cycle.

Because the \% uncertainties will tend to average out to zero over all core positions, a positive value of $B$ means that the \% uncertainty at zero burnup will be negative. It will become increasingly less negative with increasing burnup, reaching zero at some intermediate cycle burnup, and tending to become a positive \% uncertainty at end of cycle. In the case of negative values of $B$, the reverse is true. The \% uncertainty is positive at zero burnup, zero at some intemediate burnup value, and negative at end of cycle. 


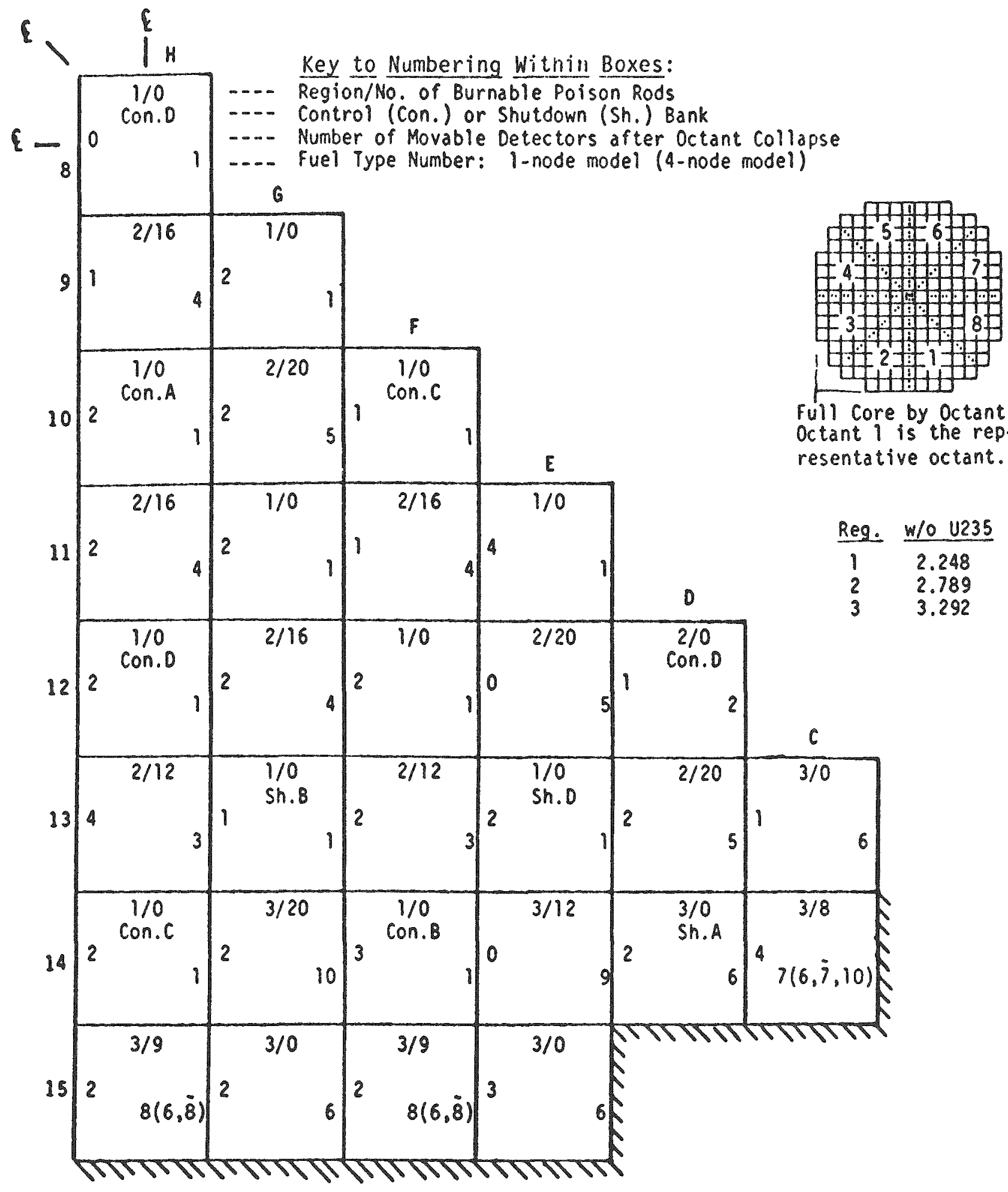

FIGURE B-1

ZION 2 CYCLE 1 CORE CONFIGURATION 
TABLE B-1

LEAST SQUARE FIT OF (CALC'D-MEAS'D) PERCENT OEVIATION OF AXIAL AVERAGE REACTION RATES VERSUS BURNUP

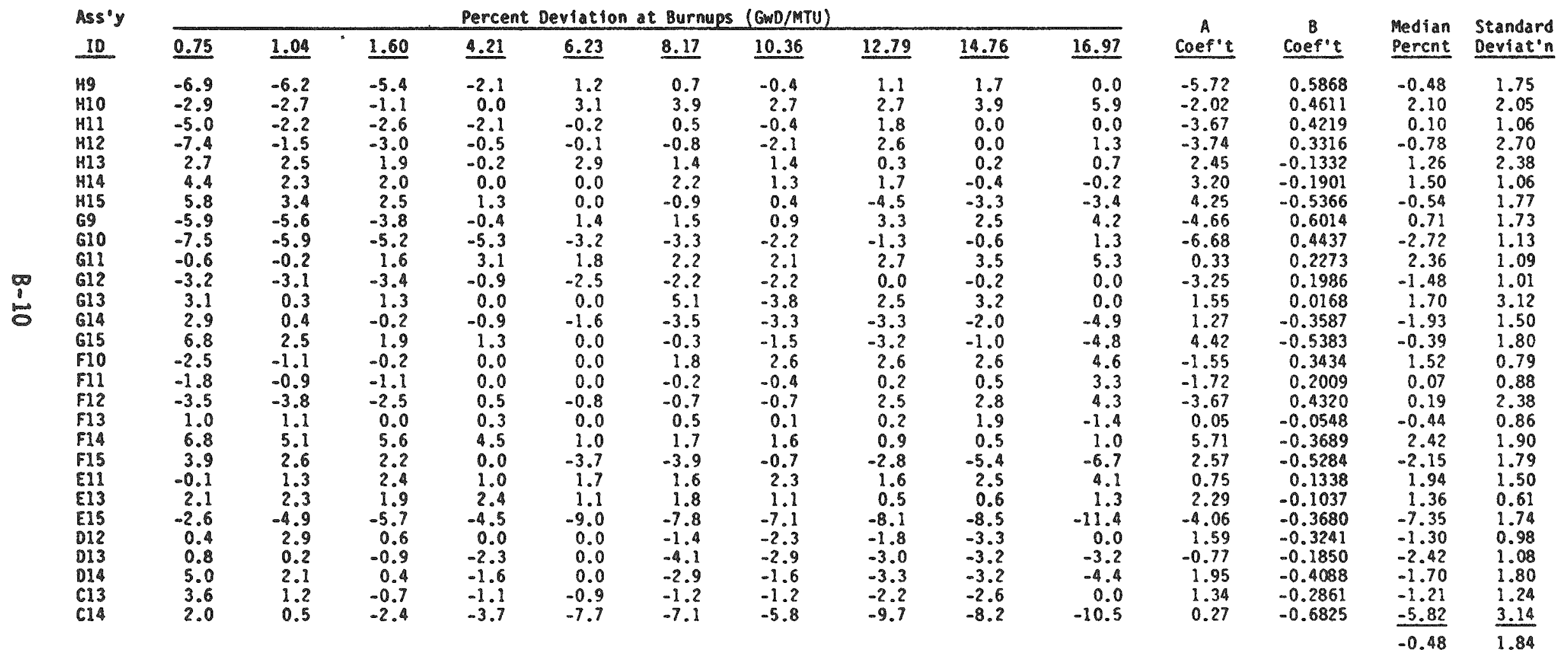



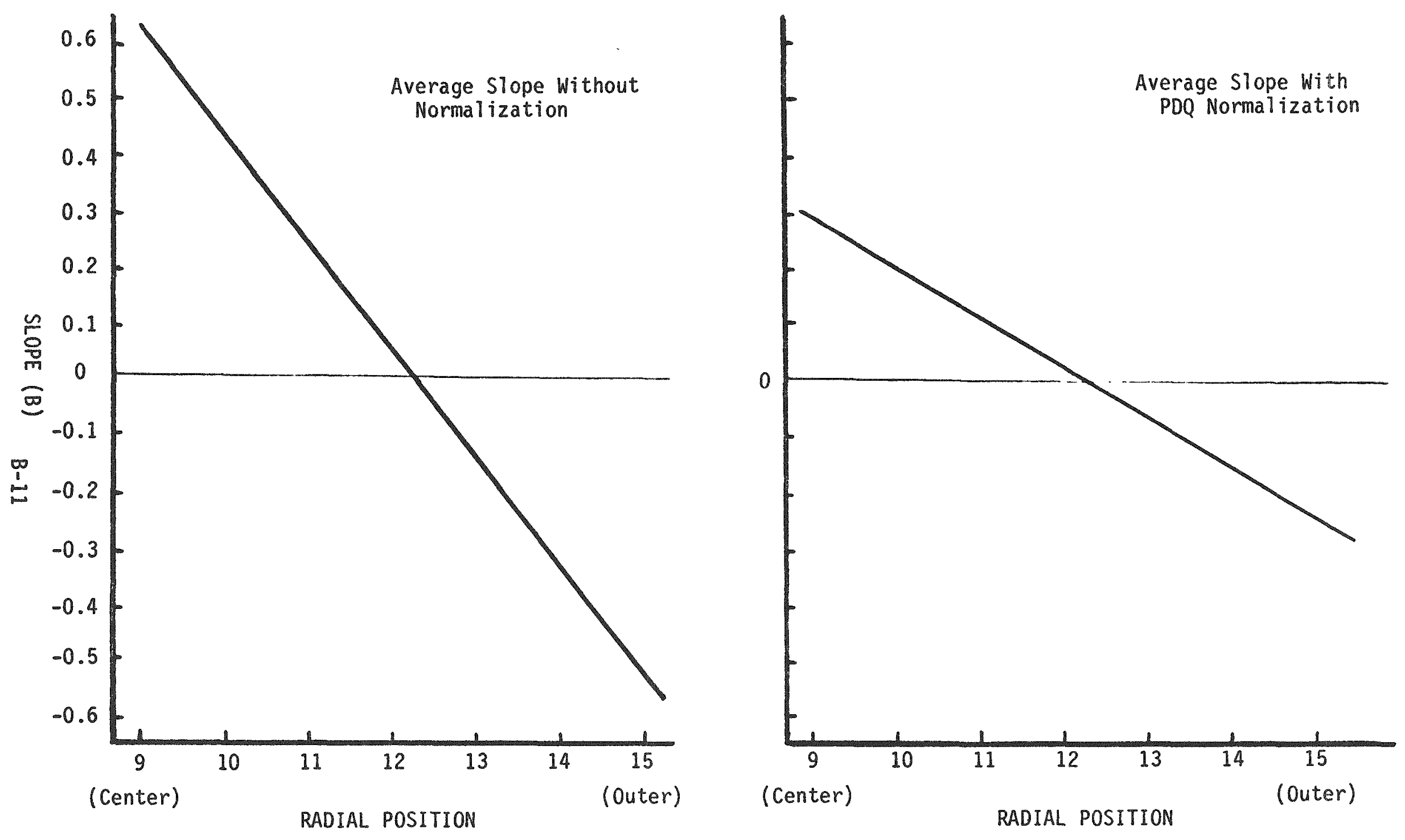

FIGURE B-2

DEPENDENCE OF ERROR REDUCTION RATE (SLOPE) ON RADIAL POSITION 
Since \% uncertainty is dependent on burnup at a given core position, and since the nature of the dependency depends on the core position as well, it follows that the standard deviation of percent uncertainties over all core positions is a function of burnup. This standard deviation is the largest at zero burnup (3.3\%) and at the end of cycle burnup $(4.6 \%)$, and is the smallest at some intermediate burnup. For example, at cycle mid-point ( 8930 MWD/MTU), the standard deviation is $2.3 \%$.

The above standard deviations do not include the random errors due to the combined errors in the calculated and measured values. From the last column of Table B-1, the random error standard deviation is estimated to be about $1.8 \%$. Combining errors in quadrature, the overall standard deviation between observed percent deviations (calculated-measured) is $3.8 \%$ at zero burnup, $2.9 \%$ at mid-cycle burnup, and $4.9 \%$ at end of cycle. The systematic errors cited in the preceding paragraph may logically be attributed to errors in the calculated values whereas the random errors are likely to be associated mostly with the measured values. Thus, the cited standard deviations of $3.3 \%$, $4.6 \%$, and $2.3 \%$ in the preceding paragraph may be interpreted as the standard deviations of calculated burnups.

In considering the $\%$ uncertainty of the average calculated burnup for a number of assemblies, the result is highly dependent on the core positions at which the assemblies in question were located. This is because of the apparent dependence of the 1 inear model parameters, $A$ and $B$, on the row number. If the assemblies in questions were all located in row 9 , say, the $\%$ uncertainty in the average burnup for these assemblies would be much larger than if they were selected at random from all rows. It is difficult to provide general results; case dependent results to cover the various possibilities can be provided.

Normalization of the data in Table B-1 to the PDQ calculated values reduces the systematic error uncertainty. This is depicted graphically in the right hand plot of Figure B-2 where the relationship between estimated slope, $B$, and row number is shown for the normalized data. Note that whereas for the Table 4-1 data the slopes varied from about -0.7 to t0.6, for the normalized data the slopes vary from about -0.4 to t0.4. The net effect on the 
systematic error standard deviations at zero burnup, median burnup, and end of cycle burnup is to reduce the systematic error standard deviations from $3.3 \%$, $2.3 \%$, and $4.6 \%$, respectively, to $2.7 \%, 2.0 \%$ and $2.6 \%$, respectively.

The Zion 2 data are for just a single cycle, the first cycle, which is typically 50\% longer than subsequent cycles. By about the third cycle, near equilibrium fuel cycle conditions have been established and thereafter fuel assemblies are in-core for three or four cycles. Each fuel cycle involves at least a partial, and normally a total reshuffling of the fuel assembly configurations. With respect to the accuracies of burnup increments in subsequent cycles, there are, again, two processes in operation -- errors that are statistically independent and errors that are correlated in burnup. In both instances the net result is an additional reduction in overall discharge burnup errors. The statistically independent errors from sucessive cycles would be added in quadrature with the result being that this percentage error components in the discharge burnup will be less than the component in a single cycle by a factor approximately equal to the square root of the number of cycles. The reshuffling of the fuel will generate a new set of analysis related errors, part of which are independent of prior analysis errors. Also, burnup errors from prior cycles will be further self corrected. A formal analysis of these errors would require information on the probable split between analysis errors related to previous errors, and those not so related. It is likely that there will be some cancellation of systematic errors of calculation from one cycle to the next, and the limiting assumption seems reasonable: that both analysis and measurement errors are statistically independent among successive fuel cycles. As a result, an error reduction factor can be used equal to the square root of the number of cycles during which an assembly is in-core.

In summary, the estimated calculation measurement error in discharge burnups is based on a number of factors attributable to either the calculation or measurement processes, as follows:

(1) The fundamental calculation measurement difference occurs at a point in a reactor. An accurate measurement technology-postdischarge high resolution gamma spectroscopy - gives a pointwise standard deviation of about $6 \%$ at the end-of-cycle condition. Because they are inherently less accurate than high resolution gamma detectors, operational in-core detectors 
would have somewhat larger standard deviations (calculationmeasurement) than $6 \%$.

(2) The average burnup of a fuel assembly is based on the axial average of relative powers. Because of the statistical independence of some of the axial pointwise calculation measurement differences, the standard deviation of axial averages is less than pointwise values. The standard deviation of the axial average of the above gamma spertroscopy data (which is about $6 \%$ pointwise), is $2.4 \%$. Using operational in-core detectors (fission chambers), the standard deviations of the series of 10 core profiles during Zion 2 first cycle ranged from $2.3 \%$ to $4.9 \%$, with the latter occurring at near-end-ofcycle conditions.

(3) Cycle burnup is based on the time average of relative powers, during the cycle. The time averaging process must reflect both time-correlated and time independent components. The time correlated component for the integral of the 10 time steps of Zion 2, Cycle 1 had a standard deviation of 2.3\% and a random component of $1.8 \%$ for an overall standard deviation of $2.9 \%$ in the calculated discharge burnups of individual assemblies at the end of cycle 1.

(4) Discharge fuel burnup is the sum of the burnup increments added during each cycle. Because of the core reconfiguration that occurs at the end of each cycle, the uncertainties in burnup increments that occur in successive cycles are likely to be largely independent. To the extent that burnup uncertainties are correlated between cycles, errors from prior cycles will tend to be reduced via reactivity feedback in the calculational process. Assuming that the net effect of these factors can be adequately represented by the assumption of statistical independence between cycles, the error reduction factor between the standard deviations on per-cycle burnup increments and the discharge burnup equals the square root of the number of cycles, which is 1.7 for 3-cycles irradiations and 2.0 for 4-cycle irradiations. Thus, the standard deviation of the relative allocation of energy to individual assemblies in the burnup calculation is about $1.7 \%$.

(5) When the approximate $1 \%$ uncertainty in the absolute measurement of gross reactor power is added (in quadrature), the resulting overall uncertainty in the absolute burnup of individual assemblies is less than $2 \%$.

$3.0 \quad$ CONCLUSION

The assembly burnups reported by utilities are based on the continuing measurement of total absolute reactor power, plus the allocation of total power to individual assemblies using computational models of the fuel 
plus in-core measurements. When utilities are using current state-of-the-art computational models, correctly normalized to start-of-cycle conditions, and adjusted periodically on the basis of in-core measurements, reported discharge burnups are probably within $2 \%$ of actual absolute burnups for fuel with 3 or more cycles of in-core irradiation. The uncertainty in core average burnups will be less than $2 \%$, but above the ultimate limit of about $1 \%$, which is imposed by the uncertainty in core total thermal power measurement. 


\section{APPENDIX C}

NEUTRON AND GAMMA MEASUREMENTS 
APPENDIX C

TABLE OF CONTENTS

THE MEASUREMENT OF NEUTRON AND GAMMA RADIATION

Page

2.0 INTERPRETATION OF NEUTRON AND GAMMA MEASUREMENTS

C-1

3.0 NEUTRON MEASUREMENTS

C-2

4.0

GAMMA MEASUREMENTS

C-10

5.0

SUMMARY OF NEUTRON AND GAMMA MEASUREMENT

C-15

C-16 
The purpose of Appendix $C$ is to summarize neutron and-gamma measurement systems and to quantify the accuracy with which these systems can measure fuel characteristics, and the accuracies of the fuel burnup and age that can be inferred therefrom. The direct measurement of neutron and gamma photon emissions from spent fuel assemblies or packages can be used to determine the burnup and/or age of the spent fuel. The significance and accuracy of such determinations depends upon a variety of factors that occur within the two basic steps that are needed. These two steps are:

(1) The detector, its recording system, and the subsequent analysis must be able to discriminate between the radiation of interest and the intense general radiation field, and

(2) The resulting data must be interpreted in terms of burnup and/or age at the point of measurement, and must be further interpreted as to what fraction of a fuel assembiy or container it represents, and what this implies with respect to the whole assembly or container.

Aithough neutrons and gammas are very different forms of radiation and therefore require different detectors, the basic processes of measurement, recording, analysis and interpretation involve similar issues. Therefore, this appendix reviews combined neutron and gamma measurement and interpretation issues together before summarizing specific neutron measurements and gamma measurements and their respective accuracies.

\subsection{THE MEASUREMENT OF NEUTRON AND GAMMA RADIATION}

The primary candidate detectors are fission chambers for neutrons and high resolution gamma (HRG) detectors, because of their relative selectivity in high radiation fields. The basic systems consist of a stand that holds the fuel to be measured and positions the detectors and supporting equipment (high voltage for the fission detector and liquid nitrogen for the HRG detector), signal conditioners which assure that detector pulses are accurately transmitted to the recorder, and recorders that count each event in 
accordance with its energy. At the completion of each measurement, computer programs analyze the data, subtract background and provide the net measurement of the radiation and its statistical accuracy. In the case of neutrons, the measurement is the total neutron count or neutron count rate. For the HRG gamma detector, the events being measured are counts in specific narrow energy bands that are characteristic of selected individual fission products or pairs or groups of fission products. The isotopes selected for measurement ideally should have a high fission yield, a long half-life and a strong gamma whose energy falls in a band not shared by other fission products. Typical isotopes and their gamma energies are:

\begin{tabular}{lcc} 
Isotope & Gamma Energy & Half-Life \\
\hline$C^{s} 137$ & 0.661 Mev. & $30.17 \mathrm{yr}$ \\
$C^{s} 134$ & $0.796 \mathrm{Mev}$. & $2.06 \mathrm{yr}$ \\
$C_{e}^{144}$ & $2.185 \mathrm{Mev}$. & $284.3 \mathrm{days}$
\end{tabular}

A useful technique with gammas is to develop count ratios of isotopes having known and different production and decay characteristics. These ratios have the experimental advantage of requiring only relative detector efficiencies for each isotope, rather than absolute values. Two ratios are needed (i.e., three different isotopes) to infer both burnup and time.

In summary, the results of the direct measurement of the neutron or gamma output of a fuel assembly or canister are the net (of background) counts or count rates, and associated statistical uncertainties of neutrons or of specific fission product isotope decay gammas at their characteristic energies. To the extent practical, the counting periods, and total counts are chosen such that the statistical uncertainty is considerably less than the uncertainties arising in the interpretation. Also, the counts can be at a single specific location on the fuel, or at various discrete points or continuously along the assembly. Finally, multiple detectors may be involved. Once the counting data are obtained, the interpretation of the data is undertaken, the methods and issues of which are now discussed.

2.0 INTERPRETATION OF NEUTRON AND GAMMA MEASUREMENTS

The purpose of interpretation is to translate the measurement net counts into burnup and/or age of the spent fuel, while properly addressing all 
of the factors or phenomena that could impact the count rate and hence the interpretation of the count rate. In the simplest ideal case, a measured count rate would be related precisely (via precise knowledge of detector efficiency) to the total decay rate of the isotope in that part of the assembly, and via a precisely known half life, to the total inventory of the fission product isotope. Then, via precise knowledge of the percent fission yield of the isotope, the total number of fissions would be known, and via precise knowledge of the energy yield per fission the total energy output, and hence the burnup of that part of the assembly would be precisely determined. The ability to achieve absolute accuracy in the determination of the burnup from count rate in this ideal situation depends upon perfect knowledge of four physical parameters(absolute detector efficiency, isotope half life, percentage fission yield, and fission energy yield) and three favorable constraints: direct fission yield of the isotope, very low neutron cross section (avoiding in-core depeletion of the fission product isotope) and a long half life (avoiding significant decay of the isotope prior to measurement). Failing precise knowledge of the absolute detector efficiency, a calibration of the counting system can be accomplished if a geometrically identical fuel assembly of precisely known burnup is used as a primary standard. In summary, the interpretation of the counting data can be accomplished in the ideal case either through precise knowledge of absolute detector efficiency and three other physical parameters or by calibration of the system with a primary standard fuel assembly of known burnup, and of identical characteristics except for burnup. The result of the interpretation in this simple ideal case is that the burnup of the measured part of the assembly can be directiy determined from the count rate, relative to the count rate and the known burnup of the standard assembiy.

Considering the real situation that is encountered in practice, the three favorable constraints of the ideal case are not encountered and the four physical parameters of the ideal case are not all known with precision. The actual situation with respect to the three favorable constraints and four physical parameters is as follows:

(1) The fission product of interest does not have a long half life, and it may not even have a simple dependence on time. The principal consequence of this is that a single measurement or measurement ratio cannot yield both the burnup and the age: 
two measurements or measurement ratios of isotopes with different time behavior patterns are necessary if both burnup and age of a spent fuel assembly or package are to be determined. A second consequence of the time varying behavior of measured isotopes is that a portion of these will decay prior to fuel discharge, and the decay fractions will be different for different core residence times and burnups. since the cooling age is measured from discharge, corrections for different pre-discharge decay should be made. The practical effect of such corrections is that post-discharge count rates are no longer proportional to burnup, even in the simplest case.

(2) The fission yield of the isotope is not direct. In fact, many of the isotopes of interest may be first or second daughters of direct-yield fission products, or may not even result from fission--they may be the product of one or more serial captures of neutrons. Furthermore, fission yields may depend on the fissioning material.

(3) Some isotopes of interest may not have small neutron cross sections and hence neutron capture will transmute that isotope into other isotopes.

(4) Absolute detector efficiency (fraction of total decays that are measured) is very difficult to calculate accurately. Some of the other four physical parameters may be known quite accurately. Many decay half lives are known with sufficient accuracy that they do not contribute significantly to overall uncertainty. The energy yield per fission (about 200 Mev/fission) is somewht dependent upon the fissioning element, but is generally known quite accurately. As mentioned above, the fission yields of some isotopes are quite accurately known, but are not relevant for other isotopes.

The purpose of the preceding is to convey some of the complexity of the processes that occur when fuel is irradiated over extended periods of time, and to indicate that simple models of measurable events cannot, in most cases, adequately represent the complex and interdependent processes that are taking place. The measurement approach that has evolved is a close coupling of direct calibration with the use of experimentally-based analytical models of fuel behavior to interpolate between calibrations, or if necessary, extrapolate beyond calibrations.

There are several computer based models of the detailed depletion and buildup of isotopes that occur during fuel irradiation. One such model is the ORIGEN2 program (Croff, 1980). However, it is not the purpose of this work to survey and 1 ist such models. Rather, the purpose is to indicate the 
types and accuracy of results that can be expected from the combination of experimental calibration of measuring equipment, coupled with the use of appropriate analytical models for interpolation or extrapolation.

Central to the measurement methodology is the detection and counting of specific events in a standard fuel assembly of known reference burnup, $B_{r}$, and known reference age, $t_{r}$. A reference net count rate, $C_{r}$, is obtained. Then an assembiy is measured which has nominally identical geometry and initial enrichment, but has undefined burnup, $B$, and age $t$. The corresponding net count rate is $C$. The analytical model is then used to characterize the burnup-dependent and time-dependent behavior of the isotope being counted. Although there are specific ways to characterize the behavior of specific isotopes, it is useful to have a general purpose characterization methodology that can be used to quantify the basic relationship and develop uncertainty estimates. This general methodology is not being suggested as a replacement of the specific methodologies that are used in specific applications, but is intended to provide a functional methodology for quantifying both magnitudes and uncertainties for a wide range of situations, and to thereby provide a common method for overviewing the measurement/analys is methodology for both neutrons and gammas.

The basic form of the suggested general purpose characterization methodology for any specific isotope using the symbols defined above is:

$$
\frac{C}{C_{r}}=\left(\frac{B}{B_{r}}\right)^{P}\left(\frac{t}{t_{r}}\right)^{-m}
$$

where the $p$ and coefficients are determined directly from the analytical results for any particular isotope or group of isotopes over the range between the reference burnup and age and the approximate burnup and age of the assembly being measured. Specific values of these coefficients for neutrons, gammas and heat have been published as part of Appendix 1C of DOE/RW-0184 (DOE 1987). In practice it should be noted that the $p$ and m coefficients each have some sensitivity to both burnup and age, and the implications of this are discussed later. The physical significance of the $p$ and m coefficients should be noted. For example a value of 1.0 for $p$ is equivalent to the standard 
assumption for many nuclides that the isotope quantity and the corresponding count rate is proportional to the burnup. However, the ability to have a $p$ value different from unity provides a general capability for making appropriate composite corrections lincluding corrections for in-reactor decay) to the strict burnup proportionality that must otherwise be assumed. Furthermore, the amounts of other nuclides such as those resulting from second, third, ect. sequential neutron absorptions, are approximately proportional to the second, third, etc. power of burnup, corresponding to $p$ values of 2,3 , etc. Thus, this form of burnup-dependence correctly characterizes a wide variety of isotopic behaviors, over defined burnup ranges. In a similar manner, the m coefficient correlation of time dependence has a physical significance: a value of $m=1.0$ represents a decay that is inversely proportional to time; and a value of $m=\lambda t_{r}$ represents the familiar $e^{-\lambda t}$ behavior of a single decaying isotope (with a decay fraction of $\lambda$ per unit time) in the vicinity of $t=t_{r}$, the age of the reference sample. However, the value of $m$ can also be chosen to correctly represent a variety of other time-dependent behaviors over defined ranges including both buildup and decay, as well as both individual isotopes and aggregates.

The solution can now be formulated for the problem of determining the burnup and age of a fuel assembly based on the measurement of that assembly, relative to the measurement of a reference assembly of known burnup and age. It was previously noted that if both burnup and age are to be determined, two measurements of isotopes with inherentiy different burnup/time behavior are required. The reference assembly will be measured (counted) for each isotope, such that two reference count rates are obtained, $c_{r, 1}$ and $c_{r, 2}$, corresponding to isotope "1" and isotope "2". The assembly with unknown burnup and age is also counted, obtaining $C_{1}$ and $C_{2}$ counts for each of the same two isotopes. Similarly, the analytical model results will be characterized as to $p$ and m values for each of the two isotopes, and these characterizations are $p_{1}$ and $m_{1}$ for the first isotope and $p_{2}$ and $m_{2}$ for the second isotope. Two simultaneous equations can then be written in the previously described form: 


$$
\begin{aligned}
& \frac{c_{1}}{c_{r, 1}}=\left(\frac{B}{B_{r}}\right)^{p_{1}}\left(\frac{t}{t_{r}}\right)^{-m_{1}} \\
& \frac{c_{2}}{c_{r_{2} 2}}=\left(\frac{B}{B_{r}}\right)^{p_{2}}\left(\frac{t}{t_{r}}\right)^{-m_{2}}
\end{aligned}
$$

The solution of these two equations is:

$$
\frac{B}{B_{r}}=\left(\frac{c_{1}}{c_{1, r}}\right)^{\frac{m_{2}}{p_{1} m_{2}-p_{2} m_{1}}}\left(\frac{c_{2}}{c_{2, r}}\right)^{\frac{-m_{1}}{p_{1} m_{2}-p_{2} m_{1}}}
$$

$$
\frac{t}{t_{r}}=\left(\frac{c_{1}}{c_{1, r}}\right)^{\frac{p_{2}}{p_{1} m_{2}-p_{2} m_{1}}}\left(\frac{c_{2}}{c_{2}, r}\right)^{\frac{-p_{1}}{p_{1} m_{2}-p_{2} m_{1}}}
$$

The form of these equations aids convenient usage: it involves only the two count ratios determined experimentally, each raised to a power that is determined from the analytical results. To the extent that estimates of the unknown burnup and age were used to obtain initial $p$ and values, some iteration may be required to obtain burnup and age values consistent with the $p$ and $m$ values from the analytical results. It should also be noted that the requirement of different burnup/time behavior between the two isotopes is very explicit in the above equations: the equation gives an indeterminant answer (infinity times zero) when

$$
\frac{p_{1}}{m_{1}}=\frac{p_{2}}{m_{2}}
$$

$C-7$ 
This suggests the selection for measurement of two isotopes or groups of isotopes which have markedly different $p / m$ ratios. For example, the largest disparity between $p /$ m ratios could be obtained by including isotopes with a large $p$ value, such as is obtained with the curium isotopes (242 and 244) responsible for neutrons.

The uncertainities in the burnup and time determined from the above equations can be derived from the analytical form of the equations assuming, for now, no uncertainty in the $p$ and values. The uncertainty equations given below can easily be extended to incorporate the uncertainties in the $p$ and $m$ values as well. This has not been done in this initial study because these terms depend in part on the actual difference in burnup and time, between the reference and measured fuel. Also the standard deviations of the $p$ and $m$ values would have to be developed. A more complete analysis would include such undertainties. The uncertainties are:

$$
\begin{aligned}
\left(\frac{\delta B}{B}\right)^{2}=\left(\frac{\delta B}{B_{r}}\right)^{2} & +\left(\frac{m_{2}}{p_{1} m_{2}-p_{2} m_{1}}\right)^{2}\left(\left(\frac{\delta c_{1}}{c_{1}}\right)^{2}+\left(\frac{\delta c_{r, 1}}{c_{r, 1}}\right)^{2}\right) \\
& \left.+\left(\frac{m_{1}}{p_{1} m_{2}-p_{2} m_{1}}\right)^{2}\left(\frac{\delta c_{2}}{c_{2}}\right)^{2}+\left(\frac{\delta c_{r, 2}}{c_{r, 2}}\right)^{2}\right) \\
\left(\frac{\delta t}{t}\right)^{2}=\left(\frac{\delta t_{r}}{t_{r}}\right)^{2} & +\left(\frac{p_{2}}{p_{1} m_{2}-p_{2} m_{1}}\right)^{2}\left(\left(\frac{\delta c_{1}}{c_{1}}\right)^{2}+\left(\frac{\delta c_{r, 1}}{c_{r, 1}}\right)^{2}\right) \\
& +\left(\frac{p_{1}}{p_{1} m_{2}-p_{2} m_{1}}\right)^{2}\left(\left(\frac{\delta c_{2}}{c_{2}}\right)^{2}+\left(\frac{\delta c_{r, 2}}{c_{r, 2}}\right)^{2}\right)
\end{aligned}
$$


where the $\delta$-terms are the uncertainties in each of the terms previously identified. The primary assumption in developing the above uncertainty relationships is that each of the uncertainties in $B_{r}, t_{r}, C_{1}, C_{2}, C_{r l}$, and $C_{r_{3} 2}$ are independent of each other. To the extent that count rates $C_{1}$ and $C_{2}$ were done at the same time, and may have uncertainty components that are not independent, these would have to be determined and the uncertainty equation modified somewhat. A similar situation would prevail for the reference count rates $C_{r, 1}$ and $C_{r, 2}$. The uncertainty terms in the count rates are the total uncertainties including both counting statistics and overall random experimental uncertainties, determined on the basis of the reproducibility of repeated measurements on the same assembly.

It is also noted that the estimates of $B$ and $t$ are positively correlated; if the estimated burnup errs on the high (low) side, the estimated age will tend to err on the high (low) side as well. This fact is obvious from the forms of the equations for $B / B r$ and $t / t r$. Specifically, the covariance between $B$ and $t$ is as follows:

$$
\begin{aligned}
\frac{\delta B t}{B t} & =\frac{m_{2} p_{2}}{\left(p_{1} m_{2}-p_{2} m_{1}\right)^{2}}\left[\left(\frac{\delta c_{1}}{c_{1}}\right)^{2}+\left(\frac{\delta C_{r, 1}}{c_{r, 1}}\right)^{2}\right] \\
& +\frac{m_{1} p_{1}}{\left(p_{1} m_{2}-p_{2} m_{1}\right)^{2}}\left[\left(\frac{\delta c_{2}}{c_{2}}\right)^{2}+\left(\frac{\delta c_{r, 2}}{c_{r, 2}}\right)^{2}\right]
\end{aligned}
$$

In summary, the preceding has outlined a general methodology for determining the magnitude and uncertainty of the burnup and age of fuel assemblies using (i) two measured count rates of neutrons and/or gammas from specific isotopes, (ii) two reference count rates from an identical assembly of known burnup and age, and (iii) the results of performing a detailed analysis of the burnup and age dependent behavior of the neutron sources or gamma emitting isotopes that were the subject of the measurements in both the reference and the unknown fuel assembly. As was noted earlier, this general 
methodology is not intended to replace specific methodologies, but is intended to facilitate an overview of neutron and gamma measurements.

The second major issue of interpreting measured data is that of assessing how much of an assembly or canister is represented by a measurement, and what the measurement implies as to other parts of the assembly, and assembly averages. Any measurement of a fuel assembly is a weighted average of a portion of the fuel which depends strongly on the measurement configuration and on the radiation being measured. Gamma measurements are typically made with narrow collimation such that the measurement represents only that portion of the fuel that can be "seen" through the collimator, and to a depth that is limited by the gamma attenuation within the fuel. Neutron measurements on the other hand, represent a weighted average of original source neutrons from a somewhat larger portion of the fuel, a portion which is somewhat dependent upon the source neutron multiplication factor. If the fuel assembly is totally scanned, or is measured at a number of discrete points, there is clearly less uncertainty in interpretation of individual measurements than if a single measurement is expected to characterize the whole assembly. In the latter case, the relationship between the characteristics of the measured portion of the fuel and the fuel average characteristics, as well as the limitations of what can be inferred, must be clearly understood to avoid misinterpretations of the measurement, or underestimates of the uncertainties.

\section{$3.0 \quad$ NEUTRON MEASUREMENTS}

Some of the transuranic elements formed in nuclear fuel from successive neutron absorptions have relatively short spontaneous fission half-lives and hence emit relatively large numbers of neutrons, and/or decay by $\alpha$-emission at a sufficient rate to produce significant neutrons from the $\alpha-\eta$ reaction. The rates of such neutron emissions have a very strong dependence upon burnup. Several systems have been developed to measure the neutron output of spent fuel as an indicator of fuel burnup and/or plutonium content. One of these, which includes parallel high-resolution gamma spectroscopy, is to be used in a spent fuel pool prior to spent fuel reprocessing in order to confirm fuel assembly burnup and age, as well as plutonium content (Bernard, 1986). A second system, which includes gross 
gamma ion chambers, has been developed at Los Alamos and used in utility spent fuel pools for the independent verification of declared fuel burnups in connection with IAEA safeguards inspections (Phillips, 1983). A third system has been developed and demonstrated on PWR fuel by Westinghouse and Virginia Power at the latter's Surry station, and is discussed further below (Goldstein, 1984). It is instructive that all three systems use two fission detectors, one each adjacent to opposite sides of the fuel assembly being measured, and that all three systems successfully demonstrated the viability and accuracy of neutron based burnup measurements of spent fuel. Also all three systems are used underwater, in spent fuel pools.

The Westinghouse/Virginia Power system consists of two fission chambers which detect neutrons on opposite faces at the mid-plane of a fuel assembly, plus associated signal conditioning, recording and data analysis hardware and software. The measurement of one fuel assembly in a reactor pool requires about 10 minutes, from grappling of the assembly in the fuel storage rack, raising, moving and emplacing it in the mounting fixture on the pool bottom, counting the assembly, and returning the assembly to its original location in the storage rack. In the demonstration at Surry, 50 fuel assemblies of identical 15 by 15 geometry were measured, covering a burnup range of 14,410 to $41,046 \mathrm{Mwd} / \mathrm{MTU}$, a cooling time range of 0.18 to $8.86 / \mathrm{yr}$, an initial enrichment range of 1.86 to $3.40 \% \mathrm{U}-235$, and considerable variation in fuel power history and cross-assembly burnup gradients. The data were analyzed to provide correlations and correction terms for burnup, enrichment and time dependence of the neutron source. The final analysis of results provided an estimated deviation of 800 Mwd/MTU for utility reported average burnups of each assembly. Since the latter probably have about a 600 MWd/MTU uncertainty, the neutron counting technique appears to provide an accurate and sensitive measure of burnup when enrichments and cooling times are known, and the system is calibrated to identical assemblies of known characteristics. This sensitivity also imposes above average requirements on the measurement process because a lack of attention to measurement details can quickly generate very inaccurate results. The following paragraphs identify the sources of the measurement sensitivity and then discuss some of the constraints and/or limitations on the methodology. 
The primary sources of neutrons are $\mathrm{Cm}-242$ which has a half-life of 163 days and $\mathrm{Cm}-244$ which has a half-life of 18.11 years. These isotopes, particularly $\mathrm{Cm}-244$ have a relatively short half-life for spontaneous fission and as a result, small quantities of these isotopes emit relatively large numbers of neutrons. These two isotopes are the fourth $(\mathrm{Cm}-242)$ and sixth (Cm-244) daughters of successive neutron absorptions in U-238. As the fourth and sixth daughters, their initial production rates are very low but they initially build up in proportion to the fourth and sixth powers of burnup. As they build up, their dependence declines somewhat to about the second and fourth powers of burnup. The relatively short half-life of $\mathrm{Cm-242}$ (163 days) means that it will be of little significance in the 10 to 30 year age range which will characterize FWMS operations.

As a result, $\mathrm{Cm}-244$, with its approximate fourth power dependence on burnup, dominates the neutron source term, contributing about $95 \%$, $92 \%$ and $78 \%$ of the source neutrons at 10,20 and 50 years cooling. It should also be noted that the spent fuel is still a neutron multiplying medium, even though it may no longer sustain a chain reaction. For example at a $K_{\text {eff }}$ of 0.8 , the fuel would multiply the original source neutrons by a factor of five. Furthermore, any physical factors in the experimental setup that would alter the fuel multiplication would alter the neutron count, independent of the fuel characteristics. Thus, such factors as the boron concentration of the pool water must be known and replicated if calibrations are to be done at different times than the measurements. The surry assessment of the neutron counting system included evaluations of two detectors on opposite faces versus a single detector and found that the standard deviation nearly doubled because of both non-uniformity of burnup across assemblies, and small positioning errors. The reproducibility of repeated count rate measurements of the same assembly was also checked. A $6 \%$ variation was found for the shortest cooled fuel with a high gamma background 10.18 years), but appeared to be under $4 \%$ for a representative population of fuel.

Another interesting feature of the measurement methodology is that the measurement was taken at the midpoint of the fuel, which would typically have the highest burnup, and the count rates obtained at the peak burnup were correlated with assembly average burnup. It turns out that no errors are introduced by this procedure if the peak-to-average burnup ratio as a 
constant, independent of burnup. It is known that peak-to-average burnup ratios are not much greater than unity for high burnup PWR fuels. Apparently the measurement of burnup in the mid-plane of the assembly provides a good measure of assembly average burnup in high burnup PWR fuels with relatively uniform axial power distribution. Comparable measurements have not been made on BWR fuels with this system.

The Los Alamos $10 \mathrm{~N}-1$ system was used to characterize the axial neutron distributions of 52 BWR assemblies from Cooper (Mckinnon, 1986). However, given the significant differences in plutonium and hence curium production in the upper portion of fuel operating with coolant voids, as compared to the lower portion of the fuel, it is questionable that a similar assumption would be valid for BWR fuels. Furthermore, BWR fuel assemblies typically include fuel rods of different enrichments such that at discharge a fuel assembly with an average burnup will have individual rods that are substantially above and below the average. It is average properties that are measured. When fuel properties are proportional to burnup, average properties are equal to the properties at the average burnup, and average burnup can be directly inferred from the measurement. However when fuel properties are not proportional to burnup, measured average properties are not representative of properties at the average burnup, and hence average burnup cannot be easily inferred from the measurement. In summary, the use of neutron measurements to infer average burnups of BWR fuel appears to require significantly greater interpretation of measurements both as to axial burnup distributions and burnup distribution between rods of BWR assemblies.

Returning now to the surry results, one of the principal conclusions of the work was that the neutron source term from $\mathrm{Cm}-244$ was proportional to approximately the fourth power of burnup. This strong dependency can be seen by use of the general methodology developed earlier. If the age of the fuel is known, the relationship between measured and reference count rates, $C$ and $C_{r}$, burnup and reference burnup, $B$ and $B_{r}$, and age and reference age, $t$ and $t_{p}$ is

$$
c_{r}^{c}=\left(\frac{B}{B_{r}}\right)^{P}\left(\frac{t_{r}}{t_{r}}\right)^{-m}
$$


where $p$ and $m$ are analytically (or experimentally) determined coefficients for burnup and time dependence. Rearranging this equation to determine burnup gives:

$$
B=B_{r}\left(\frac{c}{c_{r}}\right)^{\frac{1}{p}}\left(\frac{t}{t_{r}}\right)^{\frac{m}{p}}
$$

and the uncertainty in B (assuming time is known) is:

$\left(\frac{\delta B}{B}\right)^{2}=\left(\frac{\delta B}{B r}\right)^{2}+\frac{1}{p^{2}}\left(\frac{\delta C^{2}}{C}+\frac{\delta C_{r}^{2}}{C_{r}}\right)+\left(\ln \left(\frac{B}{B}\right)\right)^{2}\left(\frac{\delta p}{p}\right)^{2}+\left(\ln \left(\frac{t}{t_{r}}\right)\right)^{2}\left(\frac{\delta m}{p}\right)^{2}$

The last two terms in the above equation allow for the uncertainties in the sensitivity coefficients. However, because these terms also depend upon the proximity of the burnups and times of the measured and reference fuel, they have been assumed to be small, (i.e. zero) relative to the other terms. Using a reference burnup uncertainty of $2 \%$, count rate uncertainties of $6 \%$ (consistent with the $6 \%$ variation noted above) and the value of $p=4$, as determined in the Surry measurements and confirmed by ORIGEN2 data, the uncertainty in the measured burnup is $2.9 \%$. The primary reason for the high accuracy of burnups calculated from neutron measurements is the large value of $P$, for neutrons, with the consequent reduction in the impact of counting uncertainties, as is apparent from the above equation.

In summary, neutron counting of PWR assemblies in a system calibrated with identical assemblies of known burnup and age provides a very accurate estimate of burnup when the age is known. Similar measurements of BWR assemblies promise to provide adequate burnup estimates, but possibly will require more axial measurements, and a more detailed interpretation of the measurement results. 


\subsection{GAMMA MEASUREMENTS}

The two alternatives for gamma measurement are (i) gross gamma measurement using an ion chamber, and recording ion chamber current, and (ii) high resolution gamma (HRG) spectrometry using a germanium detector cooled with liquid nitrogen, and recording counts of specific energies, corresponding to the gamma emissions from specific isotopes. The HRG spectrometry is able to detect and distinguish between very small energy differences, but imposes a number of requirements on the measurement system, in addition to that of requiring a liquid nitrogen supply. HRG spectrometry requires a collimator system to reduce the incoming general radiation and minimize degradation of the gammas of interest. The use of collimators improves the spatial resolution of the resulting measurement, but increases the sensitivity of the measurement to possible positioning errors. Also, because the gammas of interest are typically only a small fraction of incoming gammas, the problems of background and background subtraction are significant, and longer counting times are required to obtain adequate statistical accuracy within the very narrow energy bands needed for good resolution.

HRG spectrometry of spent fuel has been successfully used for a number of purposes, among which are:

(1) Monitoring of $\mathrm{Cs}-137$ in PWR fuel from Robinson-2 has clearly demonstrated the local variation of fuel burnup along the length of fuel rods, particularly in the vicinity of spacer grids and has shown a nearly linear proportionality between average Cs-137 activity and average burnup (Barner, 1985).

(2) The ratios of Cs-134/Cs-137 and Ce/Pr-144/Cs-137 have been measured on 134 PWR and 6 BWR assemblies for the purposes of independently verifying both burnup and age prior to reprocessing in France (Bernard, 1986).

(3) Axial monitoring of the La-140 activity of 24 PWR assemblies from Zion 2 at the end of Cycle 1 to measure the end-of-cycle core power distribution. The accuracy of these measurements was about $3 \%$. (Rothleder, 1985)

(4) Monitoring of the energy spectrum of gammas external to the shields of storage casks under acceptance testing:

REA-2033 with Cooper BWR Fuel (Mckinnon, 1986)

Castor-V/21 with Surry PWR Fuel (Dziadosz, 1986) 
TN-23P with Surry PWR Fuel (Creer, 1987)

MC-10 with Surry PWR Fuel (Mckinnon, 1987)

Gross gamma monitoring is in extensive use in connection with nuclear fuel. This technology is the basis for many in-core fuel performance monitoring systems. The Los Alamos ION-1 system (Phillips, 1983) combines neutron fission chambers and gamma ion chambers in each of two sides of a "fork" for measuring the opposite sides of fuel assemblies when the fork is placed around the assembiy.

It is apparent from user experience that HRG spectrometry is a proven and accurate methodology for identifying and quantifying fission products that provide useful information on burnup levels. It is equally clear that this technology is not as convenient to use, requires greater attention to the measurement configuration, and requires considerably more measurement time than neutron counting. Although HRG gamma ratios involving three different isotopes can be used to determine both burnup and age of spent fuel, two of the best three isotopes, $\mathrm{Cs}_{5-134}$ and $\mathrm{Ce} / \mathrm{Pr}-144$, have short half-lives and are, therefore, useful only for shorter cooled fuels. These isotopes are of declining value for fuel aged upwards of 10 years. Other candidate isotopes, with longer half-lives, such as Eu-154 are also of much lower intensity and the feasibility of their use for fuels cooled in the 10 to 30 year range has not been demonstrated. At present Cs-137 is the primary candidate for HRG gamma measurement of fuels cooled in the 10 to 30 year range which is the anticipated range of ages of fuel to be handled in the FWMS. The gross gamma flux, which is much easjer to measure and record, also has a near proportionality to burnup, and an identifiable time decay characteristic. It is noted that, with the ION-1 system, the gross gamma measurement permits verification of the consistency (as distinguished from the absolute magnitude) of operator-declared values of cooling time and burnup to within about 10\% (Phillips, 1983).

5.0 SUMMARY OF NEUTRON AND GAMMA MEASUREMENT

The neutron counting system demonstrated at surry is capable of measuring burnup with $3 \%$ accuracy if an assembly's age and initial enrichment are known, and the system has been accurately calibrated with identical 
assemblies of known burnup, age and enrichment. This accuracy is achieved despite about a $6 \%$ uncertainty associated with both the calibration and unknown assembly counting measurements, because neutrons are produced in proportion to about the fourth power of burnup. Even if times and enrichments are not well known, reasonably accurate burnups can be inferred from neutron counting alone if the assemblies are identical to a calibration assembly of known burnup and age. Furthemore, the principal source of neutrons, Cm-244, has an 18.11 year half-life. Hence neutron counting will be usable for fuel of any age that will be encountered over the next 50 years.

However, it was noted earlier that if both burnup and age are to be independently determined, two measurements of two different isotopes are required. The principal questions are (i) whether neutron counting should be one of the two, and (ii) whether the second measurement should be a gross gamma or an HRG measurement. The accurancy of the burnup measurement will be dominated by the neutron source term, as is evident from the uncertainty relationships developed in section 1.0. Therefore, the accuracy of the burnup will be influenced only modestly by the choice of gross gamma versus HRG measurement. However, the accuracy of the age will be influenced markedly by the accuracy of the gamma term. In order to identify the impact of differing gamma uncertainties, the burnup and age uncertainty equation given in section 1.0 for two measurements was used to identify overall uncertainties in unknown fuel, using ORIGEN2 parameters in the vicinity of 20-year-cooled fuel of $30,000 \mathrm{Mwd} / \mathrm{MTU}$ burnup. Assumed values were $2 \%$ uncertainty in the reference burnup. $6 \%$ uncertainty in the neutron count rates $\left(C_{1}\right.$ and $\left.C_{r_{1}, 1}\right), p_{1}=4$ and $m_{1}=0.76$. The iatter was taken from the ORIGEN2 data and is, incidentally equal to $20 \lambda$ for $\mathrm{Cm}-244$, which is what the $m$ value should be for a single isotope. For the gamma measurements a $3 \%$ count rate accuracy was assumed for HRG counts of CS-137 (consistent with the experience with La-140 HRG counts at Zion 2) or $10 \%$ for the gross gammas, as indicated by the experience using the ION-1 gross gammas. Values of $\mathrm{p}_{2}=0.94$ and $m_{2}=0.62$ were obtained from ORIGEN2 runs at 30,000 Mwd/MTU burnup and 20 years age: and alternative values of $\mathrm{p}_{2}=1.0$ and $\mathrm{m}_{2}=0.46(=20 \lambda$ for $c s-137)$ were obtained for $C_{5-137}$. The resulting uncertainty estimates, along with the uncertainty for the single measurement when time is known, are: 
Measured

Parameter

Burnup

Age

Percentage Uncertainty in Measured Parameter

single

Measurement,

Time known

2.9
Second Gamma Measurement

HRG Gross

on $C s-137$

5.1

17
Gamma

7.1

32

There are two observations to be made with respect to these results for ages in the 10 to 30 year range. First, the value of knowing the age is evident: burnup can be determined to about 3\% if the actual age is known. Second, if the age is not known and a second measurement must be made, the uncertainty in burnup goes up to at least $5 \%$, but the uncertainty in age is three to four times the burnup uncertainty and is large. The use of HRG spectroscopy on CS-137 is definitely preferred over the gross gamma measurement.

The fuel measurement system described in "Bernard, 1986" states that through the use of Ce-144/Cs-137 count ratios, cooling time can be estimated to within +50 days for cooling times up to 2500 days (6.85 years): and that with Cs-134/CS-137 count ratios, burnups of PWR and BWR assemblies can be estimated to within 5\%. The achievability of these results was confirmed using ORIGEN2 results and the methodology described herein. Additional evaluations of the deterioration of counting statistics as the short half-life Ce-144 (0.78 year) and $C_{s-134}$ (2.06 year) isotopes decay, relative to the slower decay of the gross gammas, al so showed that these two isotopes are of no use for ages greater than 10 years, which are the ages of principal operational interest in the FWMS. A preliminary evaluation of Eu154 did not give promising results because of its small production rate. Because of this it is the finding of this preliminary evaluation that the technology for independently verifying fuel age in the 10 to 30 year range with reasonable accuracy has not yet been identified. HRG spectroscopy of Cs137 appears the most promising of established technologies.

In addition, it is noted that all of the measurement systems described herein have been used and demonstrated underwater in spent fuel storage pools. Although using these systems in a dry hot cell environment does not appear to alter the measurement technology, assuming the 
availability of shielding, demonstration of dry operation would have to be undertaken to identify the principal differences from wet, in-pool operations. 
APPENDIX D

LIFE CYCLE COSTS 
APPENDIX D

TABLE OF CONTENTS

1.0 BASES FOR LIFE CYCLE COST ESTIMATES D-1

2.0 LIFE CYCLE COSTS FOR MEASUREMENTS AT THE REACTOR D-6 SITE

2.1 Visual Inspection $\quad D-6$

2.2 Sipping $0-9$

2.3 Ultrasonic Testing $D-12$

2.4 Calorimetry D-15

2.5 Dimensional Measurement D-18

2.6 Gamma Scanning D-21

2.7 Wejghing D-24

3.0 LIFE CYCLE COSTS FOR MEASUREMENTS AT DOE D-27

FACILITIES

3.1 Visual Inspection at the MRS and Repository D-27

3.2 Direct Weighing at MRS D-31

3.3 Costs for Calorimetry at Repository D-34

3.4 Costs for Neutron and Gamma Monitoring D-37 at the Repository

4.0 SUMMARY OF LIFE CYCLE MEASUREMENT COSTS D-40

\section{LIST OF TABLES}

Table No.

Description

Page

D-1 Shipment Schedule for Typical Reactors D-2

D-2 Receipt Schedule for MRS D-4

D-3 Respository Receipts D-5

D-4 Estimared Capital Cost of Visual Inspection Equipment D-6

D-5 Estimated Annual Operating Costs for Visual Inspection D-7 of Spent Fuel Assemblies at Reactor Site

D-6 Estimated Life Cycle Costs for Visual Examination of $\quad$ D-8 Spent Fuel Assemblies at Reactor Sites

D-7 Estimated Capital Cost of Water/Gas Sipping Facility $\quad 0-9$ 
Table No.

Description

Page

D-8

Estimated Annual Operating Costs for Water/Gas Sipping D-10 of Spent Fuel Assemblies at Reactor site

D-9

Estimated Life Cycle Costs for Sipping of Spent Fuel Assemblies at Reactor Sites

$D-10$

Estimated Capital cost of an Ultrasonic Testing Facility

D-11 Estimated Annual Operating Costs for U1trasonic
Testing of Spent Fuel Assemblies at Reactor Site

Estimated Life Cycle Costs for. Ultrasonic Testing of Spent Fuel Assemblies at Reactor Sites

D-13 Estimated Capital Cost of Calorimetry of Spent Fuel Assemblies at a Reactor Site

Estimated Annual Operating Costs for Calorimetry of Spent Fuel Assemblies at Reactor Site

Estimated Capital Cost of a Dimensional Measurement Facility

Estimated Annual Operating Costs for Dimensional
Measurement of Spent Fuel Assemblies at Reactor Site

Estimated Life Cycle Costs for Dimensional Measurement of Spent Fuel Assemblies at Reactor Sites 
D-26 Estimated Annual Operating Costs for Visual Inspection of Spent Fuel Received the MRS and Repository

D-27 Estimated Life Cycle Costs for Visual Inspection of $\quad 0-30$ Spent Fuel Assemblies at the MRS and Repository

D-28 Estimated Capital Cost for Weighing D-31

D-29 Estimated Annual Operating Costs for Weighing D-32 Spent Fuel

$\begin{array}{lll}0-30 & \text { Weighing at MRS } & \text { D-33 }\end{array}$

$\begin{array}{lll}\text { D-31 Estimated Capital Cost of Calorimeter Equipment } & \text { D-34 }\end{array}$

D-32 Estimated Annual Operating Costs for Sampling D-35

D-33 Sampling Calorimetry at Repository D-36

D-34 Estimated Capital Cost of Neutron/Gamma Equipment D-37

D-35 Estimated Annual Operating Costs of Neutron/Gamma D-38 Monitoring

D-36 Neutron/Gamma Monitoring at Repository D-39

D-37 Summary of Unit Measurement Costs D-40 


\section{APPENDIX D}

\section{LIFE CYCLE COSTS}

Life cycle costs are based on estimates of equipment costs, estimates of replacement equipment costs at appropriate times in the life of the operation, and on annual operating costs. All costs are estimated in 1987 dollars and discounted at a rate of 3\% to the year 1987 from the year in which the costs are incurred. In addition, the quantities of fuel valued at $\$ 1$ per unit are discounted at the same rate to 1987 from the year in which the fuel is transferred from the reactor site to a DOE receipt facility. Unit costs are then determined by dividing the total discounted cost by the discounted total of fuel shipped or received, valued at $\$ 1$ per unit.

The necessary assumptions as to operating costs and shipping and receipt schedules are presented in the following section. Subsequent sections give detailed cost estimates of each of the measurements discussed in Section 4.0 .

\subsection{BASES FOR LIFE CYCLE COST ESTIMATES}

Operating costs in 1987 dollars are based on an earlier JAI study (JAI-254, May 1985) in which it was determined that labor, burden, and overhead could be included in a single rate to labor hours; that rate was found to be $\$ 55$ in 1987 dollars. Miscellaneous supplies were found to be covered by a rate of $\$ 8$ per labor hour and maintenance of equipment is included at $5 \%$ of initial capital costs per year. These values are used with estimates of labor required to accomplish each measurement to provide an estimate of annual operating cost. Contingencies were estimated to be $30 \%$ except for the use of $20 \%$ in instances where costs were judged to be better known.

For measurements to be made at the reactor site, life cycle cost estimates are based on the assumed shipping schedules and corresponding discounted quantities of fuel shown in Table D-1. Also shown are the number of assemblies (using 0.461 MTU/PWR assembly and 0.183 MTU/BWR assembly) handled per year since many of the costs will be based on the labor hours required for each assembiy. 
TABLE $0-1$

\section{SHIPMENT SCHEDULE FOR TYPICAL REACTORS}

PWR

\begin{tabular}{|c|c|c|}
\hline MTU/Yr. & $\begin{array}{c}\text { Assemblies } \\
\text { Per Vear }\end{array}$ & $\begin{array}{c}\text { Discounted } \\
\text { C } 3 \% / Y r \text {. } \\
\text { To } 1987\end{array}$ \\
\hline
\end{tabular}

12.00

12.00

12.00

12.00

12.00

26.67

26.67

26.67

26.67

26.67

26.67

26.67

26.67

26.67

26.67

26.67

26.67

26.67

26.67

26.67

26.67

26.67

26.67

26.67

26.67

26.67

45.00

45.00

\section{6}

26

26

26

26

58

58

58
58

58

58

58

58

58

58

58

58

58

58

58

58

58

58

58

58

58

58

98
8.67

8.42

8.17

7.93

7.70

16.62

16.14

15.67

15.21

14.77

14.34

13.92

13.51

13.12

12.74

12.37

12.01

11.66

11.32

10.99

10.67

10.36

10.06

9.76

9.48

9.20

15.07

14.64

334.48
BWR

\begin{tabular}{ccc}
\hline & & Discounted \\
MTU/Yr. & Assemblies & O $3 \% / Y r$ \\
Per Year & To 1987 \\
\hline
\end{tabular}

15.00

15.00

15.00

15.00

15.00

34.67

34.67

34.67

34.67

34.67

34.67

34.67

34.67

34.67

34.67

34.67

34.67

34.67

34.67

34.67

34.67

34.67

34.67

34.67

34.67

34.67

70.00

70.00
10.84

10.52

10.21

9.92

9.63

21.61

20.98

20.36

19.77

19.20

18.64

18.09

17.57

17.06

16.56

16.08

15.61

15.15

14.71

14.28

13.87

13.46

13.07

12.69

12.32

11.96

23.45

22.77

440.37 
For measurements to be made at DOE receipt facilities, the receipt schedule is taken to be that given in the OCRWM Mission Plan Amendment of June 1987 (DOE/RW-0128) for fuel received at the MRS and similarly for fuel received at the repository. However, it should be noted that the level unit costs calculated are not sensitive to schedule changes. Based on the assumption that two thirds of the fuel received is from PWRs and one third from BWRs, the amount of fuel, the discounted value of fuel at unit cost, and the number of assemblies of each kind are all shown in Table D-2 for MRS receipts.

Table D-3 gives the amount of fuel and the discounted amount of fuel received at the repository. The average annual number of waste packages is determined by appiying the package loadings given in the site Characterization Plan for the tuff repository, as follows:

\begin{tabular}{cc}
\multicolumn{2}{c}{ Tuff } \\
\hline PWR & BWR \\
3 & 6 \\
6 & 18 \\
1.38 & 1.09 \\
2.77 & 3.29
\end{tabular}

Assuming that the repository receives 2650 MTU of consolidated fuel from the MRS and 350 MTU of intact fuel direct from the utilities, of which $2 / 3$ is PWR fuel, the average annual number of waste packages is 1182 packages/year. 
TABLE $0-2$

RECEIPT SCHEDULE FOR MRS

PWR

\begin{tabular}{|c|c|c|}
\hline MTU/Yr. & $\begin{array}{c}\text { Assemblies } \\
\text { Per Year }\end{array}$ & $\begin{array}{c}\text { Discounted } \\
03 \% / \mathrm{Yr} \\
\text { To } 1987 \\
\end{array}$ \\
\hline 800 & 1735 & 577.94 \\
\hline 800 & 1735 & 561.10 \\
\hline 800 & 1735 & 544.76 \\
\hline 800 & 1735 & 528.89 \\
\hline 800 & 1735 & 513.49 \\
\hline 1333 & 2892 & 830.68 \\
\hline 1767 & 3833 & 1069.06 \\
\hline 1767 & 3833 & 1037.93 \\
\hline 1767 & 3833 & 1007.70 \\
\hline 1767 & 3833 & 978.35 \\
\hline 1767 & 3833 & 949.85 \\
\hline 1767 & 3833 & 922.18 \\
\hline 1767 & 3833 & 895.32 \\
\hline 1767 & 3833 & 869.25 \\
\hline 1767 & 3833 & 843.93 \\
\hline 1767 & 3833 & 819.35 \\
\hline 1767 & 3833 & 795.48 \\
\hline 1767 & 3833 & 772.31 \\
\hline 1767 & 3833 & 749.82 \\
\hline 1767 & 3833 & 727.98 \\
\hline 1767 & 3833 & 706.78 \\
\hline 1767 & 3833 & 686.19 \\
\hline 1767 & 3833 & 666.21 \\
\hline 1767 & 3833 & 646.80 \\
\hline 1767 & 3833 & 627.96 \\
\hline 940 & 2039 & 324.33 \\
\hline 3 & & 1965. \\
\hline
\end{tabular}

\begin{tabular}{ccc}
\multicolumn{3}{c}{ BWR } \\
\hline & & $\begin{array}{c}\text { Discounted } \\
\text { Assembijes }\end{array}$ \\
MTU/Yr. & $\begin{array}{c}\text { Per Year } \\
\text { To } 1987\end{array}$ \\
\cline { 2 - 3 } 400 & 2186 & 288.97 \\
400 & 2186 & 280.55 \\
400 & 2186 & 272.38 \\
400 & 2186 & 264.45 \\
400 & 2186 & 256.74 \\
667 & 3645 & 415.56 \\
883 & 4825 & 534.23 \\
883 & 4825 & 518.67 \\
883 & 4825 & 503.56 \\
883 & 4825 & 488.90 \\
883 & 4825 & 474.66 \\
883 & 4825 & 460.83 \\
883 & 4825 & 447.41 \\
883 & 4825 & 434.38 \\
883 & 4825 & 421.73 \\
883 & 4825 & 409.44 \\
883 & 4825 & 397.52 \\
883 & 4825 & 385.94 \\
883 & 4825 & 374.70 \\
883 & 4825 & 363.78 \\
883 & 4825 & 353.19 \\
883 & 4825 & 342.90 \\
883 & 4825 & 332.91 \\
883 & 4825 & 323.22 \\
883 & 4825 & 313.80 \\
470 & 2568 & 162.17 \\
\hline 19914 & & 9822.67
\end{tabular}


TABLE D-3

\section{REPOSITORY RECEIPTS}

PWR

\begin{tabular}{cr}
\hline & $\begin{array}{r}\text { Discounted } \\
\text { MTU/Yr. } 3 \% / \text { Yr. } \\
\text { To } 1987\end{array}$ \\
\cline { 2 - 2 } 267 & 166.39 \\
267 & 161.54 \\
267 & 156.83 \\
600 & 342.17 \\
1200 & 664.41 \\
2000 & 1075.10 \\
2000 & 1043.79 \\
2000 & 1013.38 \\
2000 & 983.87 \\
2000 & 955.21 \\
2000 & 927.39 \\
2000 & 900.38 \\
2000 & 874.15 \\
2000 & 848.69 \\
2000 & 823.97 \\
2000 & 799.97 \\
2000 & 776.67 \\
2000 & 754.05 \\
2000 & 732.09 \\
2000 & 710.77 \\
2000 & 690.06 \\
2000 & 669.97 \\
2000 & 650.45 \\
2000 & 631.51 \\
2000 & 613.11 \\
973 & 289.59 \\
\hline & \\
43576 & 18255.53
\end{tabular}

BWR

\begin{tabular}{|c|c|}
\hline MTU/Yr. & $\begin{array}{c}\text { Discounted } \\
\text { a } 3 \% / Y r \\
\text { To } 1987 \\
\end{array}$ \\
\hline $\begin{array}{r}133 \\
133 \\
133 \\
300 \\
600 \\
1000 \\
1000 \\
1000 \\
1000 \\
1000 \\
1000 \\
1000 \\
1000 \\
1000 \\
1000 \\
1000 \\
1000 \\
1000 \\
1000 \\
1000 \\
1000 \\
1000 \\
1000 \\
1000 \\
1000 \\
487\end{array}$ & $\begin{array}{r}82.88 \\
80.47 \\
78.12 \\
171.09 \\
332.81 \\
537.55 \\
521.89 \\
506.69 \\
491.93 \\
477.61 \\
463.69 \\
450.19 \\
437.08 \\
424.35 \\
411.99 \\
399.99 \\
388.34 \\
377.03 \\
366.04 \\
355.38 \\
345.03 \\
334.98 \\
325.23 \\
315.75 \\
306.56 \\
144.94\end{array}$ \\
\hline 21786 & 9127.01 \\
\hline
\end{tabular}


2.0 LIFE CYCLE COSTS FOR MEASUREMENTS AT THE REACTOR SITE

The purpose of this section is to quantify the costs of performing various fuel measurements at a utility reactor site. Estimates are included for visual inspection, sipping, uitrasonic testing, calorimetry, dimensional measurement, gamma scanning, and weighing.

\subsection{VISUAL INSPECTION}

The estimated capital costs for equipment to perform a thorough visual inspection of spent fuel assemblies in a reactor pool are shown in Table D-4.

TABLE D-4

ESTIMATED CAPITAL COST OF VISUAL INSPECTION EQUIPMENT

$(\$ 000,1987)$

Item

Pool Support Structure

Lights on Pool Wall

Rack to Hold Assembly

Pool Modification

CCTV system

Borescope System

Cables and Controls

Subtotal

Installation (35\%)

Engineering/Design

Subtotal

Contingency $(30 \%)$

Total
Estimated Cost

$\$ 8.0$

2.2

19.6

28.7

21.6

12.5

3.0

95.6

33.5

33.9

163.0

48.9

$\$ 211.9$

In addition to the initial capital costs, it is estimated that $\$ 50,000$ in equipment replacement costs would be incurred every fifth year. 
In order to determine operating costs, the manpower requirements are estimated to be 9.6 man-hours per PWR assembly and 6.7 man-hours per BWR assembly. Annual operating cost are estimated based on these manpower requirements, the unit costs 1 isted in Section 1.0 and the receipt schedule of Table D-1. The estimated annual operating costs are summarized in Table D-5.

\section{TABLE D-5}

ESTIMATED ANNUAL OPERATING COSTS FOR VISUAL INSPECTION OF

SPENT FUEL ASSEMBLIES AT REACTOR SITE

$(\$ 000,1987)$

Years 1-5

Labor, Burden and Overhead

PWR

$\underline{B W R}$

Supplies

$\$ 13.8$

$\$ 30.4$

Maintenance

2.0

4.4

Total

10.6

10.6

$\$ 26.4$

$\$ 45.4$

Years 6-26

Labor, Burden and Overhead

$\$ 30.7$

$\$ 70.0$

Supplies

4.5

10.2

Maintenance

10.6

10.6

Total

$\$ 45.8$

$\$ 90.8$

\section{Years $27-28$}

Labor, Burden and Overhead

$\$ 51.9$

$\$ 141.9$

Supplies

7.5

20.7

Maintenance

$\frac{10.6}{\$ 70.0}$

10.6

Total

$\$ 173.2$

Using the initial capital cost, the $\$ 50,000$ cost of equipment replacement at five year intervals, and the annual operating costs, the estimated life cycle costs are shown in Table D-6. 
TABLE D-6

ESTIMATED LIFE CYCLE COSTS FOR VISUAL EXAMINATION OF

SPENT FUEL ASSEMBLIES AT REACTOR SITES

$(\$ 000)$

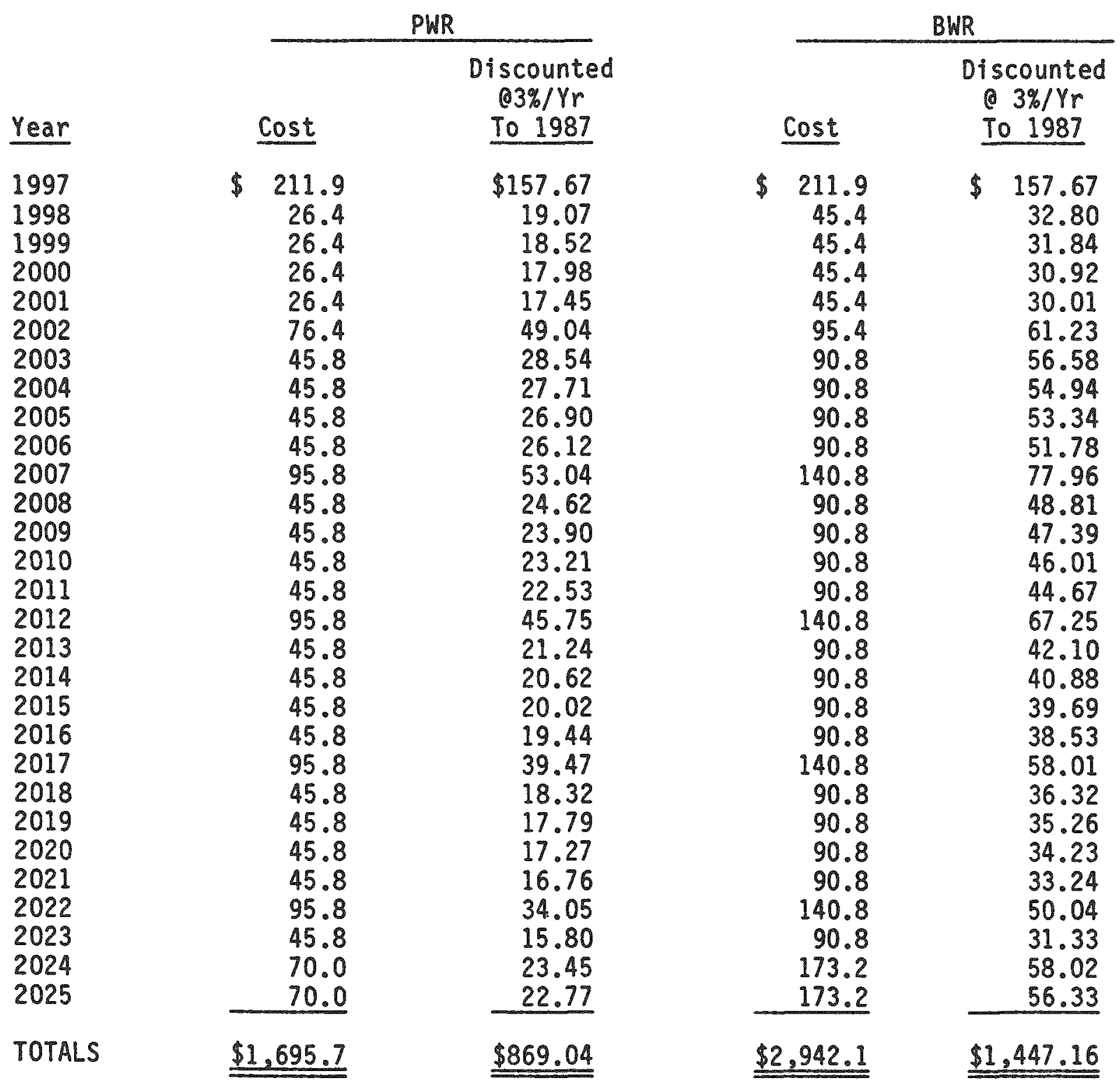

Using discounted amounts of unit-valued spent fuel from Table D-1 gives unit costs of $\$ 2.60 / \mathrm{kgU}$ for PWR assemblies and $\$ 3.29 / \mathrm{kgU}$ for BWR assemblies. 


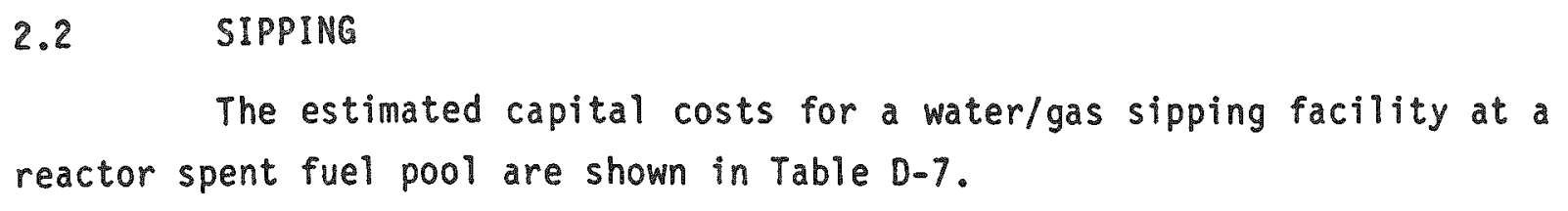

The estimated capital costs for a water/gas sipping facility at a reactor spent fuel pool are shown in Table D-7.

TABLE D-7

ESTIMATED CAPITAL COST OF WATER/GAS SIPPING FACILITY

$(\$ 000,1987)$

Item

Pool Support Structure

Lights on Pool Wall

Rack to Hold Assembly

Pool Modification

Water/Gas Sipping System

Subtotal

Installation (35\%)

Engineering/Design

Subtotal

Contingency $(20 \%)$

Total
Estimated Cost

$\$ 8.0$

2.2

19.6

28.7

182.9

241.4

84.5

50.8

376.7

75.3

$\$ 452.0$

In addition to the initial capital costs, it is estimated that $\$ 50,000$ in equipment replacement costs would be incurred every fifth year.

In order to determine operating costs, the manpower requirements are estimated to be 6.2 manhours per fuel assembly. Annual operating costs, shown in Table $D-8$, are based on the unit costs of Section 1.0 and the shipping schedule of Table D-1. 
TABLE D-8

ESTIMATED ANNUAL OPERATING COSTS FOR WATER/GAS SIPPING OF

SPENT FUEL ASSEMBLIES AT REACTOR SITE

$(\$ 000,1987)$

Years 1-5

Labor, Burden and Overhead

PWR

BWR

Supplies

$\$ 8.9$

$\$ 28.0$

Maintenance

1.3

4.1

Total

22.6

22.6

$\$ 32.8$

$\$ 54.7$

\section{Years 6-26}

Labor, Burden and Overhead

Supplies

$\$ 19.8$

$\$ 64.5$

Maintenance

2.9

9.4

Total

22.6

22.6

$\$ 45.3$

$\$ 96.5$

Years 27-28

Labor, Burden and Overhead

$\$ 33.4$

$\$ 130.6$

Supplies

4.9

19.0

Maintenance

22.6

22.6

Total

$\$ 60.9$

$\$ 172.2$

Using the initial capital cost, the $\$ 50,000$ cost of equipment replacement at five year intervals, and the annual operating costs, the estimated life cycle costs are shown in Table $0-9$. 
TABLE D-9

ESTIMATED LIFE CYCLE COSTS FOR SIPPING OF

SPENT FUEL ASSEMBLIES AT REACTOR SITES

$(\$ 000)$

PWR

Discounted
O3\%/Yr
To 1987
Cost

Year

1997

1998

1999

2000

2001

2002

2003

2004

2005

2006

2007

2008

2009

2010

2011

2012

2013

2014

2015

2016

2017

2018

2019

2020

2021

2022

2023

2024

2025

TOTALS
$\$$

452.0
32.8

32.8

32.8

32.8

82.8

45.3

45.3

45.3

45.3

95.3

45.3

45.3

45.3

45.3

95.3

45.3

45.3

45.3

45.3

95.3

45.3

45.3

45.3

45.3

95.3

45.3

60.9

60.9

\section{$\$ 1,939.1$}

$\$ 336.33$

23.70

23.01

22.34

21.68

53.15

28.23

27.41

26.61

25.83

52.77

24.35

23.64

22.95

22.28

45.52

21.01

20.39

19.80

19.22

39.26

18.12

17.59

17.08

16.58

33.87

15.63

20.40

19.81

$\$ 1058.55$
BWR

Discounted

C $3 \% / \mathrm{rr}$

Cost

To 1987

$\$ 452.0$

54.7

54.7

54.7

54.7

104.7

96.5

96.5

96.5

96.5

146.5

96.5

96.5

96.5

96.5

146.5

96.5

90.8

96.5

96.5

146.5

96.5

96.5

96.5

96.5

146.5

96.5

172.2

172.2

$\$ 3346.4$
$\$ 336.33$

39.52

38.37

37.25

36.16

67.20

60.14

58.38

56.68

55.03

81.11

51.87

50.36

48.90

47.47

69.97

44.75

43.44

42.18

40.95

60.36

38.60

37.47

36.38

35.32

52.06

33.30

57.68

56.00

Using discounted amounts of spent fuel from Table $D-1$ gives unit costs of $\$ 3.16 / \mathrm{kgU}$ for PWR assemblies and $\$ 3.89 / \mathrm{kgU}$ for BWR assemblies. 
2.3 ULTRASONIC TESTING

The estimated capital costs for an ultrasonic testing facility at a reactor spent fuel pool are shown in Table D-10.

TABLE D-10

ESTIMATED CAPITAL COST OF AN ULTRASONIC TESTING FACILITY

$(\$ 000,1987)$

I tem

Pool Support Structure

Lights on Pool Wall

Rack to Hold Assembly

Pool Modification

UItrasonic Testing System

Subtotal

Installation (35\%)

Engineering/Design

Subtotal

Contingency (20\%)

Total
Estimated Cost

$\$ 8.0$

2.2

19.6

28.7

421.6

480.1

168.0

$\frac{70.0}{718.1}$

143.6

$\$ 861.7$

In addition to the initial capital costs, it is estimated that $\$ 75,000$ in equipment replacement costs would be incurred every fifth year.

In order to determine operating costs, the manpower requirements are estimated to be 4.1 manhours per fuel assembly. Annual operating costs, shown in Table D-11 are based on the unit costs of Section 1.0 and the shipping schedule of Table D-1. 
TABLE D-11

ESTIMATED ANNUAL OPERATING COSTS FOR ULTRASONIC TESTING OF

SPENT FUEL ASSEMBLIES AT REACTOR SITE

$(\$ 000,1987)$

\section{Years $1-5$}

Labor, Burden and Overhead

PWR

BWR

Supplies

$\$ 5.9$

$\$ 18.5$

Maintenance

0.9

2.7

Total

43.1

43.1

$\$ 49.9$

$\$ 64.3$

Years 6-26

Labor, Burden and Overhead

$\$ 13.1$

$\$ 42.6$

Supplies

1.9

6.2

Maintenance

43.1

43.1

Total

$\$ 58.1$

$\$ 91.9$

Years $27-28$

Labor, Burden and Overhead

$\$ 22.1$

$\$ 86.4$

Supplies

3.2

12.6

Maintenance

43.1

43.1

Total

$\$ 68.4$

$\$ 142.1$

Using the initial capital cost, the $\$ 75,000$ cost of equipment replacement at five year intervals, and the annual operating costs, the estimated life cycle costs are shown in Table D-12. 
TABLE $0-12$

ESTIMATED LIFE CYCLE COSTS FOR ULTRASONIC TESTING OF

SPENT FUEL ASSEMBLIES AT REACTOR SITES

$(\$ 000)$

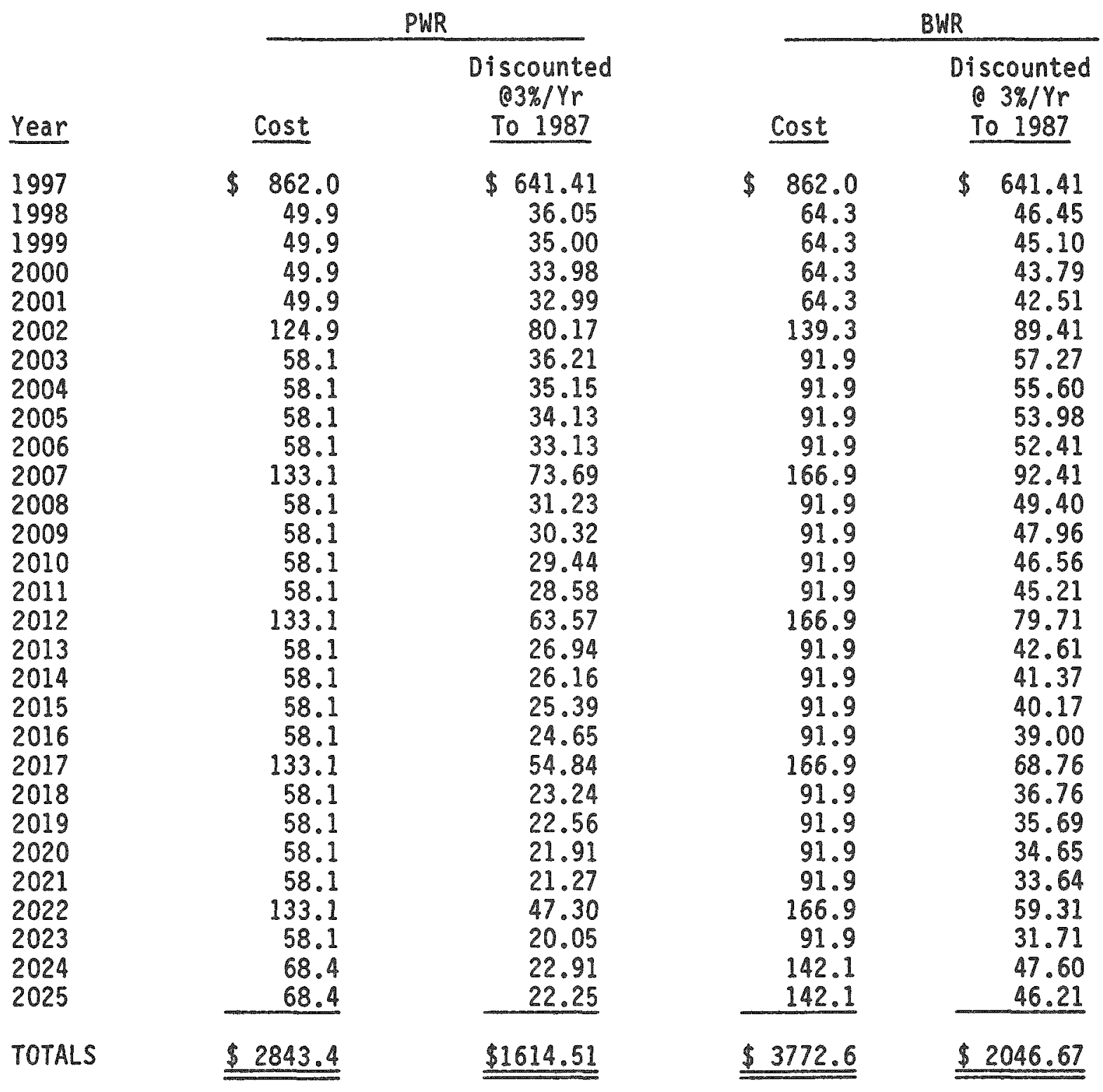

Using discounted amounts of spent fuel from Table $D-1$ gives unit costs of $\$ 4.83 / \mathrm{kgU}$ for PWR assembilies and $\$ 4.65 / \mathrm{kgU}$ for BWR assemblies. 
2.4 CALORIMETRY

The estimated capital costs for a facility to perform calorimetry of spent fuel assemblies in the reactor pool are shown in Table D-13.

TABLE D-13

ESTIMATED CAPITAL COST OF CALORIMETRY OF SPENT FUEL ASSEMBLIES

AT A REACTOR SITE

$(\$ 000,1987)$

Item

Estimated Cost

Pool Support Structure

$\$ 8.0$

Lights on Pool Wall

2.2

Rack to Hold Assembly

19.6

Pool Modification

56.5

Calorimeter and Accessories

105.5

Subtotal

191.8

Installation (35\%)

67.1

Engineering/Design

90.4

Subtotal

349.3

Contingency (20\%)

69.9

Total

$\$ 419.2$

In addition to the initial capital costs, it is estimated that $\$ 50,000$ in equipment replacement costs would be incurred every fifth year.

In order to determine operating costs, the manpower requirements are estimated to be 12.5 manhours per fuel assembly. Annual operating costs, shown in Table D-14, are based on the unit costs of Section 1.0 and the shipping schedule of Table D-1. 
TABLE D-14

ESTIMATED ANNUAL OPERATING COSTS FOR CALORIMETRY OF

SPENT FUEL ASSEMBLIES AT REACTOR SITE

$(\$ 000,1987)$

Years $1-5$

Labor, Burden and Overhead

Supplies

PWR

BWR

Maintenance

Total

$\$ 18.0$

$\$ 56.8$

2. 6

8.3

21.0

21.0

$\$ 41.6$

$\$ 86.1$

Years 6-26

Labor, Burden and Overhead

$\$ 40.2$

$\$ 131.0$

Supplies

5.8

19.1

Maintenance

21.0

21.0

Total

$\$ 67.0$

$\$ 171.1$

Years $27-28$

Labor, Burden and Overhead

$\$ 67.9$

$\$ 265.4$

Supplies

9.9

38.6

Maintenance

21.0

21.0

Total

$\$ 98.8$

$\$ 325.0$

Using the initial capital cost, the $\$ 50,000$ cost of equipment replacement at five year intervals, and the annual operating costs, the estimated life cycle costs are shown in Table D-15. 
TABLE D-15

ESTIMATED LIFE CYCLE COSTS FOR CALORIMETRY OF SPENT FUEL ASSEMBLIES AT REACTOR SITES

$(\$ 000)$

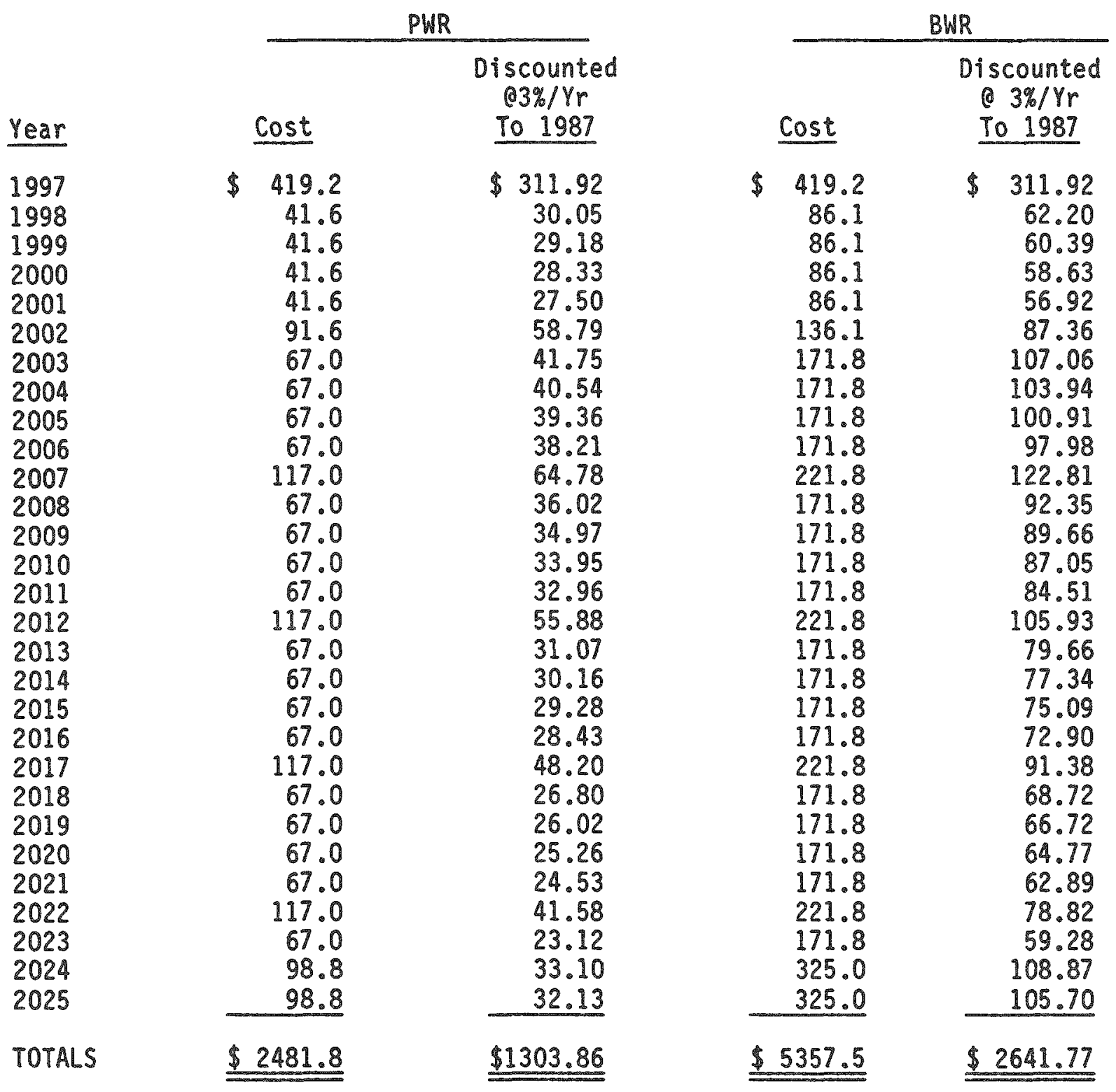

Using discounted amounts of spent fuel from Table D-1 gives unit costs of $\$ 3.90 / \mathrm{kgU}$ for PWR assemblies and $\$ 6.00 / \mathrm{kgU}$ for BWR assemblies. 
2.5 DIMENSIONAL MEASUREMENT

The estimated capital costs for a dimensional measurement facility at a reactor spent fuel pool are shown in Table $0-16$.

TABLE D-16

ESTIMATED CAPITAL COST OF A DIMENSIONAL MEASUREMENT FACILITY

(\$000, 1987)

Item

Pool Support Structure

Lights on Pool Wall

Rack to Hold Assembly

Pool Modification

Dimensional Measurement System

Subtotal

Installation (35\%)

Engineering/Design

Subtotal

Contingency (30\%)

Total

\section{Estimated Cost}

$\$ 8.0$

2.2

19.6

28.7

38.0

96.5

33.8

33.9

164.2

49.3

$\$ 213.5$

In addition to the initial capital costs, it is estimated that $\$ 25,000$ in equipment replacement costs would be incurred every fifth year.

In order to determine operating costs, the manpower requirements are estimated to be 3.3 manhours per fuel assembly. Annual operating costs, shown in Table $0-17$ are based on the unit costs of Section 1.0 and the shipping schedule of Table D-1. 
TABLE $0-17$

ESTIMATED ANNUAL OPERATING COSTS FOR DIMENSIONAL MEASUREMENT OF

SPENT FUEL ASSEMBLIES AT REACTOR SITE

(\$000, 1987)

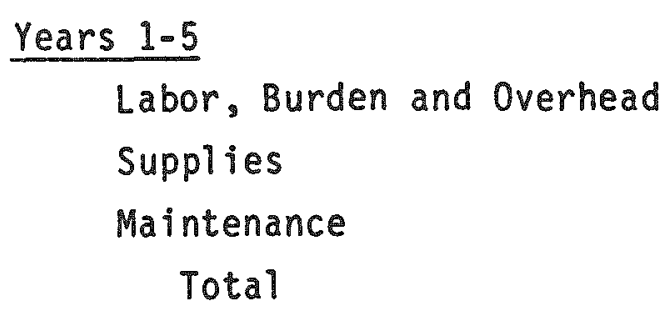

Years $6-26$

Labor, Burden and Overhead

Supplies

Maintenance

Total

\section{Years $27-28$}

Labor, Burden and Overhead

Supplies

Maintenance

Total
PWR

BWR

$$
\$ 4.7
$$

$\$ 14.9$

0.7

2.2

10.7

10.7

$\$ 16.1$

$\$ 27.8$

$\$ 10.5$

$\$ 34.3$

1.5

5.0

10.7

10.7

$\$ 22.7$

$\$ 50.0$

Using the initial capital cost, the $\$ 25,000$ cost of equipment replacement at five year intervals, and the annual operating costs, the estimated life cycle costs are shown in Table D-18. 
TABLE D-18

ESTIMATED LIFE CYCLE COSTS FOR DIMENSIONAL MEASUREMENT OF SPENT FUEL ASSEMBLIES AT REACTOR SITES

$(\$ 000)$

\begin{tabular}{|c|c|c|c|c|c|}
\hline \multirow[b]{2}{*}{ Year } & \multicolumn{2}{|c|}{ PWR } & \multicolumn{3}{|c|}{ BWR } \\
\hline & $\cos t$ & $\begin{array}{c}\text { Discounted } \\
\text { 03\%/Yr } \\
\text { To } 1987 \\
\end{array}$ & $\cos t$ & & $\begin{array}{c}\text { counted } \\
3 \% / Y r \\
01987 \\
\end{array}$ \\
\hline $\begin{array}{l}1997 \\
1998 \\
1999 \\
2000 \\
2001 \\
2002 \\
2003 \\
2004 \\
2005 \\
2006 \\
2007 \\
2008 \\
2009 \\
2010 \\
2011 \\
2012 \\
2013 \\
2014 \\
2015 \\
2016 \\
2017 \\
2018 \\
2019 \\
2020 \\
2021 \\
2022 \\
2023 \\
2024 \\
2025\end{array}$ & $\begin{array}{r}213.5 \\
16.1 \\
16.1 \\
16.1 \\
16.1 \\
41.1 \\
22.7 \\
22.7 \\
22.7 \\
22.7 \\
47.7 \\
22.7 \\
22.7 \\
22.7 \\
22.7 \\
47.7 \\
22.7 \\
22.7 \\
22.7 \\
22.7 \\
47.7 \\
22.7 \\
22.7 \\
22.7 \\
22.7 \\
47.7 \\
22.7 \\
31.1 \\
31.1 \\
\end{array}$ & $\begin{array}{r}\$ 158.86 \\
11.63 \\
11.29 \\
10.96 \\
10.64 \\
26.38 \\
14.15 \\
13.73 \\
13.33 \\
12.95 \\
26.41 \\
12.20 \\
11.85 \\
11.50 \\
11.17 \\
22.78 \\
10.53 \\
10.22 \\
9.92 \\
9.63 \\
19.65 \\
9.08 \\
8.82 \\
8.56 \\
8.31 \\
16.95 \\
7.83 \\
10.42 \\
10.11 \\
\end{array}$ & $\begin{array}{r}213.5 \\
27.8 \\
27.8 \\
27.8 \\
27.8 \\
52.8 \\
50.0 \\
50.0 \\
50.0 \\
50.0 \\
75.0 \\
50.0 \\
50.0 \\
50.0 \\
50.0 \\
75.0 \\
50.0 \\
50.0 \\
50.0 \\
50.0 \\
75.0 \\
50.0 \\
50.0 \\
50.0 \\
50.0 \\
75.0 \\
50.0 \\
90.3 \\
90.3 \\
\end{array}$ & $\$$ & $\begin{array}{l}158.86 \\
20.08 \\
19.50 \\
18.93 \\
18.38 \\
33.89 \\
31.16 \\
30.25 \\
29.37 \\
28.51 \\
41.53 \\
26.88 \\
26.09 \\
25.33 \\
24.60 \\
35.82 \\
23.18 \\
22.51 \\
21.85 \\
21.22 \\
30.90 \\
20.00 \\
19.42 \\
18.85 \\
18.30 \\
26.65 \\
17.25 \\
30.25 \\
29.37\end{array}$ \\
\hline TOTALS & $\$ \quad 957.9$ & $\$ 519.87$ & $\$ 1708.1$ & & 868.94 \\
\hline
\end{tabular}

Using discounted amounts of spent fuel from Table $D-1$ gives unit costs of $\$ 1.55 / \mathrm{kgU}$ for PWR assemblies and $\$ 1.97 / \mathrm{kgU}$ for BWR assemb7ies. 
2.6

GAMMA SCANNING

The estimated capital costs for a gamma scanning facility at a reactor spent fuel pool are shown in Table D-19.

TABLE D-19

ESTIMATED CAPITAL COST OF A GAMMA SCANNING FACILITY

$(\$ 000,1987)$

Item

Pool Support Structure

Lights on Pool Wall

Rack to Hold Assembly

Pool Modification

Gamma Scan Equipment and Accessories

Subtotal

Installation (35\%)

Engineering/Design

Subtotal

Contingency (30\%)

Total
Estimated Cost

$\$ 8.0$

2.2

19.6

28.7

254.0

312.5

109.4

$\frac{76.2}{498.1}$

149.4

$\$ 647.5$

In addition to the initial capital costs, it is estimated that $\$ 100,000$ in equipment replacement costs would be incurred every fifth year.

In order to determine operating costs, the manpower requirements are estimated to be 13.3 manhours per fuel assembly. Annual operating costs, shown in Table D-20, are based on the unit costs of Section 1.0 and the shipping schedule of Table $D-1$. 
TABLE D-20

ESTIMATED ANNUAL OPERATING COSTS FOR GAMMA SCANNING OF

SPENT FUEL ASSEMBLIES AT REACTOR SITE

$(\$ 000,1987)$

$\frac{\text { Years } 1-5}{\text { Labor, Burden and Overhead }}$
Supplies
Maintenance
Total

Years 6-26

Labor, Burden and Overhead

Supplies

Maintenance

Total

Years 27-28
PWR

BWR

$\$ 19.0$

$\$ 60.0$

3.0

9.6

32.4

32.4

$\$ 54.4$

$\$ 102.0$

$\$ 42.4$

$\$ 138.3$

6.8

22.1

32.4

$\$ 81.6$

32.4

$\$ 192.8$

Labor, Burden and Overhead

$\$ 71.7$

$\$ 280.2$

Supplies

8.4

44.8

Maintenance

32.4

32.4

Total

$\$ 112.5$

$\$ 357.4$

Using the initial capital cost, the $\$ 100,000$ cost of equipment replacement at five year intervals, and the annual operating costs, the estimated life cycle costs are shown in Table D-21. 
TABLE D-21

ESTIMATED LIFE CYCLE COSTS FOR GAMMA SCANNING OF

SPENT FUEL ASSEMBLIES AT REACTOR SITES

$(\$ 000)$

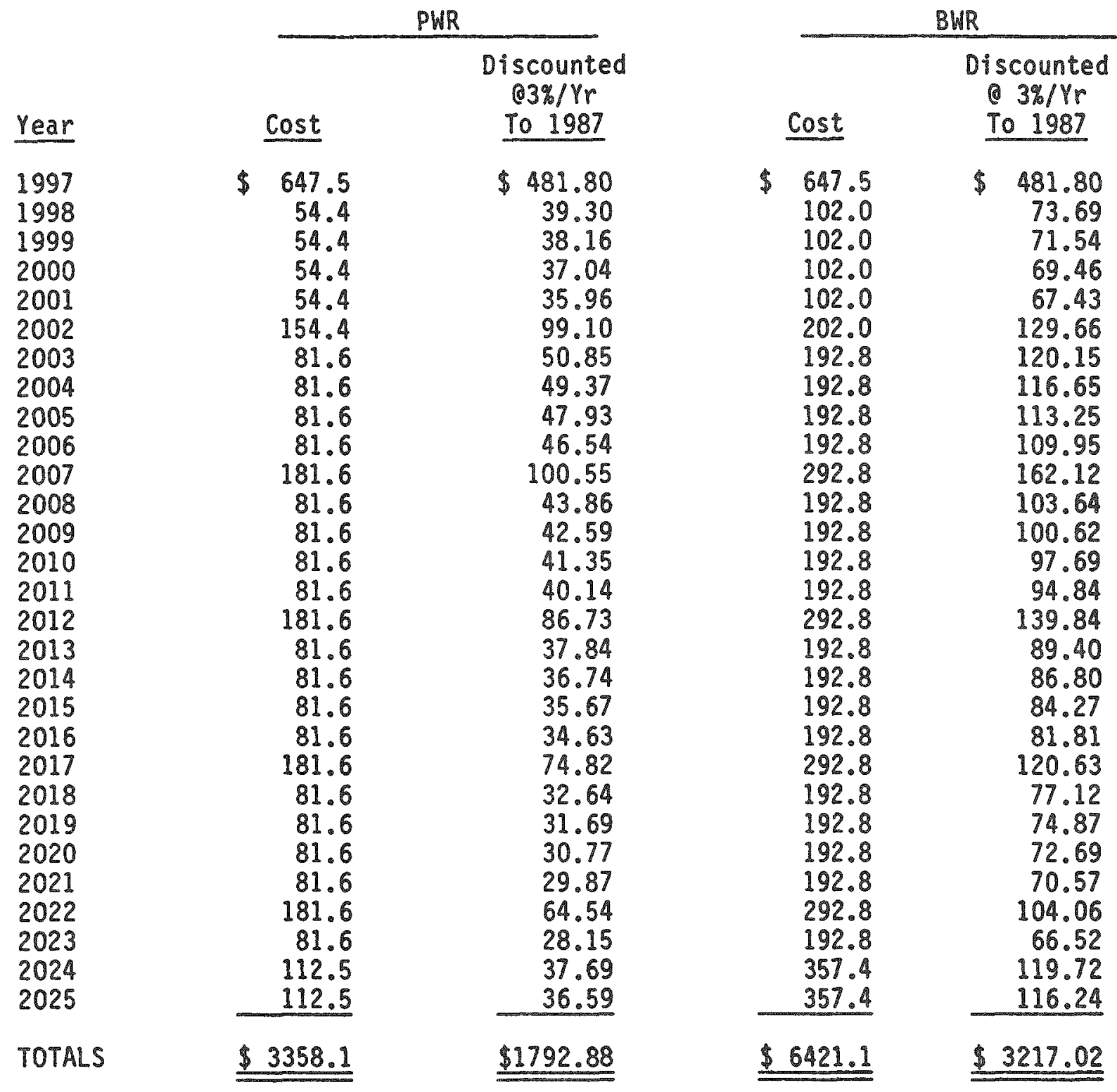

Using discounted amounts of spent fuel from Table D-1 gives unit costs of $\$ 5.36 / \mathrm{kgU}$ for PWR assembities and $\$ 7.31 / \mathrm{kgU}$ for BWR assembities. 


\subsection{WEIGHING}

The estimated capital costs for a weighing facility at a reactor spent fuel pool are shown in Table D-22.

TABLE D-22

ESTIMATED CAPITAL COST OF A WEIGHING FACILITY

$(\$ 000,1987)$

Item

Load Cell, Recorder

Installation (35\%)

Engineering/Design

Subtotal

Contingency $(30 \%)$

Total
Estimated Cost

$\$ 13.2$

4.6

5.1

22.9

6.9

$\$ 29.8$

In addition to the initial capital costs, it is estimated that $\$ 10,000$ in equipment replacement costs would be incurred every fifth year.

In order to determine operating costs, the manpower requirements are estimated to be 1.4 manhours per fuel assembly. Annual operating costs, shown in Table D-23, are based on the unit costs of Section 5.1 and the shipping schedule of Table D-1. 
TABLE D-23

ESTIMATED ANNUAL OPERATING COSTS FOR WEIGHING OF

SPENT FUEL ASSEMBLIES AT REACTOR SITES

$(\$ 000,1987)$

Years 1-5

Labor, Burden and Overhead

Supplies

PWR

$\underline{B W R}$

Maintenance

Total

$\$ 2.0$

$\$ 6.3$

0.3

0.9

1.5

1.5

$\$ 3.8$

$\$ 8.7$

Years $6-26$

Labor, Burden and Overhead

$\$ 4.5$

$\$ 14.6$

Supplies

0.7

2.1

Maintenance

Total

$\$ \frac{1.5}{\$ 6.7}$

$\frac{1.5}{\$ 21.9}$

\section{Years $27-28$}

Labor, Burden and Overhead

Supplies

$\$ 7.5$

$\$ 29.5$

1.1

4.3

Maintenance

1.5

1.5

Total

$\$ 10.1$

$\$ 35.3$

Using the initial capital cost, the $\$ 10,000$ cost of equipment replacement at five year intervals, and the annual operating costs, the estimated life cycle costs are shown in Table D-24. 
TABLE D-24

ESTIMATED LIFE CYCLE COSTS FOR WEIGHING OF

SPENT FUEL ASSEMBLIES AT REACTOR SITES

$(\$ 000)$

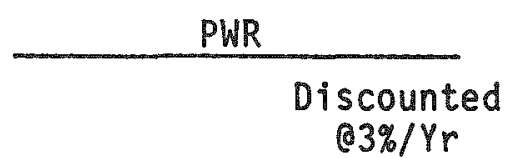

\begin{tabular}{|c|c|c|c|c|c|c|c|c|}
\hline Year & & ost & & $\begin{array}{l}3 \% / Y r \\
1987 \\
\end{array}$ & & ost & & $\begin{array}{r}3 \% / \gamma r \\
1987 \\
\end{array}$ \\
\hline $\begin{array}{l}1997 \\
1998 \\
1999 \\
2000 \\
2001 \\
2002 \\
2003 \\
2004 \\
2005 \\
2006 \\
2007 \\
2008 \\
2009 \\
2010 \\
2011 \\
2012 \\
2013 \\
2014 \\
2015 \\
2016 \\
2017 \\
2018 \\
2019 \\
2020 \\
2021 \\
2022 \\
2023 \\
2024 \\
2025\end{array}$ & $\$$ & $\begin{array}{r}29.8 \\
3.8 \\
3.8 \\
3.8 \\
3.8 \\
13.8 \\
6.7 \\
6.7 \\
6.7 \\
6.7 \\
16.7 \\
6.7 \\
6.7 \\
6.7 \\
6.7 \\
16.7 \\
6.7 \\
6.7 \\
6.7 \\
6.7 \\
16.7 \\
6.7 \\
6.7 \\
6.7 \\
6.7 \\
16.7 \\
6.7 \\
10.1 \\
10.1 \\
\end{array}$ & & $\begin{array}{r}22.17 \\
2.75 \\
2.67 \\
2.59 \\
2.51 \\
8.86 \\
4.18 \\
4.05 \\
3.94 \\
3.82 \\
9.25 \\
3.60 \\
3.50 \\
3.39 \\
3.30 \\
7.98 \\
3.11 \\
3.02 \\
2.93 \\
2.84 \\
6.88 \\
2.68 \\
2.60 \\
2.53 \\
2.45 \\
5.93 \\
2.31 \\
3.38 \\
3.28 \\
\end{array}$ & $\$$ & $\begin{array}{r}29.8 \\
8.7 \\
8.7 \\
8.7 \\
8.7 \\
18.7 \\
21.9 \\
21.9 \\
21.9 \\
21.9 \\
31.9 \\
32.9 \\
21.9 \\
21.9 \\
21.9 \\
31.9 \\
21.9 \\
21.9 \\
21.9 \\
21.9 \\
31.9 \\
21.9 \\
21.9 \\
21.9 \\
21.9 \\
31.9 \\
21.9 \\
35.3 \\
35.3 \\
\end{array}$ & $\$$ & $\begin{array}{r}22.17 \\
6.29 \\
6.10 \\
5.92 \\
5.75 \\
12.00 \\
13.65 \\
13.65 \\
13.25 \\
12.86 \\
17.66 \\
11.77 \\
11.43 \\
11.10 \\
10.77 \\
15.24 \\
10.15 \\
9.86 \\
9.57 \\
9.29 \\
13.14 \\
8.76 \\
8.50 \\
8.26 \\
8.02 \\
11.34 \\
7.56 \\
11.82 \\
11.48 \\
\end{array}$ \\
\hline TOTALS & & 259.7 & & 132.49 & 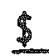 & 653.8 & \pm & 316.22 \\
\hline
\end{tabular}

Using discounted amounts of spent fuel from Table D-1 gives unit costs of $\$ 0.40 / \mathrm{kgU}$ for PWR assemblies and $\$ 0.72 / \mathrm{kgU}$ for BWR assemblies. 
3.0 LIFE CYCLE COSTS FOR MEASUREMENTS AT DOE FACILITIES

Life cycle costs are estimated for operations expected to be performed at the MRS and for those expected to be performed at the repository.

3.1 VISUAL INSPECTION AT THE MRS AND REPOSITORY

The spent fuel assemblies received at the MRS and repository are to be visually inspected for identification and condition as they are individually unloaded from the from-reactor transport cask. Each of the 4 cask unloading cells at the MRS and 1 unloading cell at the repository are assumed to be equipped and staffed for the visual inspection function. Each cell will have 2 complete sets of inspection equipment with remote change-out capability. The estimated capital cost of equipment is shown in Table D-25.

TABLE D-25

ESTIMATED CAPITAL COST OF VISUAL INSPECTION EQUIPMENT

AT MRS AND REPOSITORY

$(\$ 000,1987)$

Item

Fuel holder/manipulator w/mounting features $(1 \times 4 \times 60$.

Lights $(2 \times 4 \times 2$.

CCTV systems $(2 \times 4 \times 20$.

Cables, Controls, Disconnects $(2 \times 4 \times 10$.

Subtotal

Installation $35 \%$

Engineering (40\% of 1 system)

Subtotal

Contingency (30\%)

Total
Estimated Cost

\begin{tabular}{rr}
\hline $\begin{array}{l}\text { MRS } \\
240\end{array}$ & Repository \\
\cline { 2 - 2 } 16 & 60 \\
160 & 40 \\
80 & 20 \\
\hline 496 & 124 \\
174 & 43 \\
50 & 50 \\
\hline 720 & 217 \\
216 & 65 \\
\hline$\$ 936$ & $\$ 282$ \\
\hline
\end{tabular}


In addition to initial costs, it is estimated that $\$ 40,000$ (MRS) and $\$ 10,000$ (repository) in equipment replacement costs will be incurred every year. This is in addition to annual maintenance costs. The manpower requirements are estimated at $70 \%$ of those required for at-reactor inspections on the basis of continuous operations plus dry operations, rather than in pool water. The resulting estimates are 6.7 man-hours per PWR assembly and 4.7 man-hours per BWR assembly. Annual operating costs are based on those manpower requirements, the unit costs listed in Section 1.0 , the MRS receipt schedule in Table $D-2$ and a repository spent fuel receipt rate of 505 PWR and 640 BWR assemblies/year for 16 years from 2008 through 2023. These are summarized in Table $D-26$. 
TABLE D-26

ESTIMATED ANNUAL OPERATING COSTS FOR VISUAL INSPECTION OF

SPENT FUEL RECEIVED AT THE MRS AND REPOSITORY

$(\$ 000,1987)$

Years $1-5$ (MRS)

Labor, Burden and Overhead

Supplies

PWR

BWR

Total

Maintenance

$\$ 639$

93

$\$ 565$

82

$\$ 1,204$

175

Total

47

1,426

Year 6 (MRS)

Labor, Burden and Overhead

Supplies

1,066

155

942

137

2,008

292

Maintenance

Total

2,347

Years 7-25 (MRS)

Labor, Burden and Overhead

Supplies

1,413

205

1,247

181

2,660

386

Maintenance

Total

3,093

Year 26 (MRS)

Labor, Burden and Overhead

751

109

664

97

1,415

206

Maintenance

$-$

47

Total

1,668

Years 11-26 (Repository

Labor, Burden and Overhead

351

Supplies

27

24

51

Maintenance

Total

$\underline{14}$

Using the initial capital costs, the $\$ 40,000 / y r$. (MRS) and $\$ 10,000 / y r$. (repository) equipment replacement costs and the annual operating costs, the estimated life cycle costs are shown in Table D-27. 
TABLE $\quad$ D-27

ESTIMATED LIFE CYCLE COSTS FOR VISUAL INSPECTION OF SPENT FUEL ASSEMBLIES AT THE MRS AND REPOSITORY

$(\$ 000,1987)$

MRS

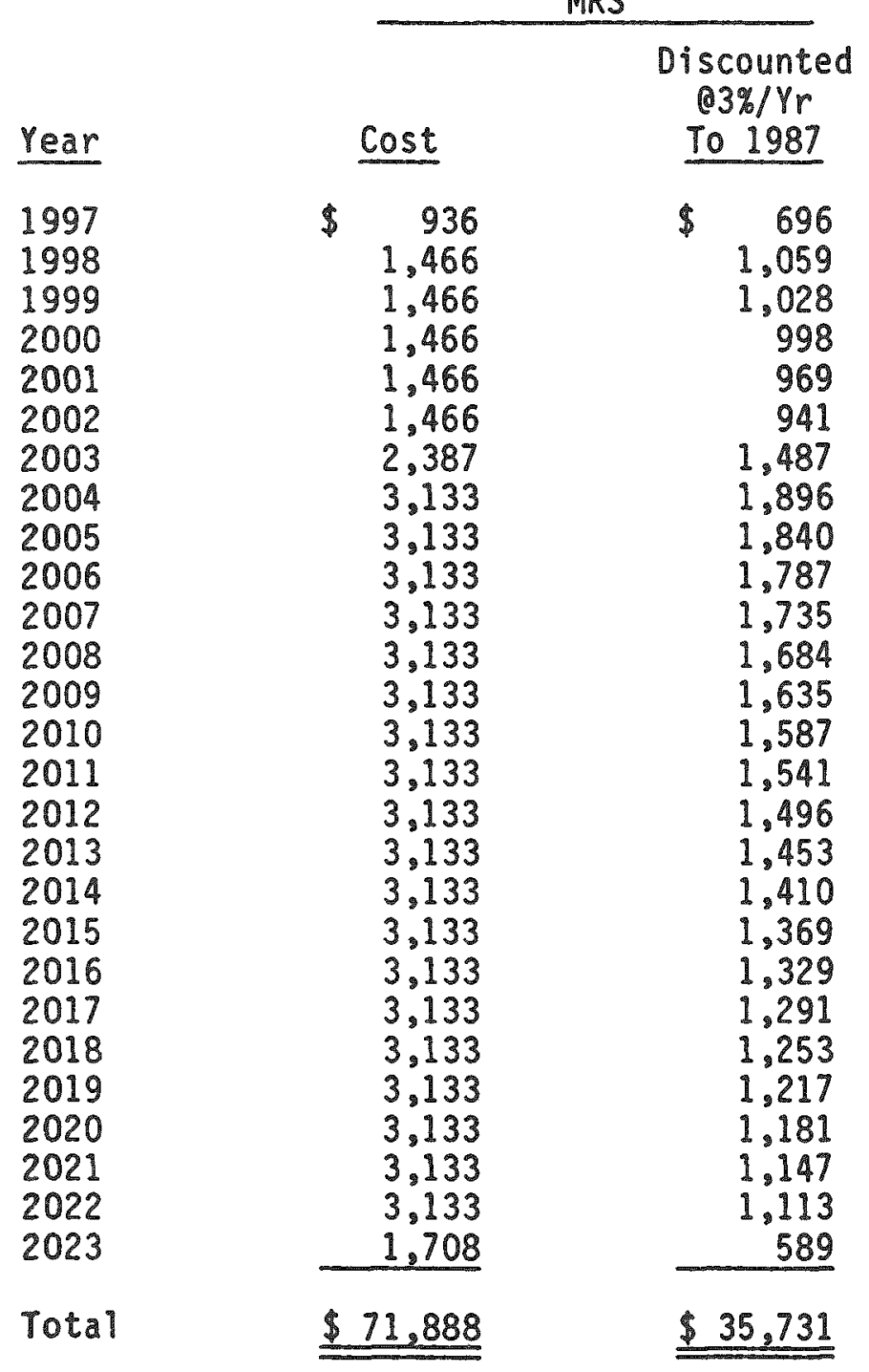

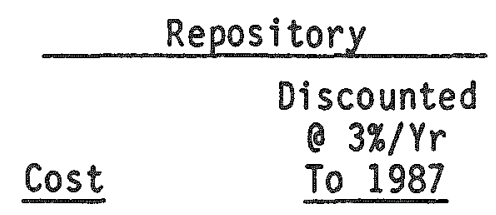

282

426

426

426

426

426

426

426

426

426

426

426

426

426

426

426

426

156

229

222

216

210

203

198

192

186

181

176

170

165

161

156

151

147

$\$ \quad 7,098$

$\$ \quad 3,119$ 
Using the discounted value of PWR and BWR fuel receipts at the MRS from Table D-2, the unit cost spent fuel visual inspection at the MRS is $\$ 1.21 / \mathrm{kgU}$. The discounted value of 350 MTU year of spent fuel received at the repository for 16 years beginning in 2008 , at $\$ 1$ per MTU is $\$ 2,434$. Using this value, the unit cost of visually inspecting spent fuel assemblies received at the repository is $\$ 1.28 / \mathrm{kgU}$. The weighted average cost for both facilities is $\$ 1.22 / \mathrm{kgU}$.

\subsection{DIRECT WEIGHING AT MRS}

Weighing of spent fuel assemblies or of cans of consolidated spent fuel rods can be easily accomplished by the incorporation of a load cell in the lifting hoist. The following cost estimates are for weighing each fuel assembly as it is received at the MRS.

Capital costs for two stations of the load cell and its instrumentation are shown in Table D-28.

TABLE D-28

ESTIMATED CAPITAL COSTS FOR WEIGHING

$(\$ 000,1987)$

Item

Load Cell and Hardware

Instrumentation

Subtotal

Installation

Engineering/Design

Subtotal

Contingency $(30 \%)$

Total
Estimated Cost

$\$ 8.0$

16.0

24.0

8.4

$\frac{9.6}{42.0}$

12.6

$\$ 54.6$

Replacement equipment costs are estimated at $\$ 12,500$ every fifth year of operation. 
Basing the operating costs on 1.0 man-hours per assembly and on the receipt rate shown in Table $D-2$, the operating costs are found to be those shown in Table $0-29$.

TABLE D-29

ESTIMATED ANNUAL OPERATING COSTS FOR WEIGHING SPENT FUEL

$(\$ 000,1987)$

Description

Labor, Burden and Overhead

Supplies

Maintenance

Total

\section{Years}

1-5

$\$ 215.7$

31.4

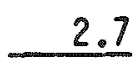

$\$ 249.8$

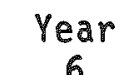

6

$\$ 359.5$

52.3

2.7

$\$ 414.5$
Years

$7-25$

$\$ 476.2$

69.3

2.7

$\$ 548.2$
Year 26

$\$ 253.4$

36.9

2.7

$\$ 293.0$

Estimated life cycle costs for weighing spent fuel upon receipt at the MRS are shown in Table D-30. Sharing of total costs between PWR and BWR fuel is based on the fractional number of assemblies received and is 0.443 for PWR and 0.557 for BWR.

Dividing the total of discounted costs by the total discounted amount of fuel given in Table D-2 yields the unit costs of $\$ 0.21 / \mathrm{kgU}$. If cost allocation is based on the fractional number of assemblies of each type, and the discounted amount of fuel of each type, the unit weighing costs for each type are $\$ 0.14 / \mathrm{kgU}$ for PWR assemblies and $\$ 0.35 / \mathrm{kgU}$ for BWR assemblies. 
TABLE D-30

WEIGHING AT MRS

$(\$ 000,1987)$

Year

PWR

1997

1998

1999

2000

2001

2002

2003

2004

2005

2006

2007

2008

2009

2010

2011

2012

2013

2014

2015

2016

2017

2018

2019

2020

2021

2022

2023

Totals

\begin{tabular}{cr}
\multicolumn{3}{c}{ PWR } \\
\hline $\begin{array}{c}\text { Annual } \\
\text { Cost }\end{array}$ & $\begin{array}{c}\text { Discounted } \\
\text { O3\%/Yr } \\
\text { To } 1987\end{array}$ \\
$\begin{array}{c}24.2 \\
110.7\end{array}$ & $\$ 18.01$ \\
110.7 & 79.97 \\
110.7 & 77.64 \\
110.7 & 75.38 \\
116.2 & 73.19 \\
183.6 & 74.58 \\
242.9 & 114.41 \\
242.9 & 146.96 \\
242.9 & 142.68 \\
248.4 & 138.52 \\
242.9 & 137.53 \\
242.9 & 130.57 \\
242.9 & 126.77 \\
242.9 & 123.08 \\
248.4 & 119.49 \\
242.9 & 118.64 \\
242.9 & 112.63 \\
242.9 & 109.35 \\
242.9 & 106.17 \\
248.4 & 103.07 \\
242.9 & 102.34 \\
242.9 & 97.16 \\
242.9 & 94.33 \\
242.9 & 91.58 \\
248.4 & 88.91 \\
129.8 & 88.28 \\
\hline & 44.79 \\
& \\
& $\$ 2736.02$ \\
&
\end{tabular}

\begin{tabular}{|c|c|c|}
\hline \multicolumn{3}{|c|}{ BWR } \\
\hline $\begin{array}{c}\text { Annual } \\
\text { Cost }\end{array}$ & & $\begin{array}{c}\text { counted } \\
3 \% / Y r \\
1987 \\
\end{array}$ \\
\hline $\begin{array}{r}30.4 \\
139.1 \\
139.1 \\
139.1 \\
139.1 \\
146.1 \\
305.3 \\
305.3 \\
305.3 \\
305.3 \\
312.3 \\
305.3 \\
305.3 \\
305.3 \\
305.3 \\
312.3 \\
305.3 \\
305.3 \\
305.3 \\
305.3 \\
312.3 \\
305.3 \\
305.3 \\
305.3 \\
305.3 \\
312.3 \\
163.2\end{array}$ & $\$$ & $\begin{array}{r}22.62 \\
100.49 \\
97.56 \\
94.72 \\
91.96 \\
93.78 \\
190.25 \\
184.71 \\
179.33 \\
174.11 \\
172.91 \\
164.11 \\
159.33 \\
154.69 \\
150.19 \\
149.16 \\
141.57 \\
137.44 \\
133.44 \\
129.55 \\
128.66 \\
122.12 \\
118.56 \\
115.11 \\
111.75 \\
110.99 \\
56.31\end{array}$ \\
\hline & & 85.43 \\
\hline
\end{tabular}




\subsection{COSTS FOR CALORIMETRY AT REPOSITORY}

Before presenting unit costs for a calorimetric facility, it is useful to comment on the number of calorimeters which would be required if there were to be a $100 \%$ calorimetry of the waste packages. Based on the expected long equilibration times, it is estimated that the throughput of a calorimeter would be only one package every two days. Allowing for $10 \%$ downtime of the facility, a 234 day work year is presumed. On this basis, the number of calorimeters required to service a tuff repository handling 1,200 packages a year is 11 calorimeters. Given the uncertainty of the need for calorimetry, as discussed in Section 4.3 , and the evident expense involved, it appears that the most effective use of calorimetry is to use a single calorimeter as an ongoing calibration standard for gamma and neutron scanning and calculation of heat generation rates. Accordingly, the following cost esitmates are based on a single calorimeter which would be used on a sampling basis. It is further assumed that calorimetry is used to confirm package loadings, rather than to confirm the prospective package contents before packaging.

The estimated capital cost for a calorimeter located in a hot cell is given in Table D-31. It is assumed that the calorimeter is located in a hot cell with other equipment and an appropriate share of the hot cell cost at $\$ 4500$ per square foot is assigned to the calorimeter.

TABLE D-31

ESTIMATED CAPITAL COST OF CALORIMETER EQUIPMENT

$(\$ 000,1987)$

Item

Vessel and Accessories

Instrumentation

Share of Hot Cell

Subtotal

Installation (35\%)

Engineering/Design (40\%)

Subtotal

Contingency (30\%)

Total
Estimated Cost

$\$ 322.7$

35.0

450.0

807.7

282.7

323.1

$1,413.5$

424.1

$\$ 1,837.6$ 
In addition to the initial capital cost, it is estimated that $\$ 100,000$ in equipment replacement costs would be incurred every fifth year. The manpower requirements are estimated to be 64 man-hours per package and the annual operating costs are based on calorimetry of 115 packages per year at a facility serving any of the repositories. The estimated annual operating costs are summarized in Table D-32.

TABLE D-32

ESTIMATED ANNUAL OPERATING COSTS FOR SAMPLING CALORIMETRY

$(\$ 000,1987)$

Description

Labor, Burden and Overhead

Supplies

Maintenance

Total
Estimated Cost

$\$ 404.8$

58.9

91.9

$\$ 555.6$

Using the initial capital cost, the $\$ 100,000$ cost of equipment replacement at five year intervals, and the annual operating cost, the estimated life cycle costs are shown in Table D-33. 
TABLE D-33

SAMPLING CALORIMETRY AT REPOSITORY

(\$000, 1987)

\begin{tabular}{|c|c|c|c|c|}
\hline Year & $\begin{array}{c}\text { Annual } \\
\text { Cost }\end{array}$ & $\begin{array}{c}\text { Discounted } \\
\text { O3\%/Yr } \\
\text { To } 1987 \\
\end{array}$ & $\begin{array}{c}\text { Emplacement } \\
\text { (MTU/Yr.) }\end{array}$ & $\begin{array}{c}\text { Di scounted } \\
\text { O } 3 \% / \mathrm{Yr} . \\
\text { To } 1987 \\
\text { (MTU/Yr.) }\end{array}$ \\
\hline $\begin{array}{l}2002 \\
2003 \\
2004 \\
2005 \\
2006 \\
2007 \\
2008 \\
2009 \\
2010 \\
2011 \\
2012 \\
2013 \\
2014 \\
2015 \\
2016 \\
2017 \\
2018 \\
2019 \\
2020 \\
2021 \\
2022 \\
2023 \\
2024 \\
2025 \\
2026 \\
2027 \\
2028\end{array}$ & $\begin{array}{r}1837.6 \\
555.6 \\
555.6 \\
555.6 \\
555.6 \\
655.6 \\
555.6 \\
555.6 \\
555.6 \\
555.6 \\
655.6 \\
555.6 \\
555.6 \\
555.6 \\
555.6 \\
655.6 \\
555.6 \\
555.6 \\
555.6 \\
555.6 \\
655.6 \\
555.6 \\
555.6 \\
555.6 \\
555.6 \\
655.6 \\
555.6 \\
\end{array}$ & $\begin{array}{r}\$ 1179.49 \\
346.23 \\
336.15 \\
326.36 \\
316.85 \\
362.99 \\
298.66 \\
289.96 \\
281.52 \\
273.32 \\
313.12 \\
257.63 \\
250.13 \\
242.84 \\
235.77 \\
270.10 \\
222.23 \\
215.76 \\
209.48 \\
203.37 \\
232.99 \\
191.70 \\
186.12 \\
180.70 \\
175.43 \\
200.98 \\
165.36 \\
\end{array}$ & $\begin{array}{r}400 \\
400 \\
400 \\
900 \\
1800 \\
3000 \\
3000 \\
3000 \\
3000 \\
3000 \\
3000 \\
3000 \\
3000 \\
3000 \\
3000 \\
3000 \\
3000 \\
3000 \\
3000 \\
3000 \\
3000 \\
3000 \\
3000 \\
3000 \\
3000 \\
1460 \\
\end{array}$ & $\begin{array}{r}249.27 \\
242.01 \\
234.96 \\
513.26 \\
996.62 \\
1612.65 \\
1565.68 \\
1520.08 \\
1475.80 \\
1432.82 \\
1391.08 \\
1350.57 \\
1311.23 \\
1273.04 \\
1235.96 \\
1199.96 \\
1165.01 \\
1131.08 \\
1098.13 \\
1066.15 \\
1035.10 \\
1004.95 \\
975.68 \\
947.26 \\
919.67 \\
434.54\end{array}$ \\
\hline Totals & $\$ 16783.2$ & $\$ 7765.82$ & 65360 & 27382.53 \\
\hline
\end{tabular}

Assuming an average tuff package loading of 2.59 MTU $(3,000$ MTU/1,182 packages), the discounted value of 115 packages/yr. for 26 years at $\$ 1 /$ MTU is $\$ 3,352$. Thus, the unit cost per $\mathrm{kg}$ measured is $\$ 2.32 / \mathrm{kgU}$. The unit cost of sampling calorimetry averaged over all spent fuel emplaced is $\$ 0.28 / \mathrm{kgU}$. 
3.4 COSTS FOR NEUTRON AND GAMMA MONITORING AT THE REPOSITORY

This section provides the estimated life cycle cost of a conceptual neutron and gamma monitoring system that would monitor every disposal container prior to final emplacement. The system would be located in a hot cell and would consist of a vertical stand into which the waste would be placed and a monitoring system with 4 heads and associated electronics that would monitor the waste package at its mid-plane at 4 positions $90^{\circ}$ apart. A11 4 heads would contain fission counters and two of the 4 heads would have high resolution gamma collimators and detectors. The monitoring system would thus have six sets of electronics for counting and recording. There would be two complete systems. It is estimated that the monitoring will require 1 hour per package including placement and removal of the waste package. It is estimated that the two units will together require $200 \mathrm{ft}^{2}$ of hot cell space at a unit cost of $\$ 4,500 / \mathrm{ft}^{2}$.

The estimated capital cost of the conceptual monitoring facility is given in Table $0-34$.

TABLE D-34

ESTIMATED CAPITAL COST OF NEUTRON/GAMMA EQUIPMENT

$(\$ 000,1987)$

Item

Waste Canister Holding Fixture Head Positioning Fixture \& Shielding

Instrumentation and Electronics Package

Share of Hot Cell

Subtotal

Installation (35\%)

Engineering/Design (40\%)

Subtotal

Contingency (30\%)

Total
Estimated Cost

$\$ 50$

280

1,200

900

2,430

850

970

4,250

1,275

$\$ \quad 5,525$ 
In addition to the initial capital costs, it is estimated that $\$ 200,000$ in equipment replacement costs would be incurred every fifth year. The manpower requirements are estimated to be 20 manhours per package and the annual operating costs assume 1,100 packages/year. The estimated annual operating costs are summarized in Table $0-35$.

TABLE D-35

ESTIMATED ANNUAL OPERATING COSTS OF NEUTRON/GAMMA MONITORING $(\$ 000,1987)$

Description

Labor, Burden and Overhead

Supplies

Maintenance

Total
Estimated Cost

$\$ 1,210$

176

276

$\$ 1,662$

Using the initial capital cost, the $\$ 200,000$ cost of equipment replacement at 5-year intervais and the annual operating cost, the estimated life cycle costs are shown in Table D-36. The unit cost of neutron and gamma monitoring with this conceptual system is $\$ 0.84 / \mathrm{kgU}$. 
TABLE D-36

NEUTRON/GAMMA MONITORING AT REPOSITORY

(\$000, 1987)

Year

2002

2003

2004

2005

2006

2007

2008

2009

2010

2011

2012

2013

2014

2015

2016

2017

2018

2019

2020

2021

2022

2023

2024

2025

2026

2027

2028

Totals
Annual

Cost

$\$$

5525
1662

1662

1662

1662

1862

$166^{\circ}$

1662

1662

1662

1862

1662

1662

1662

1662

1862

1662

1662

1662

1662

1862

1662

1662

1662

1662

1862

1662

$\$ \quad 49737$
Discounted

$03 \% / \mathrm{Yr}$

To 1987

$\$ 3546$

1036

1006

976

948

1031

893

867

842

818

889

771

748

726

705

767

665

645

627

608

662

573

557

540

525

571

495

$\$ 23037$
Discounted

C $3 \% / \mathrm{Vr}$.

Emplacement

(MTU/Yr.)

To 1987

(MTU/Yr.)

400

400

400

900

1800

3000

3000

3000

3000

3000

3000

3000

3000

3000

3000

3000

3000

3000

3000

3000

3000

3000

3000

3000

3000

1460

65360
249.27

242.01

234.96

513.26

996.62

1612.65

1565.68

1520.08

1475.80

1432.82

1391.08

1350.57

1311.23

1273.04

1235.96

1199.96

1165.01

1131.08

1098.13

1066.15

1035.10

1004.95

975.68

947.26

919.67

434.54

27382.53

Unit costs for neutron/gamma monitoring of waste packages is thus $\$ 0.84 / \mathrm{kgU}$. 
4.0 SUMMARY OF LIFE CYCLE MEASUREMENT COSTS

Table D-37 shows a summary of the unit $(\$ / \mathrm{kgU})$ life cycle measurement costs developed in this section.

TABLE D-37

SUMMARY OF UNIT MEASUREMENT COSTS

Measurement

At-Reactor:

Visual Inspection

Sipping

Uitrasonic Testing

Calorimetry (100\%)

Dimensions

Gamma Scanning

Weighing

At-DOE

Visual Inspection at MRS, Repository

Weighing

Calorimetry

Sampling Calorimetry (9\%)

Neutron and Gamma Counting

Combined Calorimetry and Counting
Life Cycle Unit Cost of Measurements, $\$ / \mathrm{kgU}$ (1987)

\begin{tabular}{ll}
\hline PWR & BWR \\
2.60 & 3.29 \\
3.16 & 3.89 \\
4.83 & 4.65 \\
3.90 & 6.00 \\
1.55 & 1.97 \\
5.36 & 7.31 \\
0.40 & 0.72
\end{tabular}

A11 Fuel

1.22

0.21

2.32

0.28

0.84

1.12

A review of the above unit costs shows that at-reactor measurements tend to have a relatively high unit cost because the equipment is assumed to be amortized over only the spent fuel output of a single reactor, and the annual measurement costs have a significant labor component. In contrast, the unit costs of measurement at DOE facilities benefit from (i) a high utilization of the measurement facilities, (ii) a relatively high productivity of labor because of routine operations, and (iii) in the case of packaged waste, fewer units to be measured (packages versus fuel assemblies). Furthermore, in the case of calorimetry performed on a sampling basis, only $9 \%$ of the packages are assumed to be measured.

It was concluded in Section 4.0 that the use of utility data, including discharge dates and utility-measured burnups, can provide more 
accurate waste characteristics than can be obtained by direct measurements. That conclusion, plus the conclusions in that section as to the limited operational value of some measurements, and the relatively high cost of measurements at utilities identified in this Appendix indicates that as a general rule direct measurements are not justified at utilities, other than the identification and visual inspections that are essential for certification of waste identification and condition at the point of transfer to DOE.

Even though the unit costs of direct measurement are lower in the DOE system, the same observations concerning the superior accuracy of characteristics determined from utility-supplied data and the limited operational value of direct measurements, lead to a similar conclusion that direct measurements are not normally justified by operational requirements within the DOE system. 


\section{INTERNAL DISTRIBUTION}

$\begin{aligned} \text { 1. } & \text { J. M. Begovich } \\ \text { 2. } & \text { A. G. Croff } \\ \text { 3. } & \text { C. W. Forsberg } \\ \text { 4-7. } & \text { E. J. Frederick } \\ \text { 8. } & \text { R. K. Genung } \\ \text { 9. } & \text { J. R. Hightower } \\ \text { 10. } & \text { E. K. Johnson } \\ \text { 11. } & \text { D. S. Joy } \\ \text { 12. } & \text { S. B. Ludwig } \\ 13 . & \text { A. P. Malinauskas }\end{aligned}$

$\begin{aligned} \text { 14-16. } & \text { M. C. McClain } \\ 17 . & \text { K. J. Notz } \\ 18 . & \text { W. H. Pechin } \\ 19 . & \text { R. R. Rawl } \\ 20 . & \text { J. W. Roddy } \\ 21 . & \text { M. W. Wankerl } \\ 22 . & \text { Central Research Library } \\ 23 . & \text { Document Reference Section } \\ 24-25 . & \text { Laboratory Records } \\ 26 . & \text { Laboratory Records - RC } \\ 27 . & \text { ORNL Patent Section }\end{aligned}$

\section{EXTERNAL DISTRIBUTION}

DOE - Oak Ridge Operations, P.O. Box 2001, Oak Ridge, TN 37831-8600

28. Office Of Assistant Manager, Energy Research and Development

DOE - Office of Civilian Radioactive Waste Management, Forrestal Building, 1000 Independence Avenue, S. W., Washington, DC 20585

29. A. B. Brownstein

30. J. H. Carlson

31. W. J. Danker

32. M. W. Frei

33. H. J. Hale
34. C. Kouts

35. W. Lemeshewsky

36. R. Stein

37. E. Svenson

38. J. Williams

DOE - Office of Nuclear Energy, 19901 Germantown Road, Germantown, MD 20874

39. J. A. Turi

DOE - Chicago Operations Office, 9800 S. Cass Avenue, Chicago, Il 60439

40. R. Rothman

DOE - Idaho Operations Office, 785 DOE Place, Idaho Falls, ID 83402

41. S. T. Hinschberger

42. M. Pellicci

43. J. E. Solecki

DOE - Nevada Operations Office, P.O. Box 14100, Las Vegas, NV 89114

44.
A. Baca

45. C. Gertz

46. D. Livingston 
DOE - Richland Operations Office, P.O. Box 550, Richland, WA 99352

47. D. Kenyon

48. D. Langstaff

Argonne National Laboratory, 9700 Cass Avenue, Argonne, Il 60439

49. M. J. Steindler

Lawrence Livermore National Laboratory, P.O. Box 808, Livermore, CA 94550

50. H. Shaw

51. W. R. Lloyd

Oak Ridge Gaseous Diffusion Plant, P.O. Box 2003, Oak Ridge, TN 37831

52. B. W. Moran

53. D. W. Swindle, Jr.

Pacific Northwest Laboratory, P.O. Box 999, Richland, WA 99352

54. L. L. Clark

55. R. L. Engel

58. G. W. McNair

56. R. Heineman

59. M. R. Shay

57. P. N. McDuffie

60. R. Smith

61. M. White

Pacific Northwest Laboratory, Battelle Washington Operations Office, 2030 M. Street NW, Washington, DC 20036

62. G. H. Beeman

63. T. R. Wood

Sandia National Laboratory, P.O. Box 5800, Albuquerque, NM 87185

64. G. Allen

65. T. L. Sanders

Babcock and Wilcox, Nuclear Power Division, P.O. Box 10935, Lynchburg, VA 24503

66. L. A. Hassler

Battelle/OSTP, 505 King Avenue, Columbus, OH 43201

67. D. Dippold

68. P. Hoffman

Combustion Engineering, 1000 Prospect Hill Road, Windsor, CT 06095

69. W. Burns

Edison Electric Institute, 1111 19th Street NW, Washington, DC 20036

70. J. Flahery
71. S. Kraft" : : 
EG\&G Idaho, Inc. P.O. Box 1625, Idaho Falls, ID 83415

72. I. K. Hall

73. J. Leatham

74. H. Worle

Electric Power Research Institute, P.O. Box 10412, Palo Alto, CA 94303

75. R. W. Lambert

76. R. Williams

General Atomics, P.O. Box 85608, San Diego, CA 92138-5608

77. Shiaw-Der Su

E. R. Johnson Associates, Inc., 10461 White Granite Drive, Suite 204, Oakton, VA 22124

78. B. M. Cole

79. E. R. Johnson

80. N. B. McLeod

LeBoeuf, Lamb, Leiby, \& McRae, 1333 New Hampshire, NW, Suite 1100 ,

Washington, DC 20039

81. L. Trosten

Nuclear Assurance Corporation, 6251 Crooked Creek Road, Suite 200, Norcross, GA 30092

82. J. V. Houston

83. W. J. Lee

84. N. Mote

Nuclear Packaging, Incorporated, 1010 South 336th Street, Federal Way, WA 98003

85. J. Schornhorst

Nutech Engineers, 1301 Hightower Trail, Suite 205, Atlanta, GA 30350

86. J. Rollins

Science Application International, Corporation, 101 Convention Center Drive, Las Vegas, NV 89109

87. R. Morrisette

Science Application International, Corporation, P.O. Box 2501, Oak Ridge, Tennessee 37831

88. R. Peterson

University of Tennessee, 327 South Stadium Hall, Knoxville, TN 37996-0710

89. W. Colglazier 
U. S. Council For Energy Awareness, 1776 I Street, NW, Suite 400, Washington, DC 20006 90. J. R. Siegel

Vanderbilt University, 108 New Engineering Building, Nashville, TN 37325

91. F. L. Parker

Westinghouse Electric Corporation, P.O. Box 3912, Pittsburgh, PA 15230

92. B. Nair

Weston, 955 L'Enfant Plaza, SW, Eighth Floor, Washington, DC 20024

93. P. Bolton

94. J. DiNunno

95. W. Wowak

96-105. Office of Scientific and Technical Information, P.O. Box 62, Oak Ridge, TN 37831 